\title{
2015.
}

\section{LAS CLÁUSULAS ECONÓMICAS DE LOS CONTRATOS DE CONCESIÓN DE TRANSMILENIO Y SITP, COMO LÍMITES AL ACCESO AL SERVICIO DE TRANSPORTE PÚBLICO.}

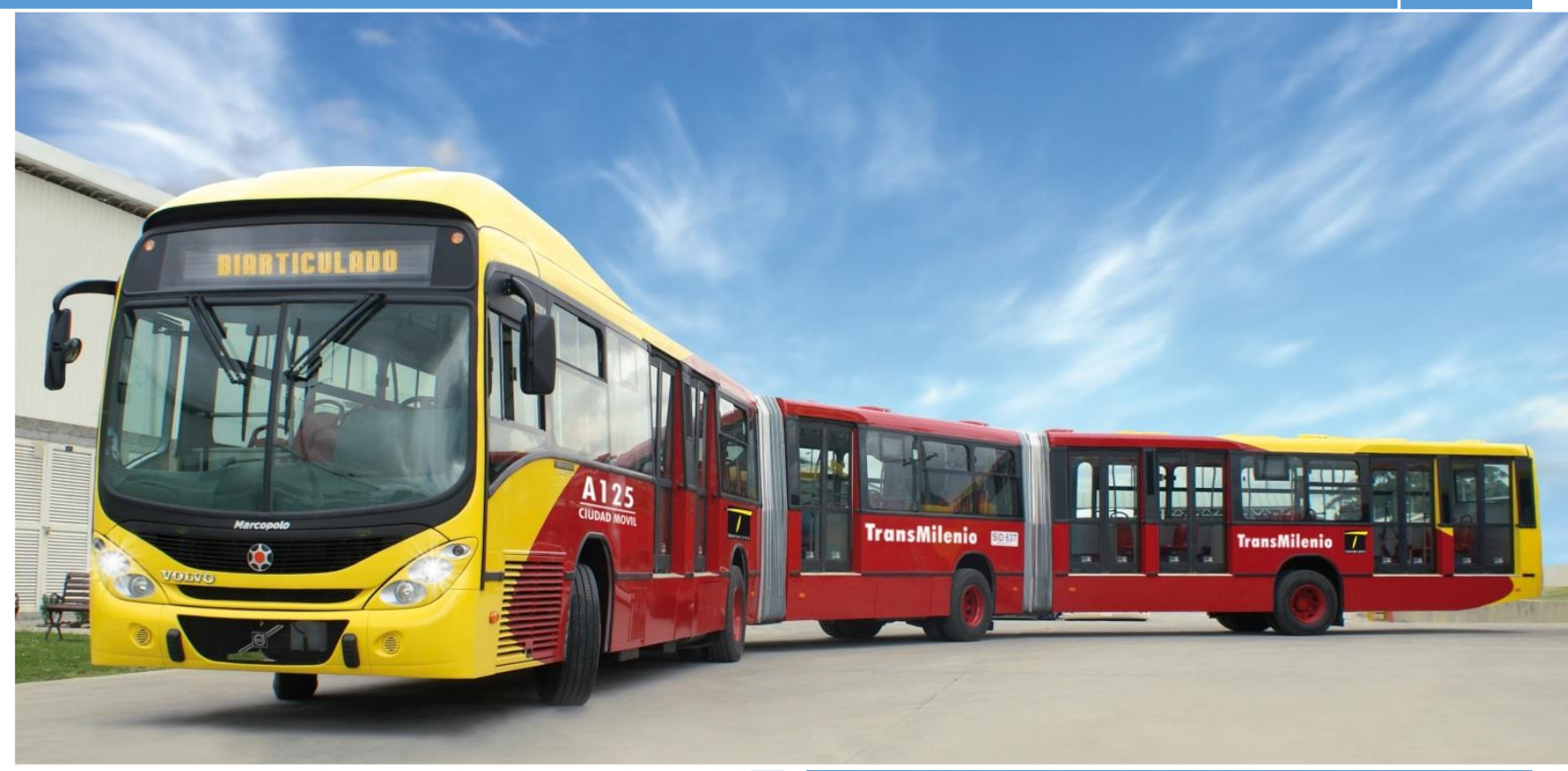

Andrés Felipe Pachón Torres

Maestría en Derecho Público

Convenio Usta-Konstanz

$1^{\circ}$ de Mayo de 2015 
LAS CLÁUSULAS ECONÓMICAS DE LOS CONTRATOS DE CONCESIÓN DE TRANSMILENIO Y SITP, COMO LÍMITES AL ACCESO AL SERVICIO DE TRANSPORTE PÚBLICO.

\title{
ANDRÉS FELIPE PACHÓN TORRES.
}

\author{
MAESTRÍA EN DERECHO PÚBLICO. \\ Convenio Usta-Konstanz. \\ 2015.
}




\title{
LAS CLÁUSULAS ECONÓMICAS DE LOS CONTRATOS DE CONCESIÓN DE TRANSMILENIO Y SITP, COMO LÍMITES AL ACCESO AL SERVICIO DE TRANSPORTE PÚBLICO.
}

\begin{abstract}
El estudio realiza una descripción del modelo de transporte público que funciona en Bogotá, en el marco de una realidad socioeconómica compleja, lo que comienza a demostrar ineficiencias en la prestación de éste servicio público esencial. El análisis se concentra en revisar la formula económica utilizada para estructurar las tarifas, las cuales resultan significativamente onerosas para una parte considerable de habitantes de la ciudad, a quienes se termina impidiendo el acceso real y efectivo a esta prestación fundamental. Finalmente, el estudio -a través de la metodología del Análisis Económico del Derecho- realiza un Análisis Costo-Beneficio sobre la regulación del servicio de transporte, desde una perspectiva tanto económica como de derechos, y plantea algunos ajustes que se deben efectuar sobre los "arreglos institucionales", con miras a lograr un sistema de transporte accesible, sostenible, que asegure intereses colectivos como el progreso y el desarrollo económico y que resuelva las necesidades de una ciudad de las características y las proporciones de la Capital de Colombia.
\end{abstract}

Abstract. The research provides a detailed description of how works the public transportation in Bogotá, in the frame of a complex socio-economic background, that start to demonstrate the inefficiencies in the provision of the essential public transportation service. The analysis focus on the review of the economic formula that is used to determine the public transportation rates, which are significantly expensive for a considerable part of the city population. Finally, the study is dedicated to construct a transport proposal, that is going to be socially efficient and is going to guarantee as individual rights and economic as the development and progress of the capital.

Palabras clave. Servicio de transporte público, Esquema Económico, Formulas tarifarias, Transmilenio, Economía Social de Mercado, Eficiencia social, Derechos Colectivos, Acceso a Servicios Públicos, Contratos de Concesión, Análisis Económico del Derecho. 


\section{TABLA DE CONTENIDO.}

\section{CAPÍTULO I.}

\section{LA ECONOMÍA SOCIAL DE MERCADO Y LOS DERECHOS RELACIONADOS CON EL SERVICIO DE TRANSPORTE PÚBLICO.}

\subsection{Fundamentos Constitucionales de la Economía Social de Mercado.}

1.1.1. La Libertad Económica.

1.1.2. La Intervención del Estado en la Economía (art. 334 CP).

1.1.3. Cláusula del Estado Social de Derecho (art. $1^{\circ}$ ).

1.1.4. Regulación Constitucional de los Servicios Públicos (art. 365).

\subsection{Los Derechos de Acceso al Transporte.}

1.2.1. El Derecho Fundamental Al Acceso al Servicio de Transporte

1.2.1.1. Escenarios Constitucionales en los que el Acceso al Servicio de Transporte es reconocido como fundamental.

1.2.1.2. Evolución Jurisprudencial.

1.2.2. El Derecho Colectivo Al Acceso Al Servicio De Transporte Público.

1.2.2.1. Norma jurídica.

1.2.2.2. Obligación Jurídica

1.2.2.3. Posición Jurídica.

1.2.3. Límites de los Derechos de Acceso al Transporte.

\subsection{Conclusiones del Capítulo I.}

\section{CAPÍTULO II.}

\section{EL SISTEMA DE TRANSPORTE PÚBLICO EN BOGOTÁ.}

\subsection{El funcionamiento operativo de Transmilenio y SITP.}

2.1.1. La problemática del Transporte en Bogotá y puesta en Marcha del Transmilenio.

2.1.2. Funcionamiento del SITP.

2.1.3. Resultados de la Implementación del Transmilenio y el SITP en Bogotá.

\subsection{Los Contratos de Concesión de Transmilenio y SITP.}


2.2.1. Esquema Económico de los Contratos de Concesiones Transmilenio y SITP.

2.2.1.1. Principios Básicos del Marco Económico.

2.2.1.2. Ingresos del Sistema.

2.2.1.3. Tarifas.

2.2.1.4. Disposición y Destinación de los Recursos Generados por el Sistema.

2.2.1.5. Derechos de Participación del Concesionario.

2.2.2. Renegociación de los Contratos.

\subsection{La Tarifa como Límite al Acceso al Servicio de Transporte Público.}

2.3.1. Aspectos Socioeconómicos de Bogotá.

2.3.2. La Realidad Económica en materia de Transporte Urbano en Bogotá.

2.3.3. La Tarifa como restricción al acceso real y efectivo al Servicio de Transporte.

\subsection{Conclusiones Capítulo II.}

\section{CAPÍTULO III.}

\section{ANÁLISIS ECONÓMICO DE LA REGULACIÓN DEL SERVICIO DE TRANSPORTE EN BOGOTÁ, CASO TRANSMILENIO Y SITP.}

\subsection{EI AED como herramienta para resolver conflictos de derechos.}

3.1.1. Análisis Económico del Derecho (AED).

3.1.2. Tipos de Análisis Económico del Derecho.

3.1.3. Utilidades del Análisis Económico del Derecho.

\subsection{Estudios sobre la Economía del Sistema de Transporte de Bogotá.}

3.2.1. El servicio público y la regulación del Medio de Transporte. (Posner).

3.2.2. Impactos Económicos de Transmilenio.

3.2.3. Estudios sobre las Tarifas del Transporte Público.

3.2.4. Pronunciamientos institucionales sobre la regulación.

\subsection{Análisis Económico sobre la Regulación del Servicio de Transporte.}

3.3.1. Herramientas y fundamentos del AED que se aplican al objeto de investigación.

3.3.1.1. El Teorema de Coase.

3.3.1.2. El concepto de eficiencia para el presente trabajo. 
3.3.1.3. Los aportes de la Nueva Economía Institucional al caso concreto.

3.3.2. La Estructuración Tarifaria o de los Costos de Transacción.

3.3.2.1. Altas Tarifas de Acceso.

3.3.2.2. Prima de Riesgo Sobrestimada.

3.3.2.3. Altos Costos Públicos. Subsidios.

3.3.2.4. Desconocimiento de las Economías de Escala.

3.3.2.5. Renegociación de los Contratos (2013).

3.3.3. Asignación de Costos y beneficios.

3.3.3.1. Derechos de Participación.

3.3.3.2. Distribución de Funciones.

3.3.3.3. Sistema Residual de Participación.

3.3.3.4. Estructura de Incentivos.

3.3.4. Externalidades Negativas. Los Costos Ocultos del Sistema de Transporte.

3.3.4.1. Congestión Vehicular.

3.3.4.2. Calidad del Servicio.

3.3.4.3. Monopolio.

3.3.4.4. La captura del regulador.

\subsection{Conclusiones del Capítulo III.}

\section{CAPÍTULO IV}

CONCLUSIONES Y UN EJERCICIO DE ANÁLISIS COSTOS-BENEFICIO DEL SISTEMA DE TRANSPORTE EN BOGOTÁ.

\subsection{Conclusiones.}

\subsection{Ejercicio de Análisis Costo-Beneficio del Sistema de Transporte en Bogotá.}

4.2.1. Resultados Análisis Costo- Beneficio.

4.2.2. Criterios para la Producción de la Regulación.

\section{Bibliografía.}




\section{INTRODUCCIÓN.}

El desarrollo urbano contemporáneo se ha visto marcado por la aparición de grandes ciudades, realidad que genera inmensos desafíos al momento de proveer los servicios públicos esenciales. Agua, electricidad, saneamiento básico, salud y movilidad, entre otros, se convierten en los principales servicios que el Estado debe proveer a sus asociados con el propósito de asegurar una vida digna. En estos grandes centros urbanos el desplazamiento de los ciudadanos adquiere cada vez mayor importancia, debido a la imperiosa necesidad de movilizarse para acudir a los lugares de trabajo, estudió, recreación, etc., ya que de la eficiencia en los tiempos de desplazamiento de un lugar a otro, depende buena parte de la productividad y el desarrollo de las grandes metrópolis. Bogotá no ha sido ajena a esta problemática, y desde la década de los 90 se evidenció la insuficiencia e ineficiencia del modelo implementado, que amenazaba con sucumbir frente al crecimiento incesante de la capital.

Ante los graves problemas de movilidad de Bogotá, las administraciones distritales en búsqueda de soluciones prontas y económicas, decidieron imitar el modelo de transporte desarrollado en la ciudad de Curitiba, Brasil, denominado BRT por sus siglas en inglés (Bus Rapit Transit), el cual funciona mediante vehículos articulados con uso de carril exclusivo, tarifa unificada, estaciones fijas y con recaudo separado de la conducción, con el principal propósito de modernizar el servicio de transporte mediante la adopción de un sistema eficiente y competitivo que facilitara la movilidad de los ciudadanos. El gran proceso de modernización de transporte en Bogotá, que inició desde el año 2000 condujo a la implementación del sistema BRT denominado Transmilenio, aspecto que sin duda constituyó un gran avance en materia de organización, optimización de tiempos, distribución de funciones, etc. En el año 2006 el Plan Maestro de Movilidad definió como etapa siguiente la puesta en marcha del Sistema Integrado de Transporte Público SITP, que entraría a reemplazar el Transporte Público Colectivo TPC, encargado de movilizar el 70\% de los viajes públicos al día. El SITP, luego de reemplazar el TPC, tendría que integrarse operativamente con Transmilenio, lo que supone la integración tarifaria, que consiste en establecer un único medio de pago y tarifas diferenciales atendiendo el tipo de servicios.

Sin embargo, dicho modelo -sin haber sido implementado en su totalidad- ha mostrado grandes señales de insuficiencia tan solo a 14 años de su implementación, y amenaza con el colapso. Buses con sobrecupo, largos tiempos de espera, inseguridad y onerosas tarifas que impiden el acceso real y 
efectivo de segmentos considerables de la población han generado la creciente inconformidad de los usuarios, pero sobretodo han develado la ineficiencia de un modelo de transporte que resulto precario para atender las necesidades que demanda la Capital Colombiana. Por esa razón, se hace necesario realizar un análisis profundo del modelo de transporte actual que opera en la ciudad de Bogotá, específicamente sobre la regulación que gobierna la prestación de éste servicio, con el fin de identificar sus problemas estructurales, principalmente en materia de acceso, a la luz de los derechos e intereses que se ven lesionados por la prestación ineficiente de un servicio público esencial, como lo es el transporte, cuya prestación resulta indispensable para asegurar la calidad de vida de los ciudadanos, aspecto que constituye una función inherente e imperativa del Estado Social de Derecho que rige en Colombia. En ese sentido, el objeto de la presente investigación es resolver la siguiente pregunta: ¿la regulación del servicio de transporte, en particular las clausulas económicas de los contratos de concesión, constituyen un límite al acceso real y efectivo a este servicio esencial?

La búsqueda de una respuesta a la pregunta formulada y el análisis que se realizará para encontrarla, está dirigido, en primer lugar a la comunidad académica, quien debe abordar con el rigor y la profundidad propia de las ciencias un asunto de vital importancia para la vida, el desarrollo y la organización del conglomerado social, como es el servicio público de transporte, a partir del cual se pueden materializar numerosos derechos fundamentales, económicos, sociales y culturales, prestación mediante la que se abren caminos para el progreso, la producción y la movilidad social. De igual manera, este trabajo no escatimará esfuerzos en aras de lograr la mayor transparencia, claridad y sencillez posible, sin afectar la profundidad que exige la investigación académica, con el propósito de resultar accesible a los usuarios del servicio público de transporte, actores decisivos e imprescindibles en la inmensa labor de exigir y construir, con su participación activa, en el debate y la acción pública, el modelo de transporte más propicio para la realidad y las necesidades que demandan las circunstancias concretas de la ciudadanía.

El objeto central de la actual investigación consistirá en demostrar que la regulación del servicio de transporte público, expresada a través de los contratos de concesión, en especial el esquema económico sobre el que se estructura el Sistema Transmilenio, que en esencia fue replicado por el Sistema Integrado de Transporte Público, SITP, genera altas tarifas fruto de una estructuración tarifaria que contiene variables sobredimensionadas o inexistentes, y una distribución de costos y beneficios 
desproporcionada y ventajosa en favor de los operadores privados, lo que convierte a este medio de transporte masivo en un sistema de costos crecientes, sumamente oneroso, situación que en la práctica impide o limita seriamente el acceso real y efectivo de una significativa parte de la población -más del $50 \%$ - que se ve excluida de un servicio esencial por no tener la capacidad económica para pagarlo, situación que torna imperativa la necesidad de revisar la alianza público-privada (APP) que le sirve de sustento.

El estudio se adelantará utilizando la metodología desarrollada por el denominado ANÁLISIS ECONÓMICO DEL DERECHO, que consiste en acudir a conceptos y metodologías propios de la ciencia económica para resolver problemas jurídicos, con el objetivo de valorar las consecuencias económicas de las decisiones que se tomen en derecho y ampliar el panorama de análisis con el propósito de tener en cuenta los efectos sociales de las decisiones públicas o "arreglos institucionales". En ese sentido, la presente investigación aplicará tres conceptos económicos para resolver el problema jurídico planteado, de la siguiente manera: i) en primer lugar se partirá del denominado teorema de Coase, y de un concepto de la eficiencia que se aleja de las escuelas neoclásicas e integra aspectos macroeconómicos al momento de su aplicación; ii) así mismo, se aplicarán dos conceptos desarrollados por la Nueva Economía Institucional, que son los costos de transacción y los derechos de propiedad, a partir de los cuales se pondrá de manifiesto la ineficiencia de la regulación y las grandes inequidades que genera fruto de la incorrecta asignación de costos y beneficios; y, iii) finalmente se aplicará el concepto de externalidades negativas, que consiste en analizar aquellos costos indirectos generados por la regulación del servicio de transporte que no son asumidos por los agentes que prestan el servicio, y que en consecuencia son asumidos por la sociedad en general. El análisis crítico que se efectúa en la presente investigación, apunta a identificar los problemas que afectan los arreglos institucionales existentes, en aras de que puedan efectuarse los ajustes regulatorios e institucionales que requiere el sistema de transporte público para asegurar tanto su sostenimiento, como el acceso real y efectivo a ésta prestación esencial por parte de la ciudadanía que lo demanda, y así garantizar la eficiencia en la prestación del servicio bajo parámetros de equidad, y productividad social, que reconozca el transporte como un servicio público fundamental, indispensable para la evolución de la ciudad y sus habitantes. 
El análisis constará de cuatro partes, así: i) en primer lugar, se examinarán los fundamentos constitucionales del sistema económico colombiano, y la denominada Economía Social de Mercado, expresión económica del Estado Social de Derecho. A partir de dicho examen, se revisará la regulación de los servicios públicos, los cuales podrán ser prestados bien sea por el Estado, o por los particulares (art 365). En la segunda parte del Capítulo I, se abordará los derechos al acceso al transporte. Así, se revisará el el derecho fundamental al acceso al transporte, su soporte constitucional, los tres escenarios constitucionales en donde se reconoce su carácter de fundamental y la evolución jurisprudencial que ha permitido su protección, agotando así el derecho de acceso desde una perspectiva individual. Por otra parte, desde la perspectiva de los Derechos Colectivos, elevados a rango constitucional (art 78 y 88), y desarrollados por la Ley (472 de 1998), se examinará el Derecho Colectivo Al Acceso Al Servicio De Transporte Público, en atención a que desde la dimensión colectiva, el análisis resulta más comprensivo de la realidad examinada, y tendría la relevancia para producir medidas colectivas de protección que corrijan de raíz las fallas presentadas por el sistema de transporte.

ii) Por su parte, en el Capítulo II se realizará una aproximación al funcionamiento operativo del sistema de transporte público en Bogotá, partiendo de las problemáticas identificadas durante la década de los 90’s, y las soluciones implementadas con la puesta en marcha del nuevo modelo, Transmilenio y SITP, examinando sus ventajas y resultados. En seguida se concentrará la atención en el funcionamiento económico del sistema, a través del estudio de los contratos de concesión que gobiernan la prestación del servicio, particularmente se examinarán de manera comparada los 5 tipos de cláusulas que definen el modelo económico que sirve de base al sistema de transporte, en especial las relacionadas con la estructuración tarifaria y la distribución de costos y beneficios tanto de las concesiones de Transmilenio como las del SITP. Luego, se efectuará un análisis sobre las renegociaciones de los contratos celebradas en 2013, mediante las cuales se adecuaron las concesiones de Transmilenio a las del SITP, aspecto que permite evidenciar - a partir del contrasteaspectos esenciales de la economía de los contratos bajo examen. Finalmente, se concluirá el Capítulo II con uno de los aspectos centrales de la presente investigación, al determinar, luego de una análisis sobre las condiciones socioeconómicas de la capital, y sobre el impacto económico que generan los costos del transporte para los usuarios, que las tarifas constituyen una poderosa restricción que afecta la prestación del servicio en términos de acceso, generando una colisión entre la regulación del 
servicio de transporte y los derechos de acceso a esta prestación esencial, reconocido a todos los asociados.

iii) En el Capítulo III, se abordará el marco conceptual que proporciona el Análisis Económico del Derecho AED, como herramienta enriquecedora del análisis jurídico al momento de ponderar y resolver los conflictos de derecho, y como metodología mediante la cual se examinará la regulación del servicio de transporte público. En seguida, se hará un breve recuento de los estudios que se han efectuado sobre la economía del transporte, lo que permite evidenciar el estado actual de la discusión objeto de análisis. Finalmente se realizará un Análisis Económico sobre la regulación del sistema de transporte, prestando particular atención a tres aspectos: la estructuración tarifaria; la distribución de costos y beneficios entre los distintos agentes, y los denominados costos ocultos, entendidos como externalidades negativas que se deben tener en cuanto al momento de efectuar una valoración sobre los impactos y efectos totales de la regulación. Dicho análisis se efectuará a partir del uso de una serie de herramientas proporcionadas por la economía y utilizadas por el AED, cuales son: i) el Teorema de Coase y el concepto de eficiencia macroeconómica; ii) los conceptos de Costos de Transacción y Derechos de Propiedad suministrados por la NEI; y, iii) El concepto de las Externalidades negativas.

iv) Finalmente, en el Capítulo IV se expondrán las conclusiones del presente trabajo y se realizará un ejercicio de Análisis Costo - Beneficio del sistema de transporte en Bogotá. Se culminará este aparte indicando los resultados del análisis Costo-Beneficio al que se arriba por los elementos arrojados por la presente investigación, e identificando una serie de criterios que se deben tener en cuenta al momento de diseñar y producir la regulación en materia de transporte público. 


\section{CAPÍTULO I.}

\section{LA ECONOMÍA SOCIAL DE MERCADO Y LOS DERECHOS RELACIONADOS CON EL SERVICIO DE TRANSPORTE PÚBLICO.}

El funcionamiento del servicio de transporte público en Bogotá, así como los derechos que tienen los usuarios para acceder a esta prestación esencial, se fundamentan en un sistema normativo establecido desde la Constitución Política. El objetivo del presente Capítulo, es identificar los derechos protegidos por la Constitución que están relacionados tanto con la prestación de servicios públicos, como con los derechos de los ciudadanos que garantizan su acceso y disfrute a tales prestaciones, y comprender las interacciones y las posibles tensiones que pueden presentarse entre los distintos intereses jurídicos tutelados, esto es, entre los derechos de quienes prestan servicios públicos, los derechos del Estado, y los derecho de los usuarios. En ese sentido, se estudiaran tres puntos fundamentales, así: i) en primer lugar se hará una breve aproximación al conjunto de normas constitucionales que regulan el sistema económico -Constitución Económica-, prestando particular atención a la regulación en materia de servicios públicos; ii) enseguida, se procederá a examinar los bienes jurídicos denominado en el presente trabajo como "los derechos de acceso al transporte", que corresponden a garantías constitucionales reconocidas a los ciudadanos, tanto desde una perspectiva individual, como colectiva, y los cuales deben ser garantizados en tanto Mandatos Constitucionales que generan especiales obligaciones para los poderes públicos; iii) se finalizará el capítulo con las respectivas conclusiones.

\subsection{Fundamentos Constitucionales de la Economía Social de Mercado.}

A continuación se examinarán una serie de enunciados normativos que se encuentran en permanente interacción, y que constituyen la base de la denominada Constitución Económica, sobre la cual se cimienta el Estado Social de Derecho. En primer lugar se encuentran las libertades económicas (art. 333) en tanto garantías indispensables para el logro del desarrollo económico y la prosperidad general, y correlativamente, se adscribió al Estado la función de dirección general de la economía, con amplios poderes de intervención (art. 334), y como guardián supremo del bien común y el interés social. Ambos elementos, al compatibilizarse dan origen a la denominada Economía Social 
de Mercado, “diseñada por el constituyente de 1991 como una expresión del Estado Social de Derecho" (Gil Alzate, 2009, p. 96), lo que conduce a concluir que el sistema económico se encuentra por lo menos en su estructura- constitucionalizado.

En efecto, tal y como lo ha sostenido la Corte Constitucional, la Constitución adoptó un modelo de Economía Social de Mercado, que protege a la empresa y, en general, a la iniciativa privada, como "motor de la economía, pero que limita razonable y proporcionalmente la libertad de empresa y la libre competencia económica, con el único propósito de cumplir fines constitucionalmente valiosos, destinados a la protección del interés general". Así entonces, la Economía Social de Mercado podría entenderse como una triada, que se encarga de articular tres elementos que orbitan alrededor del Estado Social de Derecho, así: i) por una parte los derechos económicos reconocidos a los particulares; ii) por otra, el poder de intervención asignado al Estado para asegurar el orden público y la prevalencia del interés general; y iii) finalmente, la cláusula social a la que se encuentra sujeto el Estado de Derecho y que constituye su esencia y finalidad. A continuación se estudiará cada uno de los referidos elementos.

\subsubsection{Los Derechos Económicos.}

La Libertad Económica (art. 333). El fundamento constitucional de la libertad económica se encuentra en el artículo 333, disposición que prevé lo siguiente:

“ARTICULO 333. La actividad económica y la iniciativa privada son libres, dentro de los límites del bien común. Para su ejercicio, nadie podrá exigir permisos previos ni requisitos, sin autorización de la ley.

La libre competencia económica es un derecho de todos que supone responsabilidades.

La empresa, como base del desarrollo, tiene una función social que implica obligaciones. El Estado fortalecerá las organizaciones solidarias y estimulará el desarrollo empresarial.

El Estado, por mandato de la ley, impedirá que se obstruya o se restrinja la libertad económica y evitará o controlará cualquier abuso que personas o empresas hagan de su posición dominante en el mercado nacional.

La ley delimitará el alcance de la libertad económica cuando así lo exijan el interés social, el ambiente y el patrimonio cultural de la Nación”. (Énfasis Fuera de Texto, en adelante EFT) 
Del fundamento constitucional citado, y siguiendo lo expuesto por la profesora Magdalena Correa (2009), se colige que las garantías allí reconocidas tienen una dimensión subjetiva, relativa al derecho de los individuos de participar en el mercado, y una dimensión objetiva relacionada con aquellas reglas y pautas que deben respetar todos los agentes económicos.

Otros Derechos Económicos. Tal y como lo sostiene el profesor Bassols, Citado por Correa (p. 78) "cabe tipificar una serie de derechos de naturaleza económica en el sentido de tener directa e indirectamente relación con el proceso económico y, por tanto legitiman a sus titulares a participar en el mismo". A partir de lo expuesto, dentro de la Constitución Política pueden identificarse derechos de marcada estirpe económica, pues su naturaleza se encuentra estrechamente ligada al proceso económico de producción, comercialización y consumo. Al respecto, se evidencian garantías constitucionales como el derecho al trabajo (art 25), reconocido como fundamental en el artículo 25 constitucional y en los convenios internacionales suscritos por Colombia; la libertad de profesión u oficio (art 26) que señala que "[t]oda persona es libre de escoger profesión u oficio"; la libertad de asociación (art 38) que indica que "[s]e garantiza el derecho de libre asociación para el desarrollo de las distintas actividades que las personas realizan en sociedad"; y la propiedad privada (art 58) según la cual "[s]e garantizan la propiedad privada y los demás derechos adquiridos con arreglo a las leyes civiles" fundamentos que hacen parte del catálogo de libertades económicas protegido por la Constitución Política.

\subsubsection{La Intervención del Estado en la Economía (art. 334 CP).}

En Colombia opera el principio general de intervención (art. 334), el cual constituye una habilitación general de injerencia y regulación del poder público en aras de asegurar el orden constitucional establecido. La citada disposición establece:

“ARTICULO 334. La dirección general de la economía estará a cargo del Estado. Este intervendrá, por mandato de la ley, en (...) los servicios públicos y privados, para racionalizar la economía con el fin de conseguir en el plano nacional y territorial, en un marco de sostenibilidad fiscal, el mejoramiento de la calidad de vida de los habitantes, la distribución equitativa de las oportunidades y los beneficios del desarrollo y la preservación de un ambiente sano. Dicho marco de sostenibilidad fiscal deberá fungir como instrumento para alcanzar de manera progresiva los objetivos del Estado Social de Derecho. En cualquier caso el gasto público social será prioritario. 
El Estado, de manera especial, intervendrá para dar pleno empleo a los recursos humanos y asegurar, de manera progresiva, que todas las personas, en particular las de menores ingresos, tengan acceso efectivo al conjunto de los bienes y servicios básicos. También para promover la productividad y competitividad y el desarrollo armónico de las regiones". (Énfasis fuera de texto).

Finalidades y modalidades de intervención. Así las cosas, según la profesora Correa (2009), la intervención del Estado responde a dos grandes finalidades, unas de orden social, tales como distribución equitativa de oportunidades, mejoramiento de calidad de vida y beneficios del desarrollo, acceso efectivo de todos, en particular de los de menos recursos, a los bienes y servicio básicos, promoción del desarrollo armónico, y otras de orden económico como "racionalizar la económica, promover la productividad y la competitividad" (p. 182). La intervención estatal, adopta diferentes formas mediante las cuales se concretizan las finalidades señaladas, siendo una de ellas la regulación de un determinado sector para asegurar las condiciones mínimas de acceso al mercado tanto de los agentes, como de los consumidores y usuarios. Pero esa primera forma de intervención no es la única, en ocasiones se hace necesaria una decidida intervención estatal en la economía "para corregir los errores de un mercado imperfecto y delimitar el ejercicio de la libertad de empresa, así como para preservar la sana y transparente competencia, con el fin de lograr una mejor prestación de aquellos [servicios]" (Corte Constitucional, Sentencia C 1162, 2000). Las facultades de intervención estatal, incluso permiten aplicar - tal y como se indicaba líneas atrás- la denominada reserva al sector público (Art. 365), planteada como excepción, según la cual los servicios públicos esenciales, por razones de soberanía o interés social, podrán ser prestados directamente por el Estado, incluso en condiciones de monopolio, cuando las circunstancias así lo ameriten. En ese sentido, tal y como lo definió la Corte Constitucional (Sentencia C-150, 2003), existen diferentes formas de intervención del Estado en la economía, pero para la presente investigación la más importante es la regulación en materia de servicios públicos.

\subsubsection{Cláusula del Estado Social de Derecho (art. $1^{0}$ ).}

La Constitución Política de Colombia (1991), introdujo como una de sus grandes novedades respecto de la constitución anterior, la determinación de un nuevo modelo de Estado, tal y como se evidencia en su artículo $1^{\mathrm{o}}$ : 
“ARTICULO 1. Colombia es un Estado social de derecho, organizado en forma de República unitaria, descentralizada, con autonomía de sus entidades territoriales, democrática, participativa y pluralista, fundada en el respeto de la dignidad humana, en el trabajo y la solidaridad de las personas que la integran y en la prevalencia del interés general". (EFT).

El carácter social del Estado. El signo social del Estado tiene repercusiones profundas, en el entendido que le impone obligaciones prestacionales, que implican "el despliegue de medidas de cobertura de riesgos sociales específicos, ligados justamente a la economía” (Correa, 2009, p 45). Precisamente, la nota diferencial Estado Social de Derecho es su marcado componente social, y lo social se fundamenta en el principio de igualdad material, tanto así que "sus exigencias y desafíos giran principalmente en torno a problemas sociales y de desigualdad material, y de los argumentos jurídicos, políticos y económicos para resolverlos” (p. 110). En ese sentido, la denominada cláusula social del Estado constituye un "Mandato Constitucional" dirigido a los poderes públicos, que los vincula en todas sus actuaciones, a observar plenamente los principios sobre los cuales se edificó el orden constitucional vigente: igualdad material, justicia, solidaridad, prevalencia del interés general y dignidad humana. Así entonces, la asistencia estatal en materia de servicios públicos, hace parte del núcleo esencial de las necesidades sociales, que por expresa disposición constitucional, integran las finalidades que el Estado colombiano debe asegurar.

\subsubsection{Regulación Constitucional de los Servicios Públicos (art. 365).}

Una vez identificada la estructura básica de la Economía Social de Mercado, compuesta por la triada libertad económica, intervención estatal y cláusula del Estado Social de Derecho, resulta imperativo examinar la base constitucional del funcionamiento de los servicios públicos, teniendo en cuenta que el problema fáctico que se analiza está relacionado con el servicio público de transporte urbano. Al respecto, el fundamento constitucional de los servicios públicos se encuentra contenido en el artículo 365 de la Constitución Política (CP), así:

“ARTICULO 365. Los servicios públicos son inherentes a la finalidad social del Estado. Es deber del Estado asegurar su prestación eficiente a todos los habitantes del territorio nacional.

Los servicios públicos estarán sometidos al régimen jurídico que fije la ley, podrán ser prestados por el Estado, directa o indirectamente, por comunidades organizadas, o por particulares. En todo caso, el Estado mantendrá la regulación, el control y la vigilancia de dichos servicios. Si por razones de 
soberanía o de interés social, el Estado, mediante ley aprobada por la mayoría de los miembros de una y otra cámara, por iniciativa del Gobierno decide reservarse determinadas actividades estratégicas o servicios públicos, deberá indemnizar previa y plenamente a las personas que en virtud de dicha ley, queden privadas del ejercicio de una actividad lícita. (EFT).

\subsubsection{Características del Régimen Constitucional de los Servicios Públicos.}

Finalidad Social. Lo primero es señalar que la aludida disposición constitucional prevé que los servicios públicos son "inherentes a la finalidad social del Estado", lo que implica que son de la esencia del componente social del modelo de Estado adoptado por la Constitución colombiana (1991), esto es, el Estado Social de Derecho. Lo anterior quiere decir, que uno de los objetivos principales del Estado consiste en "asegurar [la] prestación eficiente" de los servicios públicos, finalidad que genera una obligación, de origen constitucional, que impone a la organización Estatal el deber de realizar las actuaciones que resulten necesarias para garantizar el cumplimiento del mandato constitucional examinado. Así mismo, la prestación eficiente de los servicios públicos se debe asegurar "a todos los habitantes del territorio nacional", imperativo del cual emana el principio de universalidad de los servicios públicos (Gil Alzate, 2009), que genera una obligación que se debe garantizar independientemente de la forma mediante la cual se presten los servicios públicos, lo que a su vez refleja una posición jurídica, es decir, un derecho a favor de "todos los habitantes del territorio nacional" a exigir su cumplimiento.

Los Sujetos que Prestan Servicios Públicos. Frente a este tema, la Constitución Política de 1991 (en adelante CP) introdujo uno de los grandes cambios dentro de la estructura organizativa del Estado, no solo al considerar como una de sus finalidades la prestación de servicios públicos, sino al permitir que dichos servicios esenciales puedan ser prestados o bien por el Estado, de manera directa o indirecta, o bien por la comunidad organizada o por los particulares. La citada norma constitucional, cambió la regla general existente hasta el momento, que consistía en que los servicios públicos eran prestados directamente por el Estado. Ahora bien, la nueva estructura de los servicios públicos, generó correlativamente un replanteamiento del papel del Estado, pues dichos servicios, si bien podían prestarse por particulares bajo normas y criterios económicos de mercado, también se encuentran sujetos a directrices y mandatos de orden constitucional, toda vez que se trata de servicios que el Estado debe asegurar (Gil Alzate, 2009). Por esa razón, el art. 365 CP indicó que “[e]n todo caso, el 
Estado mantendrá la regulación, el control y la vigilancia de dichos servicios”, conservando así, las herramientas necesarias para dirigir la prestación de estas especiales prestaciones, en aras de garantizar los imperativos incorporados en la Constitución Política.

La entrada constante de los privados a la prestación de servicios públicos, requirió formas jurídicas adecuadas que no afectaran su efectiva prestación, y que a su vez garantizaran el control por parte del Estado. Aparecen entonces, como una de las alternativas -no la única- para la prestación de servicios públicos, los contratos de concesión como institución jurídica por medio de la cual "se confieren a personas extrañas a la organización estatal, un derecho o poder jurídico que antes no poseían pero que es del Estado o es propio de la administración pública” (Montes, 2000). En ese sentido, por medio de los contratos de concesión el Estado otorga a un particular la gestión o explotación de un servicio cuya titularidad le pertenece (Montes, 2000). El caso del transporte público resulta bastante ilustrativo, pues permite evidenciar cómo un servicio definido por la ley como servicio público esencial (artículo 5, Ley 336 de 1996), es entregado en concesión a los agentes privados encargados de su operación, la que en todo caso estará sujeta al ente regulador Transmilenio S.A. (TMSA), entidad pública encargada de la vigilancia y el control de la prestación del servicio dentro del marco regulatorio definido en dichos contratos.

El carácter esencial de los servicios públicos. Sobre el particular, la nota diferencial de los servicios públicos, respecto del resto de servicios se encuentra determinada en su carácter esencial, del cual surge su protección especial, derivada de la especial garantía que les ha reconocido el orden constitucional. Al respecto, tal y como lo sostienen el profesor Gil Alzate (2009) doctrinariamente se hace una distinción entre los bienes y servicios de mercado o no esenciales, y los bienes y servicios de carácter esencial, “en los que el Estado tiene la obligación de garantizar un estándar mínimo de cobertura en razón de que el mercado no es capaz de brindar la cobertura mínima” que demandan los usuarios y consumidor, para "acceder en términos de calidad a la prestación de un bien o servicio que es esencial e inherente a sus necesidades básicas y dignas" (p. 76). Lo expuesto, pone en evidencia que los servicios públicos pueden o no tener una connotación económica, y en caso de tenerla de ninguna manera podrán equiparse de modo absoluto a los demás servicios, pues a pesar de que lleguen a prestarse bajo las reglas del mercado, por particulares y en condiciones de onerosidad, los servicios públicos gozan de un estatus constitucional particular, luego entonces su prestación y cobertura no 
corresponde únicamente a una responsabilidad del mercado, "sino también a la intervención estatal y no solo a través de la regulación", también como prestador cuando el mercado no sea capaz de suministrar servicios en términos de acceso universal y cobertura (Gil Alzate, 2009, p. 95).

\subsection{Los Derechos de Acceso al Transportarse.}

En Colombia el servicio de transporte ha sido reconocido como una actividad fundamental para el desarrollo de las personas y de la sociedad en general, tanto así que fue incluido en el catálogo de los servicios públicos (Ley 336 de 1996), otorgándole con tal distinción el reconocimiento de servicio esencial, sin el cual no se puede garantizar la calidad de vida que está obligado a propiciar un Estado Social de Derecho. En desarrollo de lo anterior, también se ha reconocido la prerrogativa de los ciudadanos de acceder a éste servicio público esencial, tanto desde una perspectiva individual, al considerarlo como derecho fundamental bajo ciertas condiciones, como desde una perspectiva colectiva. Ambos tipos de reconocimiento jurídico, serán examinados en el siguiente acápite.

\subsubsection{El Derecho Fundamental al Acceso al Servicio de Transporte.}

La primera inquietud que surge al abordar el asunto bajo examen es la siguiente: ¿El acceso al servicio de transporte público es un derecho fundamental? La respuesta a este interrogante, en principio, indicaría que el servicio de transporte tiene un doble carácter, por una parte es concebido como un servicio público esencial (Ley 336 de 1996), y en consecuencia constituye una obligación que deben proveer las autoridades públicas, y por otra es un derecho en cabeza de los ciudadanos quienes tienen la facultad de hacer uso de él para desplazarse libremente. Sin embargo, al no encontrarse dentro del catálogo de los derechos fundamentales del Título II Capítulo I de la Constitución Política, tal prerrogativa no podría ser considerada fundamental.

No obstante lo anterior, la jurisprudencia constitucional han identificado 3 "escenarios constitucionales" (López Medina, 2013), entendidos como aquellas situaciones fácticas frente a las cuales el derecho al acceso al servicio de transporte ha sido reconocido como fundamental. Enseguida se procederá con el análisis de cada uno de los escenarios identificados. 


\subsubsection{Escenarios Constitucionales en los que el Acceso al Servicio de Transporte es reconocido como fundamental.}

Libertad de Locomoción. En primer lugar, el derecho al acceso al servicio de transporte se ha reconocido como fundamental, en la medida que en ciertas circunstancias constituye un medio indispensable para hacer efectiva la libertad de locomoción, bien jurídico que sí fue incorporado por la Constitución Política dentro de la categoría de derechos fundamentales, específicamente en el artículo 24, norma que prevé:

"ARTICULO 24. Todo colombiano, con las limitaciones que establezca la ley, tiene derecho a circular libremente por el territorio nacional, a entrar y salir de él, y a permanecer y residenciarse en Colombia."

El ámbito de protección de esta libertad se concentra, desde su dimensión personal, en "todo colombiano", dejando por fuera del alcance de la misma a los ciudadanos extranjeros, quienes estarán sujetos a una particular regulación legal sobre su circulación, permanencia y residencia. En cuanto al ámbito de protección material de la garantía bajo examen, la Corte Constitucional ha indicado que:

“(...) el artículo 24 de la Carta Política, comprende por lo menos en su sentido más elemental, la posibilidad de transitar o desplazarse de un lugar a otro dentro del territorio del propio país, especialmente si se trata de las vías y los espacios públicos. Es un derecho constitucional que como el derecho a la vida, tiene una especial importancia significativa, en tanto que es un presupuesto para el ejercicio de otros derechos y garantías, como por ejemplo, el derecho a la educación, al trabajo o a la salud". (Sentencia C-885 de 2010). (EFT).

En ese sentido, se ha reconocido que la libertad de locomoción no solo se garantiza mediante la omisión de acciones destinadas a restringirla, sino que a su vez, contiene un carácter prestacional, que implica que el Estado debe adelantar acciones positivas destinadas a asegurar su efectiva materialización, como por ejemplo la implementación de un servicio público de transporte mediante el cual los ciudadanos puedan ejercer su derecho a circular libremente. Así las cosas, el acceso al servicio de transporte público ha sido reconocido como derecho fundamental, en tanto que constituye la dimensión prestacional del derecho fundamental a la libertad de locomoción de personas que no cuentan con otros medios para desplazarse, y en consecuencia, solo mediante el aseguramiento del 
acceso real y efectivo al servicio de transporte público, se puede hacer efectiva la libertad fundamental de circulación, garantía de carácter ius-fundamental.

Conexidad con otros derechos fundamentales. Por otra parte, el segundo "escenario constitucional" en el que se ha reconocido la fundamentalidad del derecho al acceso al servicio de transporte, se presenta cuando dicha prestación resulta imprescindible para el aseguramiento de otros derechos fundamentales, como el derecho a la salud y el derecho a la educación. Sobre el Derecho a la Salud la Corte Constitucional ha señalado que está compuesto por 4 dimensiones prestacionales, una de las cuales consiste en la accesibilidad económica, que implica que cualquier obstáculo económico que restrinja el acceso efectivo al derecho a la salud, debe ser removido. Así las cosas, si un paciente presenta una condición patológica que pueda afectar de manera grave su salud, y requiere desplazarse para que le sea proveída la asistencia médica, y adicionalmente no cuenta con los recursos para solventar los costos de transporte, la EPS deberá responder por dichos costos pues los mismos se reconocen como una prestación indispensable para asegurar el derecho a la salud, y en consecuencia hacen parte íntegra de dicha garantía. Bajo similares consideraciones, la jurisprudencia constitucional ha reconocido la fundamentalidad del acceso al transporte en aquellos casos en donde la prestación de dicho servicio resulta imprescindible para acceder a la educación, razón por la cual se ha entendido como una prestación inherente al derecho fundamental de la educación, bajo particulares presupuestos fácticos.

Sujetos en condición de discapacidad. Finalmente, el tercer "escenario constitucional" se presenta frente a las personas que se encuentren en condición de discapacidad, en tanto que dadas sus particulares condiciones cuentan con especial protección constitucional, lo que ha conducido a que la jurisprudencia intensifique el ámbito de protección de su libertad de locomoción, la cual incluye el despliegue por parte de los poderes públicos de infraestructura y servicios especiales que garanticen el acceso real y efectivo al servicio de transporte. La anterior situación, siguiendo la metodología planteada por el profesor Lopez Medina (2013), queda plasmada en la Gráfica No. 1.

Una vez enunciadas las situaciones fácticas en las que el acceso al servicio de transporte ha sido reconocido como fundamental, y ante la escases de literatura y dogmática que aborde la específica cuestión bajo análisis, a continuación se examinará en detalle la evolución jurisprudencial en la 
materia, para efectos de precisar el contenido y alcance del derecho fundamental al acceso al servicio de transporte.

\section{Gráfica No. 1. Escenarios Constitucionales de Protección del Derecho al Acceso al transporte.}

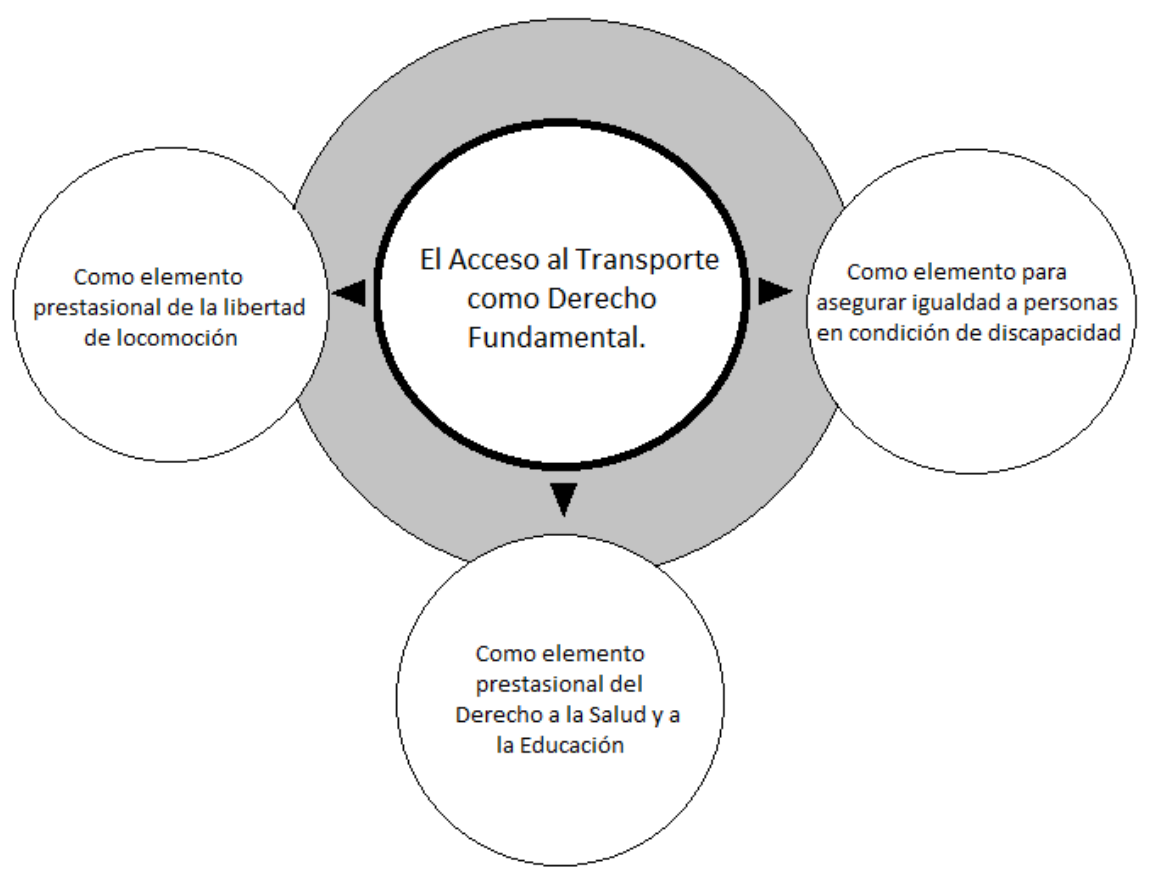

Fuente: Elaboración propia a partir de López Medina (El derecho de los jueces, 2013)

\subsubsection{Evolución Jurisprudencial.}

\section{El servicio público de transporte como elemento prestacional de la libertad de locomoción.}

Sobre el carácter fundamental del derecho al acceso al servicio de transporte, como elemento prestacional de la libertad de locomoción, en primer lugar se encuentra la Sentencia T-604 de 1992, mediante la cual se fundó dicha línea jurisprudencial. En la referida sentencia, la Corte Constitucional consideró que el servicio de transporte público es un medio indispensable para poder ejercer la libertad de locomoción, y sobre dicho particular señaló:

"Los derechos al trabajo, al estudio, a la libre circulación, a la recreación y al libre desarrollo de la personalidad resultan amenazados como consecuencia de la prestación discontinua e irregular del servicio de transporte a una zona marginal de una ciudad (...)”. 
Sin embargo, en la citada sentencia la Corte Constitucional no solo consideró que el servicio de transporte público hacía parte de un nutrido número de derechos fundamentales, sino que a su vez resaltó la importancia social y económica de dicha prestación, en los siguientes términos:

"El fenómeno de la ciudad - su tamaño y distribución - hace del transporte público urbano un medio indispensable para ciertos estratos de la sociedad, en particular aquellos que viven en las zonas marginales y carecen de otra forma de movilización.

De la capacidad efectiva de superar distancias puede depender la estabilidad del trabajo, el acceso y la permanencia en el sistema educativo, el ejercicio de la iniciativa privada y, en general, el libre desarrollo de la personalidad.

(...) La necesidad de trascender la distancia entre los sitios de habitación, trabajo, estudio, mercado, etc, en el menor tiempo y costo posibles, coloca al ciudadano carente de medios de transporte propios, a merced del Estado o de los particulares que prestan este servicio. (...)

(...) La fuerza de estructuración económica que posee el transporte público permite, cuando se accede al servicio, participar de la prosperidad general. Su carencia, en cambio, compromete un estándar mínimo de la existencia." (EFT)

Una vez marcado el rumbo sobre el carácter fundamental del servicio público de transporte, y en consecuencia, del carácter fundamental del derecho a acceder a éste, la jurisprudencia constitucional profundizó la línea decisional en ese sentido, y mediante Sentencia T-595 de 2002, la Corte Constitucional puntualizó sobre el vínculo fundamental entre la libertad de locomoción y el servicio de transporte público en los siguientes términos:

"Primero, la libertad de locomoción es de capital importancia por cuanto es una condición para el goce efectivo de otros derechos fundamentales. "

"Segundo, esta libertad se afecta no sólo cuando por acciones positivas directamente se obstruye la circulación de los ciudadanos, sino también se ve limitada cuando se genera ese efecto indirectamente o por omisión en la remoción de barreras o en la creación de una infraestructura adecuada para la circulación." 
Las Cláusulas Económicas de los Contratos de Concesión de Transmilenio y Sitp, Como Límites al Acceso al Servicio de Transporte Público. Andrés Felipe Pachón Torres

"Tercero, el servicio de transporte público es indispensable para el ejercicio de la libertad de locomoción, y de los demás derechos constitucionales que dependen de la posibilidad de movilizarse, en especial para aquellos sectores marginados de la población urbana que carecen de otra alternativa de transporte."

“Cuarto, el servicio básico de transporte debe ser accesible para todos los usuarios.

Y adicionalmente, sobre el carácter prestacional de las libertades públicas la Corte Constitucional señaló:

"En las sociedades modernas, donde el uso de la libertad individual depende de acciones y prestaciones públicas - servicio público de transporte, de telecomunicaciones, de salud, etc - y donde la seguridad personal cuesta, no es posible sostener la tesis del carácter negativo de las libertades básicas. Por el contrario, la infraestructura necesaria para hacer posible el ejercicio de las libertades fundamentales, los derechos de defensa y debido proceso o los derechos políticos, requiere de grandes erogaciones económicas y de la actuación permanente y coordinada por parte del Estado

Así las cosas, la "línea decisional predominante” (Lopez Medina, 2013) según la cual el servicio público constituye un elemento prestacional de la libertad de locomoción, se ha mantenido vigente a lo largo de los posteriores pronunciamientos de la Corte Constitucional (Véase Sentencias C-568 de 2003, C-408 de 2004, T-1094 de 2005 y C-033 de 2014, entre otras), donde se ha reiterado la íntima conexidad que existe entre el servicio de transporte y el ejercicio real y efectivo de la libre circulación.

El acceso al transporte como elementos prestacional de los derechos a la salud y a la educación. Una vez sentadas las bases sobre la existencia de elementos prestacionales de los derechos de libertad a través de la Sentencia T-427 de 1992 examinada líneas atrás, mediante Sentencia T-467 de 2002, la Corte Constitucional estimó la obligatoriedad de prestar el servicio del transporte del usuario por parte de la Empresa Promotora de Salud o la Administradora del Régimen Subsidiado bajo el cumplimiento de los siguientes supuestos:

“(i) se está ante el incumplimiento de la regulación sobre transporte de pacientes, que obliga a una EPS o a una ARS a prestar el servicio bajo ciertas circunstancias (ii) el paciente no pueda desplazarse por sus 
propios medios, ni su familia cuente con los recursos suficientes para ayudarle a acudir a los servicios de la entidad prestadora de servicios de salud a la cual está afiliado (iii) tal situación ponga en riesgo su vida o su integridad, y (iv) pese a haber desplegado todos los esfuerzos exigibles, no existen posibilidades reales y razonables con los cuales poder ofrecer ese servicio

Posteriormente, la Corte Constitucional expidió la Sentencia T-884 de 2003 que introdujo un elemento que permitiría consolidar el reconocimiento del servicio al transporte como fundamental por constituir un elemento prestacional de un derecho distinto al de la libertad de locomoción. En efecto, la Sentencia T-884 de 2003, al definir el contenido y alcance del derecho fundamental a la salud, indicó que dicha garantía incorporaba los siguientes elementos:

“(i) La no discriminación, (...)

(ii) La accesibilidad fisica, (...)

(iii) La accesibilidad económica, también denominada asequibilidad, entendida como la obligación de fijar los costos del servicio de salud bajo un criterio de equidad, bien si la atención es suministrada por entidades públicas o por privadas. La asequibilidad, igualmente, "exige que sobre los hogares más pobres no recaiga una carga desproporcionada en lo que se refiere a los gastos de salud, en comparación con los hogares más ricos".

(iv) El acceso a la información, (...)” (EFT).

Al momento de desarrollar el elemento de la accesibilidad económica del derecho a la salud, la Corte Constitucional concluyó que dicho elemento conducía a la eliminación de todas las barreras que injustificadamente impidieran el acceso a la salud, y que una de las posibles restricciones que se podían presentar consistía en los costos del transporte para el desplazamiento de los pacientes, lo que sin duda representó un cambio significativo en el reconocimiento del derecho de trasporte como fundamental, pues a partir de la Sentencia T-884 de 2003, el servicio de transporte se dejaría de entender exclusivamente como elemento prestacional de la libertad de locomoción, y comenzaría a ser reconocido como tal, respecto del derecho a la salud. En efecto, hasta el 2002 (Sentencia T-595 de 
2002), la exigibilidad del acceso al servicio de transporte para asegurar el derecho fundamental a la salud, se reconocía bajo el siguiente argumento:

"Por ejemplo, se vulnera el derecho a la libertad de locomoción de la persona que requiere de un tratamiento médico vital al que sólo puede acceder con el transporte público, cuando no se le garantiza inmediatamente el acceso al mismo de forma que se evite el daño grave e inminente que puede sufrir en caso de no recibir la atención requerida. (Sentencia T-595 de 02). (EFT)

Es decir, que el acceso al servicio de transporte solo era entendido como fundamental y objeto de amparo constitucional bajo la premisa de que se afectaba el elemento prestacional de la libertad de locomoción. Solo fue hasta la expedición de la Sentencia T-884 de 2003, que el acceso al transporte fue reconocido como fundamental por su conexidad directa con el derecho a la salud, evitando toda remisión a la libre locomoción. En dicha jurisprudencia, la Corte Constitucional indicó que:

“(...) en ocasiones, para que los usuarios puedan acceder a un servicio de salud, requieren que les sean financiados los gastos de desplazamiento, así como aquellos correspondientes a la estadía en el lugar donde se les pueda prestar atención médica, distinto a aquel en el que residen. (...) [E]sta obligación se traslada a las entidades promotoras de salud, únicamente en los eventos concretos donde se acredite que (i) ni el paciente ni sus familiares cercanos tienen los recursos económicos suficientes para pagar el valor del traslado y (ii) de no efectuarse la remisión se pone en riesgo la vida, la integridad física o el estado de salud del usuario.

(...) Por lo tanto, toda persona tiene derecho a que se remuevan las barreras y obstáculos que impidan a una persona acceder a los servicios de salud que requiere con necesidad, cuando éstas implican el desplazamiento a un lugar distinto al de residencia, debido a que en su territorio no existen instituciones en capacidad de prestarlo, y la persona no puede asumir los costos de dicho traslado. "(EFT).

Posteriormente la Corte Constitucional mediante Sentencia T-197 de 2003, fue más allá al reconocer también el derecho al acceso de transporte y los gatos de estadía y manutención al acompañante del paciente, siempre y cuando se cumplieran los siguientes requisitos: 
“(i) [Que] el paciente sea totalmente dependiente de un tercero para su desplazamiento, (ii) requiera atención permanente para garantizar su integridad física y el ejercicio adecuado de sus labores cotidianas y (iii) ni él ni su núcleo familiar cuenten con los recursos suficientes para financiar el traslado."

A partir de los anteriores pronunciamiento, se reconoció jurisprudencialmente que bajo ciertas condiciones fácticas, el servicio de transporte se erigía como una barrera que impedía el acceso efectivo al derecho a la salud, y por lo tanto, los gastos de desplazamiento, esto es, el acceso al servicio de transporte entraba a formar parte del derecho a la salud, pues frente a particulares circunstancia constituye un presupuesto indispensable para efectivizar ésta garantía fundamental.

Las anteriores reglas jurisprudenciales fueron reiteradas a través de diferentes sentencias de la Corte Constitucional (T-905 de 2005, T-1087 de 2007, T-542 de 2009, T-709/11). Al respecto, la Sentencia T-760 de 2008, sintetiza la línea jurisprudencial en esta materia, y prevé:

"Si bien el transporte y hospedaje del paciente no son servicios médicos, en ciertos eventos el acceso al servicio de salud depende de que al paciente le sean financiados los gastos de desplazamiento y estadía en el lugar donde se le pueda prestar atención médica.

(...) toda persona tiene derecho a acceder a los servicios de salud que requiera, lo cual puede implicar tener derecho a los medios de transporte y gastos de estadía para poder recibir la atención requerida. (...) $(E F T)$.

Así mismo, el derecho al acceso al transporte se ha reconocido como parte del derecho fundamental a la educación, bajo similares consideraciones a las expuestas con respecto al derecho a la salud, aunque no con la misma frecuencia y cantidad. En efecto, el derecho a la educación también comprende cuatro dimensiones de contenido prestacional, tal y como lo explica la Sentencia T-1259 del 2008, así:

“i) La asequibilidad o disponibilidad del servicio, (...) 
ii) La adaptabilidad, que se refiere a la necesidad de que la educación se adapte a las necesidades y demandas de los educandos (...)

iii) La aceptabilidad, la cual hace alusión a la necesidad de asegurar la calidad de la educación que se imparte;

iv) Y, finalmente, la accesibilidad, que se refiere a la obligación del Estado de garantizar el ingreso de todos en condiciones de igualdad al sistema educativo y al deber de facilitar tanto como sea posible el acceso al servicio desde el punto de vista geográfico y económico. (EFT).

En dicho pronunciamiento, la Corte Constitucional amparó los derechos fundamentales a la educación y la vida digna de todos los niños residentes del municipio de Tuta, Boyacá, quienes tenían que efectuar largos desplazamientos para llegar a su escuela. La Corte Constitucional señaló que las entidades territoriales encargadas de ejecutar las políticas educativas, "al no adoptar un plan para solucionar el problema de accesibilidad material al sistema educativo", habían afectado el proceso de aprendizaje de los menores, "razón por la cual se encontraba amenazado el derecho a la educación”.

Bajo las anteriores consideraciones, la Corte Constitucional ha reconocido que el acceso al servicio de educación implica el aseguramiento de una serie de condiciones (físicas, económicas y sociales) para que el goce de este derecho sea real y efectivo. Por lo tanto, el Estado deberá proveer las condiciones especiales, según las condiciones concretas de los habitantes de un determinado territorio, para garantizar el acceso a la educación, lo cual podrá incluir la prestación del servicio de transporte, como elemento indispensable para lograr la accesibilidad material de la población al derecho a la educación. En ese sentido, la Corte Constitucional mediante Sentencia T-690 de 2012, manifestó:

"El transporte escolar de niños y niñas, en especial de aquellos que residen en zonas alejadas de la institución educativa o de difícil acceso, es una prestación propia del derecho a la educación”.(EFT).

\section{La especial protección constitucional a los discapacitados y el derecho a acceder a los} servicios de transporte público. Por otra parte, el acceso al servicio de transporte también se ha reconocido como fundamental en los casos relacionados con las personas que se encuentren en 
condición de discapacidad. El fundamento de dicha situación se encuentra en que la Constitución Política de Colombia, incorporó la protección especial de grupos "marginados" o "desventajados" de la sociedad, en desarrollo del derecho a la igualdad (art. 13 C.P.) que obliga al Estado a promover condiciones para que la igualdad "sea real y efectiva" y adicionalmente le impone la obligación de adoptar medidas en favor de grupos "discriminados", especialmente a aquellos que por su condición económica, física o mental, "se encuentren en circunstancia de debilidad manifiesta". Así mismo el artículo 47 constitucional señala que:

“El Estado adelantará una política de previsión, rehabilitación e integración social para los disminuidos fisicos, sensoriales y psíquicos, a quienes se prestará la atención especializada que requieran”.

En desarrollo de los anteriores preceptos constitucionales, la jurisprudencia de la Corte Constitucional, mediante Sentencia T-595 de 2002 identificó un nuevo "escenario constitucional" relacionado con unos sujetos de especial protección y su derecho al acceso al servicio de transporte. De esta manera la Corte Constitucional amplió su línea jurisprudencial en esta materia, y manifestó:

"El que una prestación amparada por un derecho sea de carácter programático [accesibilidad de personas en condición de discapacidad] no quiere decir que no sea exigible o que eternamente pueda incumplirse. La libertad de locomoción, en su faceta prestacional, es un derecho constitucional que al igual que los demás debe ser respetado desarrollado y garantizado, máxime si es para remover los obstáculos que impiden el acceso a una persona discapacitada al sistema de transporte de su ciudad con el fin de alcanzar la igualdad real y efectiva (artículo 13, CP)".

"En conclusión, el ámbito de protección de la libertad de locomoción de una persona discapacitada contempla la posibilidad de acceder al sistema de transporte público básico de una ciudad en condiciones de igualdad, es decir, sin tener que soportar limitaciones que supongan cargas excesivas. La dimensión positiva de este derecho fundamental supone, por lo menos (i) contar con un plan, (ii) que permita, progresivamente, el goce efectivo del derecho, y (iii) que posibilite la participación de los afectados en el diseño, ejecución y evaluación de dicho plan, en este caso en los términos de las leyes vigentes que desarrollan la Constitución en este ámbito". (EFT). 
Posteriormente, la Corte Constitucional expidió la Sentencia C-439 de 2011, a través de la cual reafirmó que el servicio de transporte público lleva implícito el derecho de libre locomoción, pero adicionalmente intensificó su protección en tratándose de sujetos de especial protección constitucional, como ocurre con las personas en condición de discapacidad. Sobre el particular, la Corte afirmó:

“En consecuencia, el servicio público de transporte lleva implícito el derecho de libre locomoción y por tanto de libre acceso, lo cual implica: (i) que el usuario pueda transportarse a través del medio y modo que escoja en condiciones de comodidad, calidad y seguridad, (ii) que los usuarios sean informados sobre los medios y modos de transporte que le son ofrecidos y las formas de su utilización, (iii) que las autoridades competentes diseñen y ejecuten políticas dirigidas a fomentar el uso de los medios de transporte, racionalizando los equipos apropiados de acuerdo con la demanda y propendiendo por el uso de medios de transporte masivo, (iv) que el diseño de la infraestructura de transporte, así como la provisión de los servicios de transporte público de pasajeros, supongan que las autoridades competentes promuevan el establecimiento de las condiciones para su uso por los discapacitados físicos, sensoriales y psíquicos.” (EFT).

En ese orden de ideas, las prestaciones que deben asegurar las autoridades públicas en materia de servicio de transporte, se intensifican con respecto a las personas en condición de discapacidad, pues se deben promover de manera real y efectiva (mediante planes, programas y acciones objetivas), el establecimiento de las condiciones indispensables para que este grupo de personas puedan acceder a dicho servicio, so pena de lesionar el derecho fundamental a la libre locomoción de estos sujetos de especial protección, lo que implica el diseño de infraestructura y la provisión de servicios especiales para garantizar su acceso al servicio público de transporte.

De esta manera queda expuesta la evolución jurisprudencial que ha tenido el reconocimiento del derecho al acceso al servicio de transporte como fundamental. En un primer momento, el acceso al transporte solo fue reconocido como esencial al ser identificado como elemento prestacional de la libertad de locomoción, sobre todo para los sectores marginales y que se encontraban en condiciones económicas deficitarias. Más tarde, la fundamentalidad de este derecho se reconoció cuando su prestación resultaba indispensable para el aseguramiento de derechos fundamentales como la salud y la educación. Finalmente, la Corte Constitucional al examinar la situación de las personas en condición 
de discapacidad, dispuso que su libertad de locomoción contenía un espectro más amplio de protección, al punto de incluir dentro del ámbito de su garantía, la elaboración de planes, programas y acciones objetivas destinadas a promover las condiciones necesarias para asegurar el acceso real y efectivo de este grupo de sujetos de especial protección. En los tres "escenarios constitucionales" examinados, el acceso al servicio de transporte público constituye un derecho fundamental que debe ser asegurado por los poderes públicos.

Límites. Finalmente, el derecho fundamental al acceso del servicio de transporte, como todos los derechos constitucionales, no es absoluto y encuentra una serie de limitaciones que se explicarán en conjunto con los límites que se presentan respecto del derecho colectivo al acceso al servicio de transporte, en la medida que la mayor parte de las limitaciones se originan en el ámbito del acceso, razón por la cual las restricciones se producen independientemente del sujeto que demande la prestación, que bien puede corresponder a un individuo (derecho fundamental al acceso), o a una colectividad (derecho colectivo al acceso).

\subsubsection{El Derecho Colectivo Al Acceso Al Servicio De Transporte Público.}

Como quedó visto, el análisis de la cuestión problemática objeto de la presente investigación, podría llevarse a cabo en términos del derecho fundamental al acceso al servicio de transporte, en los específicos escenarios constitucionales en los que ha sido reconocido. Sin embargo, para tener un panorama completo de los derechos que se encuentran en interacción alrededor de la prestación del servicio público de transporte, resulta necesario examinar el derecho colectivo al acceso al servicio público, interés jurídico tutelado por el ordenamiento jurídico, que permite abordar la problemática desde una perspectiva más amplia, teniendo en cuenta la dimensión colectiva, pues sin duda los problemas del servicio de transporte afectan a los individuos, pero a su vez, superan la órbita de los derechos individuales, pues están en juego intereses de naturaleza social, cuya incidencia impacta grupos significativos de interés, razón por la cual un análisis que tenga en cuenta únicamente los derechos fundamentales podría resultar incompleto y no tener en cuenta variables macro de particular importancia que determinan la valoración final. En ese sentido, se analizará el referido derecho 
colectivo para efectos de tener una visión completa, desde una perspectiva de derechos, del fenómeno bajo estudio.

Los Derechos Colectivos como Derechos Subjetivos. Para efectos de establecer el concepto y alcance del Derecho Colectivo bajo examen, se utilizará la metodología y los fundamentos planteados por el profesor Rodolfo Arango (2012), en su obra "el concepto de los derechos sociales fundamentales", que consiste en abordar el análisis desde el concepto de los derechos subjetivos. Se parte, de que el derecho subjetivo es "el poder legal reconocido a un sujeto (individual o colectivo) por medio de una norma legal, para la persecución de intereses propios mediante la exigencia a otro de hacer, permitir u omitir algo" (Arango, 2012, p. 90). A partir de esta definición, el profesor Arango distingue tres características indispensable del derecho subjetivo, así: i) una norma jurídica, ii) una obligación jurídica de otro, derivada de esta norma, y iii) un poder jurídico para la consecución de intereses propios reconocidos al sujeto (es decir una posición jurídica). Sobre estos tres elementos se abordará el análisis del Derecho Colectivo al Acceso al Servicio de Transporte Público. Es válido aclarar que los derechos subjetivos, se contraponen al derecho objetivo, entendido como aquel que es definido por una norma jurídica, que genera una obligación jurídica, pero que no crea posiciones jurídicas, es decir, no reconoce a ningún sujeto la posibilidad de exigir su cumplimiento. A manera ilustrativa, el profesor Arango cita el ejemplo anglosajón donde se utilizan vocablos diferentes para diferenciar el derecho objetivo al que se le denomina law, del derecho subjetivo que es identificado con el vocablo right. Aclarado lo anterior, se examinarán cada una de las características aludidas.

\subsubsection{Norma jurídica.}

Los artículos 78, 79 y 80 de la Constitución Política son los enunciados normativos que contienen los Derechos Colectivos, y fueron desarrollados por la ley 472 de 1998, que en su artículo $4^{\circ}$, introdujo un listado enunciativo de los derechos colectivos, que pueden ser amparados mediante las acciones populares, y en su literal j) estableció como derecho o interés colectivo el siguiente: “j) El acceso a los servicios públicos y a que su prestación sea eficiente y oportuna”. Frente a lo anterior, se advierte que la norma hace referencia a los servicios públicos en general, lo que indica que a dicha disposición podrá adscribírsele el cumplimiento específico de todos aquellos servicios que el legislador haya reconocido como públicos. 


\subsubsection{Obligación jurídica.}

La obligación jurídica constituye el núcleo esencial del derecho, y se entiende como el imperativo coercible de dar, hacer, o no hacer algo. Sin obligación jurídica no habría derecho en sentido material. La Constitución Política (art. $1^{\circ}$ ), tal y como se indicó en la primera parte de este capítulo reconoció que los servicios públicos constituyen una actividad inherente a los fines propios del Estado Social de Derecho, el cual tiene por objeto servir a la comunidad, promover la prosperidad general y garantizar la efectividad de los principios, derechos y deberes consagrados en la Constitución (Sentencia C- 066, 1997). En ese sentido, del Derecho Colectivo analizado, emerge una obligación jurídica -en cabeza del Estado-, que consiste en asegurar la prestación efectiva, en términos de eficiencia y oportunidad, de los servicios públicos, en el presente caso, del servicio público de transporte. En efecto, las obligaciones derivadas de los derechos colectivos asumen la forma de "Mandatos Constitucionales", entendidos como "obligaciones jurídicas objetivas en cabeza de los órganos legislativos o administrativos para la realización de la meta o el programa formulado en el mandato" (Arango, 2012, p. 43). Ahora bien, el derecho colectivo al acceso al servicio público no tiene un mayor desarrollo normativo, razón por la cual ha sido la jurisprudencia, la que al momento de resolver acciones populares ha procedido a nutrir su concepto, a partir de los diferentes elementos que lo componen. Así, el Consejo de Estado se ha pronunciado sobre el referido derecho, de la siguiente manera: "el Derecho a la prestación eficiente y oportuna de los servicios públicos se concibe como un derecho de naturaleza prestacional", por cuanto el Estado debe velar por el mejoramiento de las condiciones de vida de los asociados, y "debe propender por la ampliación y cobertura de dichas actividades económicas" (2006). En tal sentido, los elementos de la obligación jurídica que emerge del derecho analizado, son los siguientes: i) el acceso, ii) la noción de servicios públicos, iii) la eficiencia y iv) la oportunidad, aspectos que se explicarán a continuación.

Servicio Público. Los servicios públicos son aquellas actividades que suministra un proveedor a unos usuarios, para solucionar "necesidades que determinan su calidad de vida individual o el desarrollo colectivo de la sociedad", luego estamos frente a un concepto que estará siempre determinado por los valores fundamentales que imperen en una determinada colectividad (Atehortúa, 2003). En ese sentido, el carácter de servicios públicos, así como el de Derechos Colectivos estará determinado por la ley, pues frente a estos conceptos opera la reserva legal. Sobre el servicio de 
transporte, es pertinente indicar que en virtud del Estatuto Nacional de Transporte, Ley 336 de 1996 dicho servicio fue reconocido no solo como público, sino como esencial. Al respecto, los artículos 4 y 5 establecen lo siguiente:

"Artículo $4^{o}$-El transporte gozará de la especial protección estatal y estará sometido a las condiciones y beneficios establecidos por las disposiciones reguladoras de la materia, las que se incluirán en el plan nacional de desarrollo, y como servicio público continuará bajo la dirección, regulación y control del Estado, sin perjuicio de que su prestación pueda serle encomendada a los particulares."

“Artículo $5^{\circ}$-El carácter de servicio público esencial bajo la regulación del Estado que la ley le otorga a la operación de las empresas de transporte público, implicará la prelación del interés general sobre el particular, especialmente, en cuanto a la garantía de la prestación del servicio y a la protección de los usuarios, conforme a los derechos y obligaciones que señale el reglamento para cada modo". (Ley 336, 1996) (Énfasis Fuera de Texto).

Por su parte, los contratos de concesión tanto del Transmilenio como del SITP, incluyeron cláusulas que reafirman la naturaleza pública y esencial de este servicio, como se puede visualizar mediante Tabla No. 1, así:

Tabla No. 1. Carácter de Servicio Público.

\begin{tabular}{|c|c|}
\hline Contrato Transmilenio & Contrato SITP \\
\hline $\begin{array}{l}\text { CLAUSULA 2.- OBJETO DEL CONTRATO. } \\
\text { El presente contrato tiene por objeto: } \\
2.1 \text { Otorgar en concesión no exclusiva al } \\
\text { CONCESIONARIO, la explotación económica del } \\
\text { servicio público de transporte terrestre } \\
\text { automotor urbano masivo de pasajeros, en los } \\
\text { términos, bajo las condiciones y con las } \\
\text { limitaciones previstas en el presente contrato. }\end{array}$ & $\begin{array}{l}\text { CLÁUSULA 6. NATURALEZA DEL } \\
\text { SERVICIO. } \\
\text { El CONCESIONARIO expresamente declara y } \\
\text { acepta que el servicio que presta tiene el carácter } \\
\text { de servicio público esencial para todos los } \\
\text { efectos legales y con las consecuencias que de su } \\
\text { naturaleza jurídica se deriven. (Contrato } \\
\text { Concesión SITP, 2010) }\end{array}$ \\
\hline
\end{tabular}

Fuente: Elaboración propia a partir de (Contrato Concesión SITP, 2010) y (Transmilenio S.A., 2001)

Se trata entonces, de una actividad esencial que permite a los ciudadanos materializar derechos y libertades fundamentales, así como asegurar -en parte- su calidad de vida y el desarrollo de la sociedad, por lo cual el Estado está en la obligación de garantizar el acceso real y efectivo a este servicio. 
Acceso. En cuanto a la noción del acceso, lo primero es advertir que este elemento, al lado del concepto de servicio público constituye el aspecto principal de este específico Derecho Colectivo, toda vez que los otros dos elementos, la eficiencia y la oportunidad, son los componentes que entran a calificar la forma y las condiciones en las cuales se debe verificar dicho acceso. Así las cosas, el acceso al que se refiere el derecho, "consiste en la posibilidad [real y efectiva] de recibir el servicio en la cantidad, calidad y tiempo adecuados" (Gil, 2004). El acceso al derecho se refiere a la real oportunidad que tienen los ciudadanos de poder disfrutar de los beneficios de un servicio, lo cual está ligado con el tema de la cobertura, ya que en la medida que un servicio llegue a más lugares y a más usuarios, se incrementan los niveles de acceso. No obstante, es relevante aclarar que el acceso no consiste en la simple posibilidad de recibir la prestación del servicio, es necesario que esta se realice en la cantidad, calidad y tiempo adecuado, aspecto que conecta lo hasta aquí referido con los otros dos componentes, la eficiencia y la oportunidad.

Eficiencia y Oportunidad. En cuanto a la eficiencia, esta se considera como la "capacidad de lograr el objetivo deseado optimizando los recursos disponibles". Este concepto hace parte de los principios fundamentales de los "Estados Democráticos Modernos", y es piedra angular del discurso de la liberalización económica. Por su parte, el Consejo de Estado ha señalado que: "es precisamente la infraestructura física y organizacional, la que permite establecer los parámetros para la prestación eficiente de los servicios públicos, en aras de optimizar las condiciones de vida de la población" (Sala de lo Contencioso Administrativo, Sección Tercera, 2006). Justamente, el argumento principal que sustenta los procesos de privatización es la falta de eficiencia de las empresas estatales, por lo que se recurre entonces al sector privado, que por su ánimo de lucro está obligado a incrementar su eficiencia para obtener mayores márgenes de ganancia. Luego entonces, puede afirmarse que la eficiencia a la que se refiere el derecho colectivo al acceso a los servicios públicos consiste en que los servicios públicos lleguen al mayor número de usuarios, en las mejores condiciones, a los menores costos posibles. En cuanto a la oportunidad, este componente se refiere al factor temporal, toda vez que no es suficiente con que los servicios se presten en condiciones de calidad y eficiencia, es necesario que se haga en el tiempo en el que subsiste la necesidad, en el que se configura la escases de un servicio esencial para la calidad de vida de las personas. En esos términos queda establecido el contenido del Derecho Colectivo al acceso al servicio público de transporte, y a que su prestación sea en condiciones de eficiencia y oportunidad. 


\subsubsection{Posición Jurídica.}

La diferencia entre el derecho objetivo y los derechos subjetivos, está marcada por la posición jurídica, entendida como la situación que ocupa un sujeto dentro de un orden normativo, situación que lo habilita para exigir un derecho, otorgándole una posición desde la cual puede reivindicar el cumplimento de una obligación jurídica. En ese sentido, existe una estrecha relación entre los derechos subjetivos y la teoría de la argumentación jurídica que irradia sus efectos sobre todo el sistema normativo, pues la posibilidad de que algún sujeto reivindique un determinado derecho, depende de que las razones en las que fundamente sus demandas resulten razonables, jurídicamente válidas y suficientes. Así mismo, es válido anotar que a partir de la interpretación sistemática e integral del ordenamiento jurídico, pueden identificarse tanto obligaciones jurídicas, como posiciones jurídicas implícitas, que subyacen dentro del sistema de valores y la lógica del orden constitucional vigente. Bajo tales consideraciones, la posición jurídica de los derechos colectivos dentro del sistema constitucional colombiano, es reconocida a la colectividad en general, por lo tanto cualquier grupo, colectivo, minoría, e incluso cualquier persona en nombre de la sociedad en general, se encuentra en posición para exigir el cumplimiento del derecho colectivo al acceso al servicio de transporte público.

En el caso del transporte público en la ciudad de Bogotá - tal y como se demostrará en detalle en el capítulo segundo de la presente investigación-, se pueden identificar dos grupos a los que no se les está garantizando plenamente el derecho al acceso a un servicio de primera necesidad como el transporte, en los términos que establece el orden jurídico. El grupo número uno G1, está constituido por las personas de estrato 1 y 2 que quedan excluidos del servicio de transporte por los altos costos. El grupo dos G2 estaría comprendido por personas del estrato 3 quienes si bien no se ven directamente excluidos del servicio, si ven seriamente afectada su economía familiar dadas las onerosas tarifas reduciendo o limitando su acceso a esta prestación esencial. En línea con lo anterior, y teniendo en cuenta que los colectivos G1 y G2 se encuentran en una situación deficitaria respecto del derecho a acceder de manera real y efectiva al servicio de transporte, tales grupos podrían exigir al Estado el cumplimiento de sus obligaciones jurídicas, derivadas del derecho colectivo bajo análisis, que consisten en el deber de asegurar la posibilidad de utilizar el servicio de transporte. Frente a tales exigencias y reivindicaciones, y teniendo en cuenta los imperativos que emanan de la formula social del Estado, así como de los Mandatos Constitucionales que imponen la provisión de ciertas 
prestaciones esenciales, el poder público, en aras de garantizar el derecho colectivo reconocido por el sistema jurídico, deberá adoptar las medidas que sean necesarias, sin anular los demás derechos en interacción, para asegurar la garantía colectiva aquí examinada. Así, puede colegirse que una de las ventajas de los derechos colectivos, respecto de los individuales, consiste en que por la vía del derecho colectivo al acceso al servicio de transporte, la posibilidad de exigir al Estado el aseguramiento de las condiciones necesarias para que las personas puedan usar de manera real y efectiva este servicio esencial, es directa, y el radio de acción que generan tales obligaciones prestacionales resulta sumamente amplio, permitiendo el despliegue de medidas estructurales que pueden resultar más efectivas en aras de salvaguardar intereses sociales, logrando así un mayor impacto.

Concepto del Derecho Colectivo al Acceso al Servicio de Transporte. Por lo hasta aquí expuesto, y teniendo en cuenta que los derecho subjetivos -dentro de la que se encuentran los colectivos- "son todas las posiciones jurídicas que se le pueden adscribir a un enunciado normativo o a una "red de enunciados normativos" por medio de razones válidas" (Arango, p. 20), se puede hablar con total certeza de la existencia del DERECHO COLECTIVO AL ACCESO AL SERVICIO DE TRANSPORTE PÚBLICO, el cual constituye un poder jurídico reconocido a toda la sociedad, para exigir al Estado el cumplimiento de Mandatos Constitucionales de carácter prestacional, que lo obligan a asegurar las condiciones necesarias para garantizar el acceso real y efectivo de toda la población a este servicio esencial en condiciones de oportunidad y eficiencia, logrando así la protección de dicho beneficio público tutelado por la Constitución.

\subsubsection{Límites de los Derechos de Acceso al Transporte.}

Ahora bien, todo derecho es objeto potencial de limitación dentro del sistema constitucional que se ha diseñado, y el discurso jurídico-político desarrollado en la actualidad. Los derechos no son absolutos, son limitables. Y la primera fuente de las limitaciones es la propia constitución. De ahí que exista la necesidad de conciliar las tensiones que surjan entre los intereses y las posiciones jurídicas que protege el ordenamiento constitucional, en desarrollo del principio hermenéutico de unidad de la constitución, fundamentado en la existencia de un sistema armónico y coherente, que obliga a los 
poderes públicos a buscar la máxima efectividad de todas las normas de la Constitución (Correa, 2009).

Ahora bien, los límites del derecho colectivo al servicio público de transporte, y al derecho fundamental al acceso al transporte, no son distintos a los límites que se presentan respecto de los demás servicios esenciales, y principalmente se encuentran identificados tres grandes tipos de restricciones generales. En primer lugar, se encuentran las restricciones de infraestructura, que se refieren a la posibilidad técnica de prestación del servicio. En materia de transporte esto se traduce en que no se puede prestar el servicio por todas las rutas necesarias, por lo que resulta forzoso priorizar, e ir resolviendo las necesidades paulatinamente, al ritmo que la economía lo permita. Por otra parte, se encuentran limitaciones de acceso físico, relativas a los acondicionamientos apropiados para asegurar el acceso de las personas en condición de discapacidad. Finalmente, se encuentran las limitaciones de acceso de orden económico, reflejadas en la capacidad de los ciudadanos de pagar la tarifa, que es el precio que se fija como contraprestación por el uso del servicio. Así las cosas, el objeto de la presente investigación se concentra en éste último tipo de restricciones, pues precisamente la cuestión que intenta resolver la investigación consiste en determinar si las tarifas derivadas de la regulación existente en materia de transporte público, constituyen una limitación que afecte el acceso real y efectivo de la población, en especial de los sectores más vulnerables, y establecer si como consecuencia de dicha limitación se afectan derechos y valores constitucionales que están obligado a asegurar los poderes públicos. Por tal razón, en el Capítulo II se realizará una aproximación al funcionamiento operativo, y a la economía del sistema de transporte de Bogotá, para contrastarlos con la realidad socioeconómica de la capital, con el fin demostrar que las tarifas del sistema de transporte no se adecuan a la capacidad de pago promedio de los ciudadanos, y por lo tanto se erigen en poderosas barreras que impiden el acceso a un servicio esencial.

\subsection{Conclusiones Capítulo I.}

Al examinar los fundamentos constitucionales del sistema económico colombiano, se identifican tres aspectos sobre los cuales se erige la Constitución Económica. En primer lugar se encuentran las libertades económicas reconocidas por el ordenamiento, también denominados derechos económicos constitucionales, compuestos por la libertad de empresa (art. 333), el derecho al trabajo (art. 25) la 
libertad de asociación (art. 38), la libertad de profesión u oficio (art. 26), el derecho a la propiedad privada (art. 58), entre los más relevantes. En segundo lugar, se incorpora la intervención económica del Estado (art. 334), mediante la cual los poderes públicos deben asegurar la prevalencia del interés general y el cumplimiento de los valores y principios estipulados en el texto Constitucional; de las diferentes formas de intervención estatal, para efectos de la presente investigación, resulta de particular importancia la regulación de los servicios públicos. Finalmente, estos dos pilares sobre los que se cimienta la estructura económica, deben ser interpretados y efectivizados en el marco de la denominada cláusula social del Estado, compuesta por los valores y principios fundantes del Estado Social de Derecho.

La conjugación y articulación de los tres elementos referidos, dan origen a la denominada Economía Social de Mercado, que constituye la expresión económica del Estado Social de Derecho. Ahora bien, en desarrollo de la Economía Social de Mercado, el constituyente introdujo una nueva regulación de los servicios públicos, entendidos como aquellas prestaciones esenciales para asegurar las condiciones necesarias para que los asociados gocen de una vida digna, en adelante, los servicios públicos podrán ser prestados bien sea por el Estado, o por los particulares (art. 365), situación que generó un gran fenómeno de liberalización de los servicios públicos que dejaron de ser monopolios estatales, para dar paso a agentes económicos particulares quienes bajo las reglas del mercado entraron a prestar servicios públicos. No obstante, en atención a que los servicios públicos son inherentes a las finalidades del Estado, su prestación no se rige como cualquier bien o servicio de mercado, pues cuentan con una regulación específica, que en todo caso deberá garantizar la prevalencia del interés general y la prestación real y efectiva de tales servicios a la población, generando nuevas funciones en cabeza del Estado, quien si bien ya no sería su directo operador, continuaría con las labores de inspección, vigilancia y control, dando paso al denominado Estado Regulador.

La segunda parte del Capítulo I, abordó el análisis de los derechos de acceso al transporte reconocidos por el ordenamiento jurídico. Se examinaron los tres "escenarios constitucionales" en los cuales el acceso al servicio de transporte se ha reconocido como fundamental, explicando los fundamentos constitucionales que se han tenido en cuenta para ello. Así mismo se efectuó un análisis sobre la evolución jurisprudencial que permitió identificar que en un primer momento se reconoció el acceso al transporte como prestación ius-fundamental solamente cuando la libertad de locomoción se 
viera comprometida, es decir, en aquellas circunstancias donde una determinada persona por sus condiciones económicas no tuviera una alternativa para movilizarse diferente del servicio público, situación que convertía el acceso al transporte en fundamental por resultar indispensable para garantizar la libre circulación. Por otra parte, se identificaron las sentencias que modificaron la línea decisional, ampliando el ámbito fundamental de protección del servicio de transporte, al reconocer que bajo particulares circunstancias, el acceso al transporte podría considerarse inexorable para asegurar derechos fundamentales como la salud o la educación. Finalmente, se analizaron las sentencias que reconocieron un alcance mayor a la libertad de locomoción cuando se encontraban vinculados sujetos de especial protección constitucional como las personas en condición de discapacidad, supuesto fáctico en el cual la protección de la libre circulación se intensificaba, incluyendo dentro del espectro de protección, la realización de planes, programas y demás acciones objetivas destinadas a proveer diseños de infraestructura y servicios especiales que permitieran el acceso real y efectivo de esta población al servicio de transporte.

De igual forma se examinó el derecho colectivo al acceso al servicio de transporte público, lo cual resultó sumamente útil, pues al examinar el problema desde la dimensión colectiva se logra una mayor y más profunda comprensión de la realidad examinada, y al superar la órbita de los derechos individuales, se realza la importancia de los intereses de naturaleza social, cuya incidencia impacta grupos significativos de interés, razón por la cual un análisis desde los derechos fundamentales podría resultar incompleto y no tener en cuenta variables macro de particular importancia que determinan la valoración final. Dicho examen, concluyó afirmando que en el ordenamiento jurídico colombiano se protege tanto el derecho fundamental a transportarse, en los tres escenarios constitucionales descritos, como el DERECHO COLECTIVO AL ACCESO AL SERVICIO DE TRANSPORTE PÚBLICO, entendido éste último como el poder jurídico reconocido a toda la sociedad, para exigir al Estado el cumplimiento de Mandatos Constitucionales de carácter prestacional, que lo obligan -en el caso concreto- a asegurar las condiciones necesarias para asegurar el acceso real y efectivo de toda la población al servicio de transporte público, en condiciones de oportunidad y eficiencia, prestación esencial para garantizar la calidad de vida de la sociedad comprendida en su conjunto (art. $1^{\mathrm{o}}$ ), y destinado -como Derecho Colectivo- a producir un beneficio público superior a los beneficios individualmente considerados. 
Una vez identificado el marco jurídico-constitucional que gobierna la prestación de los servicios públicos, en el Capítulo II se realizará el análisis concreto, sobre el servicio de transporte público de Bogotá, con el propósito de establecer si tanto derechos económicos, como derechos colectivos, están siendo protegidos, o si por el contrario existen tensiones entre los diferentes intereses jurídicos tutelados por el ordenamiento. Así las cosas, en el Capítulo II se realizará una aproximación al sistema de transporte en Bogotá, examinando su funcionamiento operativo, pero concentrando el análisis en su funcionamiento económico, para lo cual se realizará un estudio comparado de los contratos de concesión de Transmilenio y SITP, y se tendrá en cuenta la renegociación efectuada en 2013, mediante los cuales se regula la prestación del servicio por parte de los agentes privados, y se definen las normas tanto para la estructuración de la tarifa que se cobra al público, como para la distribución de costos y beneficios derivados de la prestación del servicio de transporte. Dicho funcionamiento económico, será contrastado con la realidad socioeconómica de Bogotá, a fin de establecer si las tarifas de transporte se adecuan a la capacidad de pago de la población capitalina, o si por el contrario la desconocen, convirtiéndose en una seria limitación para el uso y goce de un servicio de primera necesidad. 


\section{CAPÍTULO II.}

\section{EL SISTEMA DE TRANSPORTE PÚBLICO EN BOGOTÁ.}

Una vez identificada la estructura normativa que opera en Colombia en materia económica y de servicios públicos, y reconocidos los derechos tanto individuales como colectivos que el Estado debe asegurar, en el presente capítulo se abordaran los siguientes temas: i) en primer lugar realizará una aproximación al funcionamiento operativo del sistema de transporte en Bogotá, tanto de Transmilenio como del SITP; ii) en segundo lugar, se estudiará el funcionamiento económico del sistema, para lo cual se realizará una exposición comparativa de las principales clausulas económicas de las concesiones de Transmilenio y SITP; y en seguida, se efectuará una análisis sobre la renegociación de los contratos de Transmilenio celebrada en el 2013, lo que permite dar cuenta de ciertas variaciones que afectan la economía tanto de unas, como de otras concesiones; iii) finalmente, teniendo claro cómo funciona el sistema de transporte, se realizará un acercamiento a la realidad socioeconómica de Bogotá, especialmente a los costos en los que incurren las familias de la capital para acceder al servicio de transporte, con el propósito de demostrar que la tarifa del servicio de transporte público (\$1.700), 1) se deriva de las particulares condiciones establecidas en los contratos de concesión, y 2) desconoce la capacidad de pago de un porcentaje significativo de los usuarios, y en consecuencia, impide el acceso real y efectivo a más del $50 \%$ de la ciudadanía que demandan su uso.

\subsection{El funcionamiento operativo de Transmilenio y SITP.}

El continuo crecimiento de la ciudad de Bogotá, que cuenta hoy con cerca de 8 millones de habitantes (DANE, 2005), genera constantemente la necesidad de implementar medidas que atiendan los requerimientos que los ciudadanos demandan. La administración continuamente se ve avocada a desarrollar acciones administrativas principalmente en materia de infraestructura urbana, equipamiento público y prestación de servicios esenciales como salud, educación, vivienda, servicios públicos domiciliarios, entre otros, que en virtud del artículo 365 de la Constitución Política -como se viopueden prestarse directamente por el Estado, o a través de los particulares. Desde hace décadas, uno de los mayores problemas que reclama solución por parte de la ciudadanía es la movilidad, entendida como la prestación del servicio de transporte urbano de pasajeros, debido a que el sistema de 
transporte que venía operando en la capital, comenzó a mostrar señales de insuficiencia e inviabilidad, situación que condujo a la construcción e implementación de un nuevo modelo de transporte público, que respondiera a las necesidades de una ciudad en expansión, con grandes limitaciones sociales y económicas. A continuación, se examinará la problemática del transporte en Bogotá durante la década de los 90’s, y las soluciones planteadas desde el Estado, de marcada tendencia neoliberal, a partir de la puesta en marcha del Sistema Integrado de Transporte Público, SITP, en Bogotá, tanto desde sus etapas iniciales mediante la implementación del subsistema Transmilenio, como con las fases posteriores de integración a través del SITP propiamente dicho. Se concluirá esta primera parte haciendo una evaluación sobre los resultados obtenidos luego de una década de implementación del nuevo modelo de transporte.

\subsubsection{La problemática del Transporte en Bogotá y Puesta en Marcha del Transmilenio.}

El desarrollo e implementación del Sistema Integrado de Transporte Público para Bogotá, SITP, tuvo como origen los sobre diagnosticados problemas que se venían evidenciando desde mediados de la década de los 90, época en la que se hizo patente la necesidad de la intervención pública en aras de adecuar el sistema de transporte a los requerimientos de una ciudad sobrepoblada. Para esta época los principales problemas en materia de transporte pueden sintetizarse en 4 grandes puntos, así: i)

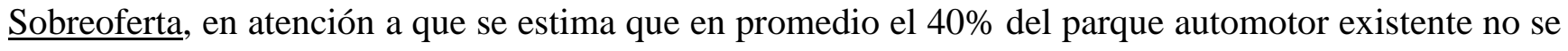
requiere, tal y como lo ha señalado el Departamento Nacional de Planeación (DNP, Anexo 2, 2003), lo que se explica por la superlativa longevidad de la vida útil del parque automotor a través de la repotencialización, que alcanza los 18 años por vehículo, situación que demanda acciones encaminadas a la reducción del número de vehículos que prestan el servicio (chatarrización). ii) Largos tiempos de viaje. La sobreoferta sumada a la insuficiencia en infraestructura y al creciente aumento del uso de transporte particular, producto de la ausencia de incentivos por el uso de transporte público, afectan significativamente el tiempo de los viajes, cuyo promedio en hora pico oscila entre 8 y $12 \mathrm{~km} / \mathrm{hora}$. iii)

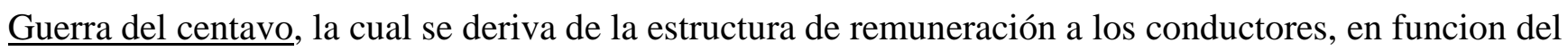
número de pasajeros recogidos, "este esquema permite que la propiedad de los equipos sea privada pero asigna los riesgos operacional y comercial del negocio al conductor y lo motiva a realizar durante la labor, cualquier tipo de maniobra" lo que conduce inevitablemente a que en aras de aumentar el 
beneficio propio se generen externalidades negativas, "e incluso sobre costos pues no hay estímulos claros para emplear mejores técnicas de conducción encaminadas a reducir los costos operacionales e incidentes que pongan en peligro los pasajeros o el equipo" (DNP, 2003). iv) Tarifas ineficientes, en virtud de los problemas anteriormente referidos más otros adicionales, como la concentración de rutas, la deficiente y subutilizada infraestructura vial, entre otros, generan altos costos de operación y mantenimiento reduciendo la tasa de ganancia o rentabilidad de los prestadores del servicio de transporte, lo que ha conducido a la proliferación de dos fenómenos de alto impacto, el primero referido a la reducción de los costos laborales a través del despido de empleados y la sobreexplotación de los trabajadores, "estableciendo jornadas laborales del orden de 10 a 15 horas diarias"; y en segundo lugar, el aumento de las presiones para incrementar las tarifas que se cobran a los usuarios (DNP, 2003, pag. 12).

Una fotografía del estado del transporte en Bogotá durante este periodo puede apreciarse en la Gráfica No. 2, elaborada En el Documento COMPES 3260 (2003, Pág. 2).

\section{Gráfica No. 2. Problemática del transporte urbano en Bogotá.}

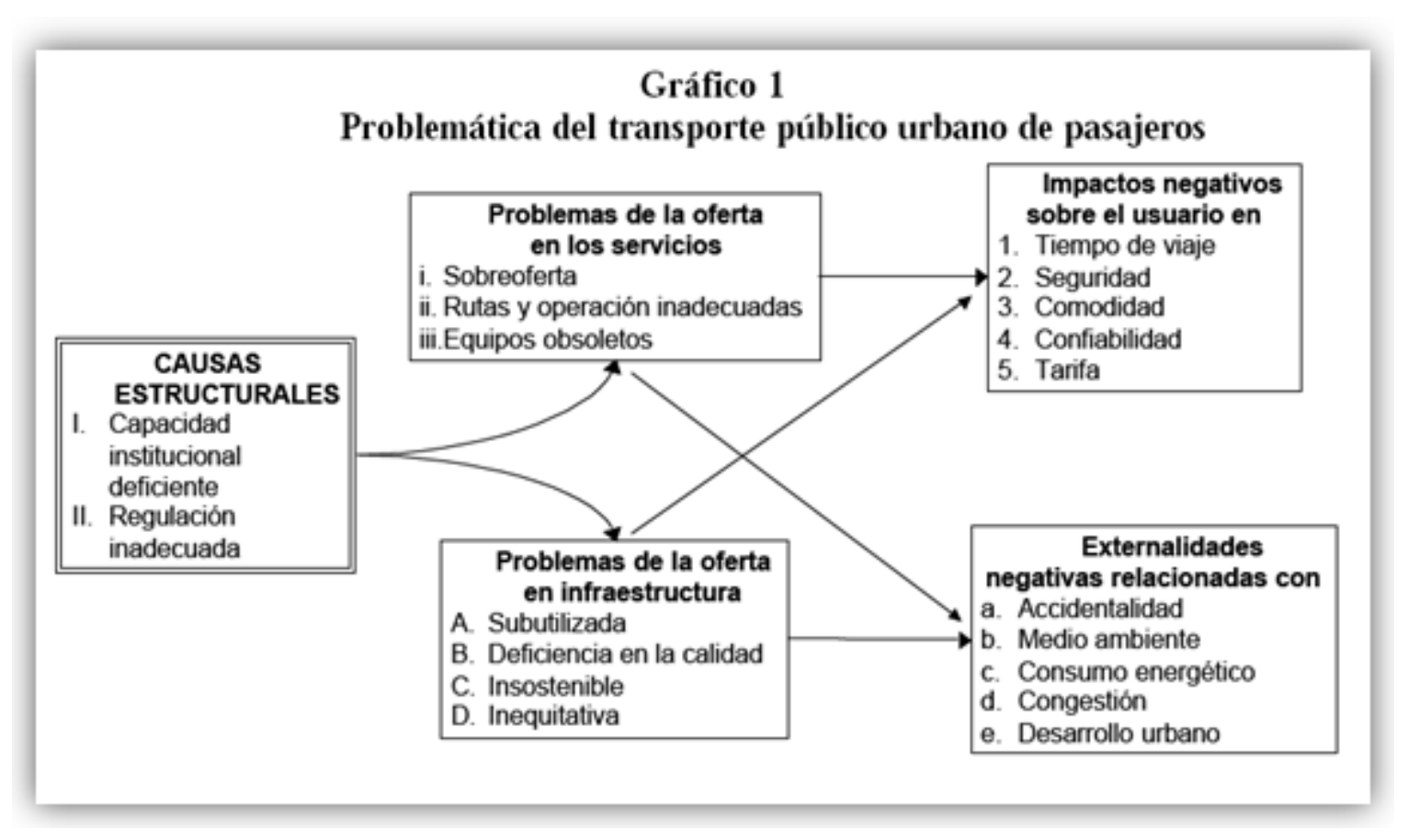

Fuente: Consejo Nacional de Política Económica y Social, COMPES No. 3260 (2003). 
Para enfrentar la preocupante situación en el tema de movilidad, la Nación fijó una estrategia y una política nacional en materia de transporte urbano de pasajeros, la cual quedo consignada en el Documento COMPES No. 3167 (2002), emitido por el Departamento Nacional de Planeación, DNP, y posteriormente en el Documento COMPES No. 3260 (2003) instrumentos técnicos en los que se trazaron las pautas para enfrentar los 4 grandes problemas del transporte público referidos lineas atrás.

Puesta en Marcha del Transmilenio. Identificadas las insuficiencias del esquema de movilidad, resultaba necesario elaborar un nuevo modelo de transporte que les brindara una solución eficiente a las problemáticas evidenciadas, razón por la cual el Concejo de Bogotá (1998), mediante el Acuerdo No. 6, estableció en su artículo 32 como "principal proyecto prioritario" la implementación del Sistema Integrado de Transporte Público (SITP). Se facultó al Alcalde Mayor de la ciudad para que creara la empresa de Transporte Tercer Milenio Transmilenio S.A. (en adelante TMSA), como una sociedad constituida entre entidades públicas del orden distrital, quien tendría a su cargo la obligación de adelantar todas las labores pertinentes para implementar el Sistema Masivo de Transporte Transmilenio (en adelante TM). Desde un inicio se estableció que existían dos aspectos centrales, i) en primer lugar la construcción de infraestructura vial sobre la cual operaria el sistema de transporte, y de la cual se encargaría el Instituto Distrital de Desarrollo Urbano (IDU) a través de contratos de obra; y, ii) en segundo lugar se debía determinar, a través de licitación pública, quienes serían las empresas privadas que operarían los buses del sistema, con quienes se firmarían contratos de concesión; sobre éste aspecto se concentrará el análisis de la presente investigación. La implementación del TM se dividió en fases, las tres primeras, consistían en poner en funcionamiento los buses troncales del Transmilenio (buses rojos) y los alimentadores (buses verdes), en las principales arterias viales de la capital, (Avenida Caracas, Autopista Norte, Américas, Avenida NQS, Avenida Suba, Ramal Eje Ambiental, Ramal 80 y Tunal). Según datos de TMSA (2013), éste sistema de transporte a logrado movilizar más de lo que se había calculado. "Los sistemas BRT tipicamente logran movilizar hasta 10.000-12.000 pasajeros /hora/sentido, mientras transmilenio ha logrado movilizar más de 45.000 pasajeros /hora/sentido" (pag. 2), lo cual corresponde a la demanda teórica de un sistema ferreo tipo metro.

El sistema Transmilenio “moviliza 1'800.000 pasajeros en promedio en un día, ésto significa que esta movlizando aproximadamente el $15 \%$ de los viajes totales que se realizan diariamente en la 
ciudad, o cerca del 30\% de los viajes de transporte público" (Transmilenio S.A., 2013). El 70\% restante de los viajes en transporte público se llevan a cabo a través del Transporte Público Colectivo (en adelante TPC), lo que convierte al sistema tradicional en el principal medio de movilización en Bogotá, que en la actualidad, bajo el nuevo modelo, se está integrando funcional y tarifariamente al sistema Transmilenio, con la implementación del SITP (Secretaria de Movilidad, 2011). Para el primer semestre del 2013, Transmilenio contaba con una flota de operación de 1.289 buses, que recorren la fase I (Avenida Caracas, Autopista Norte,), fase II (Américas, Avenida NQS, Avenida Suba, Ramal Eje Ambiental, Ramal 80 y Tunal) y fase III (Calle 26, Avenida 10ma), las cuales cuentan con un total de $109,3 \mathrm{~km}$ de longitud en sistema troncal, 123 estaciones sencillas, 9 portales y 8 estaciones intermedias (Transmilenio, Informe de Gestión, 2013).

\subsubsection{Funcionamiento del SITP.}

Pero el desarrollo del sistema de transporte no podía limitarse a la implementación del sistema Transmilenio, para el 2006 con la expedición del Plan Maestro de Movilidad, ya se veía la necesidad de integrar este sistema con el TPC, fijándose como uno de los objetivos principales en la materia "mejorar la cobertura del servicio de transporte público a los distintos sectores de la ciudad, la accesibilidad a ellos y su conectividad, y realizar la integración operacional y tarifaria del sistema de transporte público y establecer un nuevo modelo de organización empresarial de prestación del servicio" (Decreto Distrital No. 319, 2006) (Énfasis Fuera de Texto, en adelante EFT). Los principales cambios fueron los siguientes:

Integración del SITP con Transmilenio. El paso siguiente en materia de transporte sería la implementación del Sistema Integrado de Transporte Público SITP, el cual suponía dos aspectos fundamentales, a saber: i) el primero relacionado con la transformación del TPC, lo cual incluía desde la eliminación de la sobreoferta de buses (de los 17.000 vehículos que hacen parte del TPC solamente quedaran en operación 11.000 vehículos), pasando por la supresión y cambio de rutas, hasta la incorporación de nueva tecnología para la realización del pago a través de tarjetas inteligentes como sucede con Transmilenio; y, ii) el segundo cambio trascendental del SITP, consistiría en la articulación de este nuevo componente integrado, SITP, con Transmilenio ahora considerado un subsistema. La 
transformación del TPC a los nuevos buses azules, y su posterior integración con Transmilenio sería el gran reto en materia de movilidad que tendría que asumir el Distrito en cabeza de la empresa creada para dicho objetivo, TMSA. El funcionamiento del SITP introdujo los siguientes cambios: i) En primer lugar se eliminaron las rutas que iban de extremo a extremo de la ciudad, dicho papel sería atendido por las rutas troncales de Transmilenio. Bogotá seria dividida en 13 zonas, en las que operarían rutas circulares o complementarias (buses naranjas) que solo cubrirían su respectivo circuito sin salirse de la zona asignada, y su objetivo - en la práctica- consistiría en alimentar los usuarios que quieran salir de su zona a las rutas troncales de Transmilenio, cumpliendo un rol similar al de los alimentadores (buses verdes), pero con circuito mucho más largos para cubrir.

\section{Gráfica No. 3 Distribución Zonal del SITP}

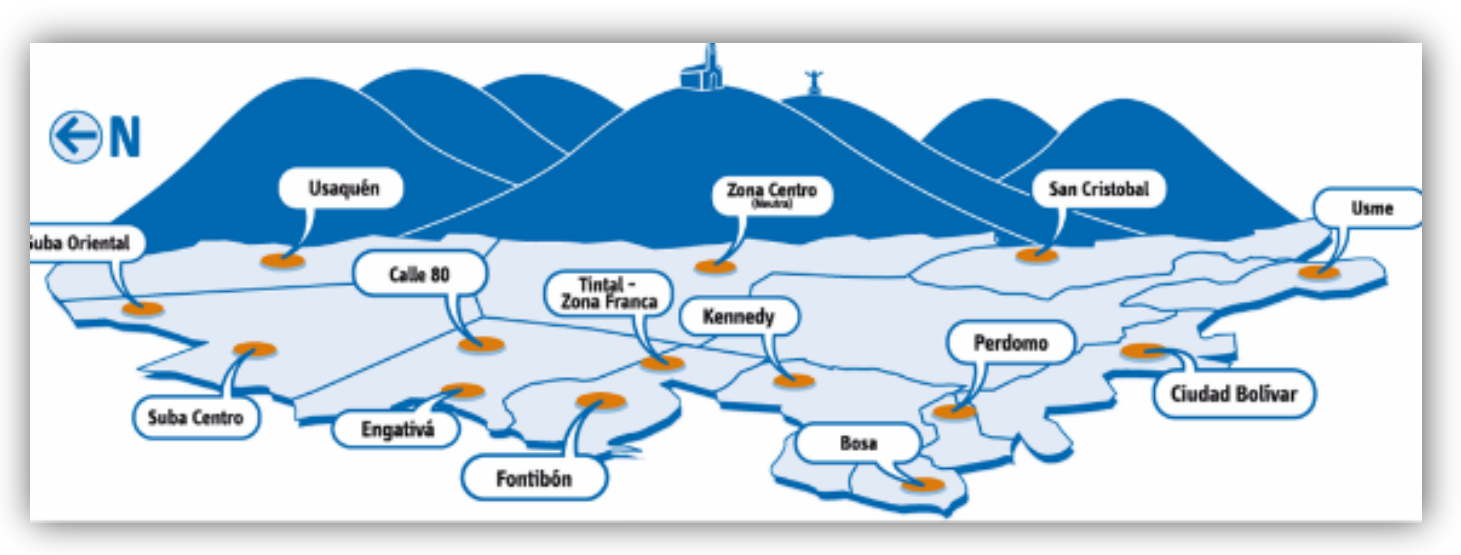

Fuente: SITP, Distribución Zonal de Bogotá. 2013.

Adicionalmente, el SITP opera 2 tipos más de servicios, por una parte los Buses denominados urbanos que podrían pasar de un circuito a otro (buses azules) pero sin lograr la cobertura de los antiguos buses que iban de extremo a extremo de la ciudad, y por otra parte los denominados servicios especiales, que son buses más pequeños, tipo colectivo, que cubren zonas periféricas de difícil acceso (buses vino tinto).

Eliminación de la función de recaudo. Otra modificación importante, consiste en que los buses del SITP ya no manejan dinero, sino que su acceso se realiza mediante una tarjeta inteligente, tal y como sucede en Transmilenio, evitando que los conductores tengan la doble función de manejar y adelantar labores de recaudo. Esta medida más allá de modernizar el sistema de transporte y librar de 
una tarea adicional a los conductores, tiene como propósito principal lograr la integración tarifaria del sistema, para que con una sola tarjeta un usuario pueda transitar de una ruta urbana (bus azul) a una ruta troncal (Bus rojo de Transmilenio) y luego a una circular (bus naranja) con el mismo medio de pago. Dicha integración tarifaria es una medida indispensable para lograr el objetivo principal, lograr la integración operacional, que consiste en alcanzar el funcionamiento armónico entre el componente troncal (Transmilenio) y el componente integrado (-SITP- buses azules, naranjas y vino tinto). Se expondrá un ejemplo simple para efectos de lograr una mayor ilustración sobre la forma como debería funcionar el transporte en Bogotá atendiendo los objetivos del SITP. Un usuario que va de un destino A en una zona periférica de la ciudad y se dirige al centro para trabajar, tendría que tomar una ruta circular (bus naranja) o un alimentador (bus verde) utilizando su tarjeta inteligente, dicha ruta lo articularía a la estación de Transmilenio más cercana en la que utilizaría el sistema troncal para llegar hasta el centro, donde, de ser necesario, podría tomar una nueva ruta circular que lo llevara desde su estación de Transmilenio hasta su destino final. Toda esta operación la podría adelantar con la misma tarjeta, pagando un servicio completo (bus complementario) más una fracción adicional por realizar el $\underline{\text { transbordo }}$, si toda la operación transcurre dentro de un periodo de tiempo determinado, 70 minutos, de lo contrario será necesario pagar nuevamente la tarifa plena, en virtud de la cláusula 68 de los Contratos de Concesión del SITP (2010).

Nueva Estructura Empresarial. Finalmente, el último de los cambios significativos se refleja en la estructura empresarial de los operadores, pues el SITP ya no funcionaría como antes donde cientos de pequeñas empresas solicitaban el respectivo permiso para que les fuera asignada una ruta y la explotaban bajo cierta regulación. En adelante, la prestación del servicio se sometería a licitación pública, en la cual luego de un proceso de selección objetiva se elegiría a las mejores propuestas para otorgarles en concesión la explotación del servicio de transporte público. El negocio ya no estaría disperso en cientos de cooperativas, empresas familiares, o medianas empresas de transporte, sino que pasaría a un puñado de grandes empresas encargadas de la explotación de zonas completas de la ciudad, constituyéndose en la práctica un modelo de oligopolio, tal y como sucedió con la estructuración de Subsistema Transmilenio.

\subsubsection{Resultados de la Implementación del Transmilenio y el SITP en Bogotá.}


Transmilenio. Ante tal panorama, la puesta en marcha de Transmilenio (2000) trajo resultados positivos en varios aspectos. La destinación de un carril exclusivo para el TM, aunado a la incorporación de un carril de sobrepaso en algunos tramos del componente troncal, elevaron significativamente la velocidad de viaje, pasando en hora pico de 8 y $12 \mathrm{~km} / \mathrm{hora}$, a una velocidad promedio de $26 \mathrm{Km} /$ hora, mejorando los tiempos de viaje, que constituyen una de las variables más importante para los usuarios. Según Echeverry (2005) Transmilenio "limitó las externalidades de congestión en los corredores por los que opera". Adicionalmente, los tiempos de viaje para los usuarios que optaron por utilizar el nuevo sistema "cayeron en un 32\%, la velocidad promedio de los vehículos en Bogotá aumentó de 16.8 millas por hora a 20 millas por hora” (pág. 73). Sin embargo, no todos los problemas fueron atendidos favorablemente, pues la sobreoferta de vehículos no se redujo a los niveles estimados, ya que de la flota existente "sólo 1,410 de los 6,080 que operaban, fueron efectivamente chatarrizados y los 4,670 restantes fueron relocalizados hacia otras avenidas de la ciudad" empeorando los problemas de congestión (Echeverry, 2005, pág. 74).

En definitiva, sobre los problemas que el nuevo modelo de transporte debía solucionar, se evidencia lo siguiente: i) La sobreoferta de vehículos con la externalidad directa que genera (congestión vehicular), no se ha solucionado por las bajas tasas de chatarrización, y solamente desplazó la congestión a otras zonas de la ciudad. ii) En cuanto a los tiempos de viaje, si bien hay una reducción significativa en el desplazamiento, la misma se ve afectada por los tiempos de espera de los buses y alimentadores, que en algunos casos superan los 20 minutos (principal causa de las manifestaciones en TM), y la demora en la compra de los pasajes, fruto de las largas filas en las taquillas, lo que termina aumentando el tiempo total de desplazamiento. iii) Por su parte, la división

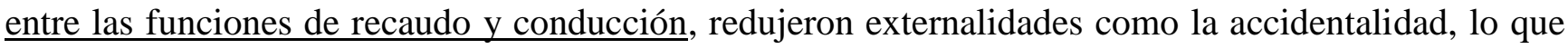
sumado al cambio del esquema de remuneración para los conductores, a quienes se les fijo un sueldo independiente del número de pasajeros recogidos, significó grandes avances en el desmonte de la "guerra del centavo", pero a su vez condujo al incremento del sobrecupo en los buses articulados debido a que la mejor forma de bajar costos consiste en enviar menor número de buses. Adicionalmente, la división no solo se efectuó en torno a las funciones, sino que también se hizo respecto de las concesiones pues se distribuyeron las funciones de operación y recaudo a agentes privados diferentes, situación que generó un incremento significativo en los costos de funcionamiento 
del sistema, ya que a cada uno debe garantizársele sus respectivas utilidades, que para los operadores del recaudo es del 7\% de los ingresos del sistema. iv) Así mismo, el establecimiento de tarifas por encima del nivel de eficiencia, generó incentivos para la entrada de nuevos buses del TPC y la sobreoferta en la provisión del servicio (Echeverry, 2005), debido a que un segmento importante de usuarios siempre buscan alternativas más económicas Sobre el problema de las tarifas, se elaborará un análisis detallado más adelante, ya que la ineficiencia de las mismas, reflejadas en su alto costo, constituyen uno de los principales problemas en materia de acceso al servicio de transporte, especialmente por las condiciones socioeconómicas que se presentan en la ciudad de Bogotá, las cuales constituyen uno de los problemas centrales dentro de la presente investigación.

Sistema Integrado de Transporte Público. Por su parte, el SITP se ha venido implementando gradualmente, y desde su entrada en funcionamiento el día 29 de septiembre 2012, se encuentran en operación 66 de las 508 rutas; de la flota de buses (11.000) están circulando 1.234; de los 6.737 paraderos, están prestando su servicio 2.306; y, de 26.715 conductores, apenas 3.408 se encuentran vinculados, lo cual quiere decir que el avance de implementación del componente integrado del SITP es solamente del 10\% (Transmilenio S.A., 2013). Frente a este panorama, lo primero es señalar que los enormes retrasos en su implementación han dejado cuantiosas pérdidas al Distrito por falta de comunicación, incumplimiento en los cronogramas y fallas en el proceso de chatarrización, lo que ha conducido a que los vehículos generado que los buses del TPC, continúen utilizando sus rutas lo que ha derivado en mayor congestionamiento, pues en una misma ruta hay agentes tanto del TPC, como de los buses nuevos de SITP, generando a su vez una subutilización de las nuevas rutas que están trabajando a perdidas. De la misma manera, el SITP, en la práctica, generó la necesidad de tomar más de dos rutas para llegar a un destino, al que antes se arribaba con una sola, lo que aumentó no solo los tiempos de desplazamiento por los lapsos que los usuarios deben esperar para hacer un transbordo, sino que además aumentó la tarifa, particularmente de los usuarios que viven en las periferias, pues los obliga a pagar un transbordo que antes no pagaban, y adicionalmente, en caso de no alcanzar a realizar todo su recorrido dentro de la ventana de tiempo de 70 minutos, se verían obligados a pagar nuevamente la tarifa plena, situación que afecta principalmente a los sectores económicos más deprimidos. 
Adicionalmente, la estructuración del sistema se fundamentó en Transmilenio como eje central (cláusula 6, Concesiones SITP, 2010), y el SITP, que movilizará el porcentaje que antes movilizaba el TPC, es decir, el 70\% de los viajes públicos diarios, funcionará en un gran porcentaje como alimentador de las rutas troncales, lo que significa un incremento exponencial de la utilización de servicios troncales, arribando a Transmilenio miles de usuarios que antes no tenían la necesidad de su utilización, incrementando la demanda del subsistema Transmilenio, y con ello la congestión, el hacinamiento y los problemas de seguridad y comodidad que se derivan de aquellos. En síntesis, se puede colegir que si bien la implementación del SITP en Bogotá significó un avance importante en materia de movilidad, debido a que organizó y modernizó el transporte, el mismo ha evidenciado grandes falencias que conducen a concluir, incluso antes de su cabal implementación, que resultará insuficiente para satisfacer las necesidades de una ciudad del tamaño y las características socioeconómicas de la Capital de Colombia, tesis que se demostrará a lo largo de la presente investigación.

\subsection{Los Contratos de Concesión de Transmilenio y SITP.}

La Ley 80 de 1993 estableció los principios que debían gobernar la contratación pública, adecuándola a los nuevos postulados constitucionales. Dicho régimen, incorporó la institución de los contratos de concesión como un mecanismo que permite desarrollar el esquema económico definido por el constituyente de 1991, y definió este tipo particular de contratos en su artículo 32.4, en los siguientes términos:

“4o. Contrato de concesión. Son contratos de concesión los que celebran las entidades estatales con el objeto de otorgar a una persona llamada concesionario la prestación, operación explotación, organización o gestión, total o parcial, de un servicio público, o la construcción, explotación o conservación total o parcial, de una obra o bien destinados al servicio o uso público, así como todas aquellas actividades necesarias para la adecuada prestación o funcionamiento de la obra o servicio por cuenta y riesgo del concesionario y bajo la vigilancia y control de la entidad concedente, a cambio de una remuneración que puede consistir en derechos, tarifas, tasas, valorización, o en la participación que se le otorgue en la explotación del bien, o en una suma periódica, única o porcentual y, en general, en cualquier otra modalidad de contraprestación que las partes acuerden. 
Al examinar los elementos de los contratos de concesión y sus características, identificadas por la Corte Constitucional (Sentencia C-250, 1996), se advierte, que las concesiones de TM y SITP reúnen todos los elementos de este tipo particular de contratos estatales, debido a que, en primer lugar son negocios jurídicos de naturaleza pública administrativa, en atención tanto al criterio orgánico, por la participación de una entidad pública como una de las partes (Transmilenio S.A.), como respecto del criterio material, en atención a que el objeto del contrato, versa sobre la prestación de un servicio público, así definido tanto legal como contractualmente (Ley 336, 1996). De igual forma, al explorar el contenido tanto de los contratos del subsistema Transmilenio, como del SITP se evidencia la aparición de cláusulas exorbitantes (Capítulo 18 Concesión TM y 28 Concesión SITP), “como expresión del poder estatal y de su sumisión al dominio del interés general que la administración asume a través de la ejecución de un servicio público" (Expósito, 2003), lo que a su vez conduce a concluir que se trata de un contrato estatal de concesión de servicios, sujeto a las normas de los contratos administrativos y cuyo juez corresponde en principio al juez de lo contencioso administrativo. De lo anterior también se concluye, que la intervención del Estado en el servicio público de transporte urbano de Bogotá, se expresa a través de la regulación contenida en los contratos de Concesión tanto de TM, como del SITP. Con esa claridad, se abordará el análisis de los contratos para establecer el esquema económico de la regulación del servicio de transporte, con el propósito de determinar si el modelo económico implementado es el causante de las altas tarifas.

\subsubsection{Esquema económico de los Contratos de Concesión de Transmilenio y SITP.}

Al examinar las cláusulas que componen las concesiones de TM y SITP, se advierte que ambos tipos de contratos se encuentran estrechamente relacionados, pues se erigen sobre similares distribuciones tanto de costos y beneficios, como de riesgos. Para efectos de la presente investigación, el estudio se concentrará en la estructuración tarifaria y en la distribución de costos y beneficios, aspectos que constituyen el núcleo central del esquema económico de los Contratos de Concesión. Para tal efecto, se abordará el estudio de las principales cláusulas económicas tanto de los contratos iniciales de TM (Contrato 041, 2000), como de los contratos del SITP (Contrato SITP, 2010). Del estudio minucioso de tales contratos, se evidencian 5 grupos de cláusulas de principal importancia, así: i) el marco económico que regula dichos contratos y contiene los principios que guían la prestación del 
servicio; ii) las cláusulas que regulan los ingresos del sistema; iii) las relativas al cálculo y definición de la Tarifa Técnica y la Tarifa al Usuario; iv) las cláusulas que establecen la disposición y distribución de los recursos del sistema; y, finalmente v) las cláusulas que prevén la participación de los agentes del sistema en los ingresos operacionales obtenidos por la prestación del servicio. A continuación, se procederá a efectuar un estudio comparativo entre las cláusulas de TM y SITP, a fin de exponer el funcionamiento económico del sistema de transporte en Bogotá.

\begin{tabular}{|c|c|}
\hline \multicolumn{2}{|c|}{ 2.2.1.1. Principios Básicos del Marco Económico. Tabla No. 2.} \\
\hline Contrato TM & Contrato SITP \\
\hline $\begin{array}{l}\text { CLAUSULA 66. El marco económico del } \\
\text { presente contrato, la interpretación de las } \\
\text { cláusulas que lo regulan, y el ejercicio de las } \\
\text { facultades, obligaciones y derechos que se } \\
\text { confiere a cada una de las partes, se orientará al } \\
\text { cumplimiento de los siguientes principios: } \\
66.1 \text { Tarifa técnica. La tarifa al usuario por la } \\
\text { prestación del servicio de transporte ofrecido al } \\
\text { público por el Sistema Transmilenio, deberá } \\
\text { corresponder permanentemente a una tarifa de } \\
\text { equilibrio, técnicamente estructurada, y que } \\
\text { refleje la variación de costos y eficiencia del } \\
\text { sistema. } \\
\text { 66.2 Autosostenibilidad del sistema en el } \\
\text { tiempo. El sistema deberá ser permanentemente } \\
\text { autónomo en sus flujos, de manera que no } \\
\underline{\text { requiera en el tiempo ningún tipo de subsidio }} \\
\underline{\text { externo a la operación para remunerar a todos }} \\
\underline{\text { los agentes del mismo. }} \\
66.3 \text { Costeabilidad de la tarifa para el } \\
\text { usuario. La tarifa al público deberá considerar } \\
\text { la capacidad de pago del usuario y ser } \\
\underline{\text { competitivo con los sistemas de transporte }} \\
\text { análogos o sustitutos que se encuentren vigentes } \\
\text { en cada momento. (Énfasis fuera de texto) }\end{array}$ & $\begin{array}{l}\text { CLÁUSULA 44. El marco económico del presente } \\
\text { Contrato, la interpretación de las cláusulas que lo } \\
\text { regulan, y el ejercicio de las facultades, obligaciones y } \\
\text { derechos que se confieren a cada junta de las partes, se } \\
\text { orientará al cumplimiento de los siguientes principios: } \\
\square \text { Costeabilidad: El modelo tarifario del SITP } \\
\text { considerará la capacidad de pago promedio de los } \\
\text { usuarios. } \\
\square \text { Equilibrio: La Tarifa Técnica del SITP reflejará } \\
\text { permanentemente el monto necesario para remunerar los } \\
\text { costos de operación y garantizará la eficiencia del } \\
\text { Sistema. } \\
\square \text { Sostenibilidad: El diseño tarifario garantizará la } \\
\underline{\text { sostenibilidad financiera del Sistema en el tiempo, }} \\
\underline{\text { obedeciendo los principios de costeabilidad y }} \\
\text { equilibrio antes enunciados. En todo caso, el diseño } \\
\underline{\text { tarifario deberá permitir remunerar la totalidad de los }} \\
\underline{\text { costos operacionales en condiciones de eficiencia y }} \\
\text { equilibrio. } \\
\square \text { Integración: El diseño tarifario del SITP integrará los } \\
\text { costos de los servicios que se incorporen al Sistema } \\
\underline{\text { Integrado de Transporte Público en la ciudad de }} \\
\text { Bogotá D.C., y estará abierto a su integración con } \\
\text { sistemas de transporte de pasajeros intermunicipales. } \\
\text { Tarifario estará abierto a la implementación de tarifas }\end{array}$ \\
\hline
\end{tabular}




\begin{tabular}{|l|l|}
\hline & $\begin{array}{l}\text { para grupos poblacionales específicos, siempre y } \\
\text { cuando no se perjudique a los usuarios del servicio y la } \\
\text { sostenibilidad financiera del sistema, caso contrario } \\
\text { se deberá garantizar una fuente presupuestal } \\
\text { independiente de los ingresos corrientes del SITP. (EFT) }\end{array}$ \\
\hline
\end{tabular}

Fuente: Elaboración propia a partir de (Contrato Concesión SITP, 2010) y (Transmilenio S.A., 2001).

Sobre los principios que rigen el marco económico de los contratos de concesión, sobresalen tres aspectos principales que quedan recogidos en los principios aludidos, así:

El principio rector de la costeabilidad se encuentra inserto en ambos contratos, y se refiere particularmente a que el modelo tarifario, el cual se expresa en las tarifas que se cobren al público (Tarifa Usuario), debe considerar la capacidad de pago promedio de los usuarios y ser competitivo con sistemas de transporte análogo. Este último aspecto, es eliminado de las Concesiones del SITP, en parte, porque uno de los elementos indispensables de su implementación consiste en la sustitución del transporte análogo y su integración al SITP. Lo principal entonces, se contrae a determinar cómo se calcula la capacidad de pago promedio de los usuarios, para poder definir si la tarifa que se cobra al público se adecúa a lo exigido por el principio de la costeabilidad.

Sobre el principio de la auto- sostenibilidad, ahora denominado simplemente de sostenibilidad hay una variación importante de las concesiones TM a las del SITP, ya que se elimina como directriz la autonomía del sistema, que consistía en que el mismo no requeriría de ningún tipo de subsidio externo a la operación para la remuneración de los agentes. La eliminación del prefijo auto, está calculada para que el sistema de transporte pueda funcionar a partir de subsidios y de recursos externos a la operación, aspecto que en un principio había sido excluido del sistema, y presentado como uno de las grandes ventajas del modelo de transporte en Bogotá. Por el contrario, el nuevo principio de sostenibilidad, hace énfasis en que el diseño tarifario garantizará la sostenibilidad financiera y la costeabilidad, pero sobre la base de asegurar la remuneración de la totalidad de los costos operacionales bien sea con recursos derivados de la operación o con recursos de otro tipo. Sobre este aspecto, se evidencia un cambio sustancial en el modelo de transporte, pues en adelante, y casi que por regla general, los subsidios públicos serán una herramienta primordial para garantizar la sostenibilidad del sistema, a pesar de mantener la misma estructura de operación como negocio privado. 
El principio de la tarifa técnica (TT), indica que la tarifa que se cobre al usuario (TU), será sustentada en una tarifa equilibrada técnicamente, que deberá reflejar el monto necesario para remunerar los costos de operación y la eficiencia del sistema, este principio se mantiene en ambas concesiones. Ahora bien, otra novedad consiste en la inclusión, como principio, de tarifas especiales para poblaciones específicas, las cuales en todo caso no podrán perjudicar a los usuarios del servicio, ni la sostenibilidad financiera del sistema, caso en el cual deberá garantizarse una fuente presupuestal independiente de los ingresos corrientes del SITP, lo cual quiere decir que cualquier tarifa diferencial que se implante (ej. tarifa menor para estudiantes, o tarifa menor hora valle), deberá ser subsidiada por recursos externos a la operación, que por regla general serán recursos públicos.

De lo anterior, puede concluirse que respecto de los principios que rigen el marco económicos de los contratos, se mantuvieron dos reglas básicas, cuales son: i) asegurar la remuneración de los agentes privados de la totalidad de los costos; y, ii) diseñar un modelo tarifario que garantice dicha remuneración integral. Así mismo, se introdujo una modificación sustancial a la regla de la autosostenibilidad, que consiste en que el sistema no se sostendrá únicamente por los recursos que genere su operación, sino que podrá acudir a recursos externos para responder por el pago de los operadores privados.

\subsubsection{Ingresos del Sistema. Tabla No. 3 .}

\begin{tabular}{|lr|}
\hline \multicolumn{2}{|c|}{ Contrato TM } \\
\hline CLAUSULA 67.- & INGRESOS \\
DEL & SISTEMA \\
TRANSMILENIO & \\
\hline
\end{tabular}

El Sistema TransMilenio tendrá como fuente principal de ingresos el recaudo diario de la venta de pasajes de transporte al público, según la tarifa al usuario que sea aplicable conforme a lo previsto en el presente contrato, que será única e integrada dentro del Sistema, independiente-mente del número de servicios que utilice, la longitud de los trayectos, y la zona urbana

\section{Contrato SITP}

CLÁUSULA 45. INGRESOS DEL SISTEMA INTEGRADO DE TRANSPORTE PÚBLICO DE BOGOTÁ -SITP

El Sistema Integrado de Transporte Público de Bogotá SITP tiene y tendrá como fuente principal de ingresos el Recaudo diario de la venta de unidades de transporte, según la Tarifa al Usuario que sea aplicable conforme a lo previsto en el presente Contrato.

La Tarifa al Usuario será integrada con cobros diferenciales por tipo de servicio y transbordo. Este concepto permite a los usuarios del SITP la utilización de uno o más servicios de transporte, bajo un esquema de cobro diferenciado por tipo de servicio, con pagos adicionales por transbordo inferiores al primer cobro, válido en condiciones de viaje que estén dentro de un lapso 


\begin{tabular}{|l|l|}
\hline $\begin{array}{l}\text { en donde se utilice el servicio. Sin } \\
\text { embargo la tarifa podrá tener } \\
\text { ajustes en su estructura de acuerdo } \\
\text { a lo previsto en el presente } \\
\text { contrato. }\end{array}$ & $\begin{array}{l}\text { de tiempo que establezca el ente gestor, el cual inicialmente se } \\
\text { fijará en } 75 \text { minutos, y que considerará las características de } \\
\text { longitud de viaje y velocidades de operación en la ciudad de } \\
\text { Bogotá. La integración tarifaria implica la utilización de un } \\
\text { Medio de Pago común a los servicios integrados. } \\
\text { La diferencia entre lo que debe remunerarse a los agentes SITP } \\
\text { y los ingresos recaudados correspondientes a las validaciones } \\
\text { de entrada al SITP se cubrirá con recursos provenientes del } \\
\text { Fondo de Estabilización Tarifaria (FET), hasta el monto que } \\
\text { permita su utilización. El riesgo de que los recursos } \\
\text { disponibles en el Fondo de Estabilización Tarifaria (FET) no } \\
\text { sean suficientes para cubrir dicha diferencia no se encontrará } \\
\text { atribuido al CONCESONARIO y se encuentra garantizado con el } \\
\text { compromiso de pago extendido por el Distrito Capital, suscrito } \\
\text { como un compromiso unilateral a favor de TRANSMILENIO S.A., } \\
\text { en su calidad de gestor del Sistema TransMilenio por medio del } \\
\text { cual se ha obligado a reconocer los valores que conforme a lo } \\
\text { previsto en el presente Contrato tendría derecho a percibir el SITP } \\
\text { y a través del mismo, sus Concesionarios y agentes. (EFT). }\end{array}$
\end{tabular}

Fuente: Elaboración propia a partir de (Contrato Concesión SITP, 2010) y (Transmilenio S.A., 2001).

En cuanto a los ingresos del sistema, estos se componen principalmente por el dinero obtenido de las ventas de pasajes, a lo cual se debe sumar los subsidios y demás recursos externos, que como se explicó líneas atrás, entran a jugar un papel importante dentro del SITP. Ahora bien, las cláusulas relativas a los ingresos del sistema, hacen referencia fundamentalmente a dos aspectos: i) el primero relacionado con las nuevas características y el funcionamiento de la tarifa en el SITP; y, ii) el segundo referido al funcionamiento financiero cuando los recursos que ingresan resultan ser menores a los costos de operación del sistema.

Sobre las características y funcionamiento de la tarifa en el SITP. La tarifa que se le cobra al usuario estará integrada con cobros diferenciales por tipo de servicio o transbordo. Así, usar el servicio troncal (buses rojos) tendrá un costo de $\$ 1.700$, pero usar el servicio integrado (buses azules, naranja o vino tinto) tendrá un costo diferente, \$1.400. A su vez, si un usuario necesita un servicio troncal y luego un servicio integrado (escenario principal dentro del SITP), frente al primer servicio pagará la tarifa plena y frente al segundo pagará un transbordo que será un menor valor al de la tarifa plena, 
siempre que haga uso del servicio dentro de un lapso de tiempo determinado, que en un principio se fijó en 75 minutos. La concurrencia de cobros diferenciados, y la integración del sistema, implican la exista de un medio de pago común, es decir, una sola tarjeta que sirva para acceder a todos los servicios del sistema integrado de transporte. Así mismo, se requiere la existencia de una unidad de valor que permita realizar los pagos diferenciados dependiendo de los distintos servicios utilizados por los usuarios, lo que condujo a una modificación técnica en el SITP, pues se pasa de la venta de pasajes, a la venta de unidades de transporte, la cual será equivalente al dinero recargado en las tarjetas. Por ejemplo, usar Transmilenio cuesta $\$ 1.700$ y si un usuario necesita hacer un transbordo a un bus del SITP, dicho transbordo tendrá un costo de \$300. Antes, un usuario tenía que pagar \$1.700 para obtener un pasaje de Transmilenio, ahora puede cargar en su tarjeta la suma de dinero que desee, la cual estará representada en unidades de viaje, entonces, si un usuario paga en la taquilla \$2.000 se recarga en la tarjeta 2.000 unidades de transporte, si usó el Transmilenio se le descargarán 1.700 unidades de transporte, quedándole un saldo de 300 unidades, que podrá utilizar en un transbordo para usar el servicio complementario del SITP, siempre que haga uso del servicio dentro de un lapso de tiempo determinado.

Funcionamiento financiero del sistema de transporte. En teoría, al diseñarse el modelo tarifario de manera técnica y teniendo en cuenta que debe remunerarse la totalidad de los costos del sistema, los ingresos obtenidos por la venta de unidades de transporte, deberían resultar suficientes para cubrir los costos de operación, sin embargo, puede presentarse que los mismos no alcancen a cubrirlo todo. Previendo este tipo de escenarios, dentro de las cláusulas de los ingresos del sistema, se estableció que la diferencia negativa entre lo que debe remunerarse a los agentes SITP (incluidos los agentes de TM) y los ingresos recaudados correspondientes a las validaciones de entrada al SITP se cubrirán con recursos provenientes del Fondo de Estabilización Tarifaria (FET). Dicho fondo, que será alimentado por la diferencia positiva que surja entre lo que debe remunerarse y los recaudos, constituye el mecanismo financiero utilizado por el sistema para resolver los desajustes financieros que puedan presentarse. En otras palabras, si el recaudo obtenido por las entradas efectivas al SITP (buses de TM y buses del SITP) es superior a los costos, la diferencia será consignada en el FET, si por el contrario, el recaudo obtenido es inferior a los costos de operación de los agentes del sistema, la diferencia se cubrirá con los recursos obrantes en el Fondo de Estabilización Tarifaria. Ahora bien, si el FET no cuenta con los recursos suficientes para cubrir el faltante de los 
costos de operación, dicho riesgo no se encuentra atribuido al CONCESONARIO, por el contrario, se encuentra garantizado con el compromiso de pago extendido suscrito por el Distrito Capital como un compromiso unilateral a favor de TRANSMILENIO S.A., en su calidad de gestor del Sistema, mediante el cual el Distrito se ha obligado a reconocer los valores que conforme a lo previsto en los Contratos, tendría derecho a percibir el SITP y a través del mismo, sus Concesionarios y agentes.

En definitiva, las cláusulas referidas a los ingresos del sistema regulan uno de los aspectos medulares de las concesiones tanto de TM como de SITP, pues no solo incorporan el mecanismo financiero de los fondos para cubrir eventuales desajustes entre los ingresos y los costos, sino que introducen el compromiso de pago extendido suscrito por el Distrito, como suprema garantía que vincula todos los recursos públicos que sean necesarios, para asegurar el pago efectivo de los derechos otorgados a los operadores del sistema.

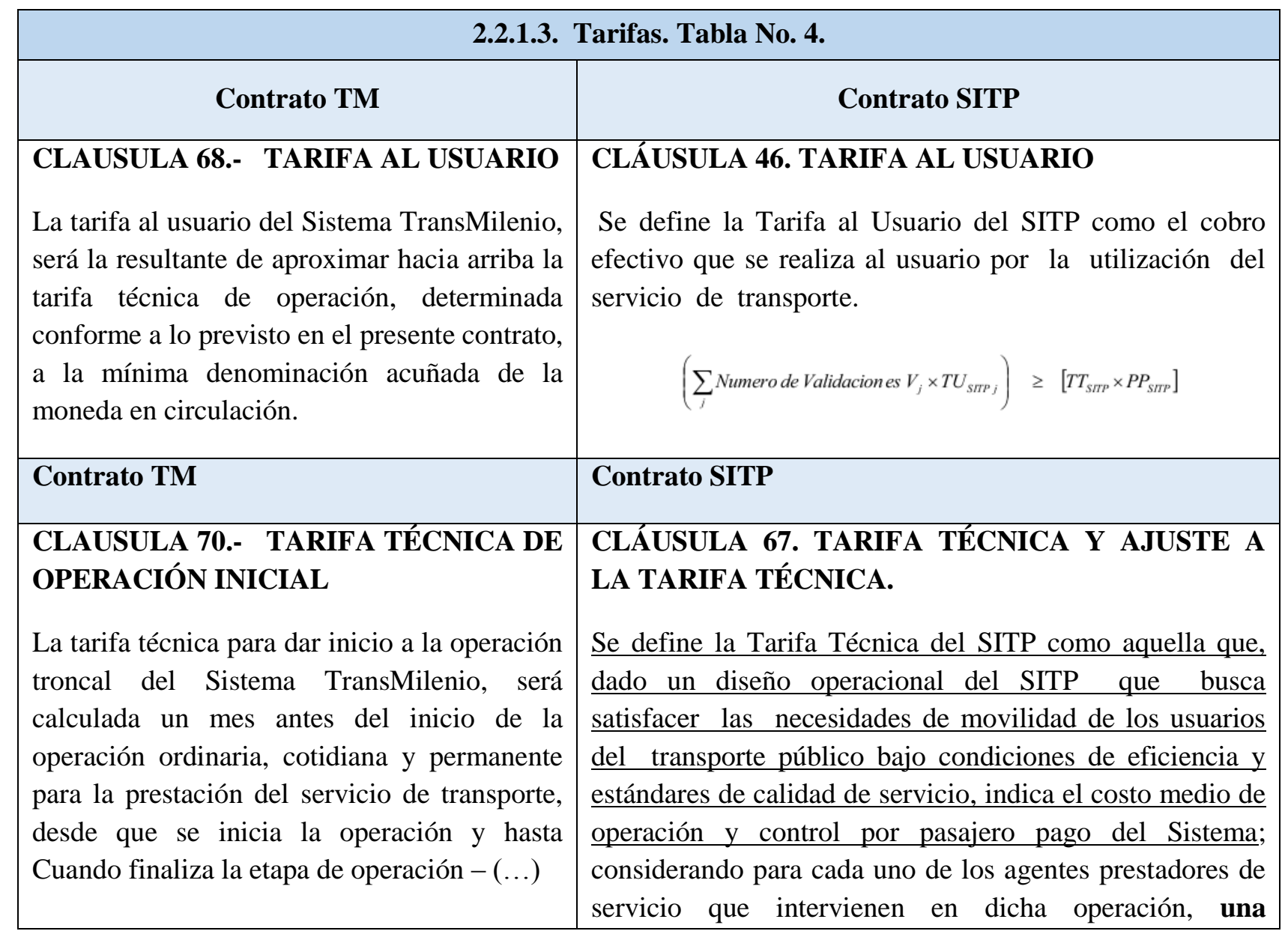


$70.4 \mathrm{El}$ componente de la tarifa técnica correspondiente a la remuneración del Gestor del Sistema (CG), está determinado como un porcentaje de la tarifa, que para la tarifa técnica inicial se establecerá convencionalmente como el $\mathbf{3 \%}$ de la tarifa técnica.

Dicho costo representa la remuneración por la concesión total de cada uno de los concesionarios pertenecientes al sistema TransMilenio.

\section{Clausula 71 CLAUSULA 71.- AJUSTE DE LA TARIFA TECNICA}

Durante los primeros seis (6) meses de la etapa de operación regular, periodo en el cual el sistema se encuentra aún en etapa de implementación, la tarifa técnica será actualizada de forma mensual dentro de los primeros diez (10) días hábiles de cada mes (...). adecuada reestructura de costos, y una rentabilidad razonable conforme a las condiciones definidas en el pliego de condiciones.

En todo momento y hasta el fin de las concesiones del actual Sistema TRANSMILENIO (léase Subsistema TRANSMILENIO - SbTM) coexisten dos esquemas de tarifa técnica: una tarifa técnica del Subsistema TRANSMILENIO (SbTM) y otra tarifa técnica SITP. La tarifa técnica del Subsistema TRANSMILENIO y la remuneración a sus actuales concesionarios se calcularán conforme a lo estipulado en los contratos de las actuales concesiones del SbTM.

En cuanto a la integración tarifaria con el subsistema TRANSMILENIO, el SbTM recibirá por cada pasajero que valide su entrada en las estaciones y portales de las troncales, el equivalente a la tarifa técnica del subsistema TRANSMILENIO. La formulación de TTSITP es la siguiente:

$T T_{S T P}=\frac{\left[\left(T T_{T M} \times P P_{T M}\right)-\sum D \operatorname{ctos} T M-R T T M_{\mathrm{t}}\right]+\left(\sum_{i} R T_{i}\right)+\left(\sum R Z O N A_{i}\right)+(R S I R C I)+R M F+R A+R R+R F_{S T r P}+R P}{\left(1-\% G_{S T r}\right) \times P P_{S T I P}}$

(Esta fórmula se explicará más adelante)

Fuente: Elaboración propia a partir de (Contrato Concesión SITP, 2010) y (Transmilenio S.A., 2001).

El diseño tarifario, constituye el elemento central sobre el cual se erige el esquema económico de los contratos bajo análisis (TM y SITP), pues por una parte su estructuración recoge la totalidad de los costos operativos del sistema (costos fijos, costos variables, costos de capital), y por otra, permite determinar el costo que tendrá que pagar el usuario por el uso del servicio. Sobre el diseño tarifario resulta necesario realizar las siguientes precisiones:

Tarifa al usuario y tarifa técnica. Existe una tarifa al usuario (TU), que es la que se cobra efectivamente al público, que para junio de 2014 está en $\$ 1.700$ hora pico, o \$1.400 hora valle para servicios troncales (buses TM), y en $\$ 1.400$ para servicios integrados o zonales (buses SITP). Dicha tarifa se calcula mediante la siguiente formula: 


$$
\left(\sum_{j} \text { Numero de Validaciones } V_{j} \times T U_{S \pi T P_{j}}\right) \geq\left[T T_{S \pi T P} \times P P_{S \pi T P}\right]
$$

Dicha fórmula indica, básicamente, que la sumatoria de todas las entradas al sistema multiplicadas por la tarifa que se cobra a los usuarios del SITP (TU), debe ser mayor a la tarifa técnica (TT) del SITP multiplicada por los pasajes efectivamente pagos, precisamente con el objetivo de que el sistema sea sostenible y pueda funcionar sin necesidad de acudir a recursos externos. Así las cosas, la estructuración de la tarifa al usuario (TU) depende de manera directa de la tarifa técnica (TT). Por su parte, la tarifa técnica (TT) indica el costo medio de operación y control por pasajero pago del sistema, considerando para cada uno de los agentes prestadores de servicio que intervienen en dicha operación, una adecuada estructura de costos, y una rentabilidad razonable. La tarifa técnica (TT), se calcula entonces, teniendo en cuenta la totalidad de los costos de operación (costos fijos, costos variables, costos de capital) incluida la correspondiente utilidad razonable para cada uno de los agentes del sistema.

Quien define la tarifa al usuario. El alcalde mayor con fundamento en la evaluación previa que adelante la Secretaria Distrital de Movilidad, del estudio técnico y financiero presentado por el Ente Gestor (TMSA), el cual se fundamentará en los principios y estructura del diseño financiero y tarifario adoptado para el SITP con los contratos de operación de buses y recaudo, control e información y servicio al usuario SIRCI (Contrato Concesión SITP, 2010). Así entonces, la tarifa al usuario se fundamenta en la tarifa técnica y la tarifa técnica se determina por la estructura tarifaria contenida en los contratos. El ente gestor TMSA, debe realizar una planeación tarifaria, que implica la proyección en el tiempo de costos de remuneración a los agentes del sistema, demanda y oferta del sistema, tarifas técnicas del sistema $\left(\mathrm{TT}_{\mathrm{SITP}}\right.$ y $\left.\mathrm{TT}_{\mathrm{TM}}\right)$, utilización y recursos acumulados en el Fondo de Estabilización Tarifaria FET; y recomendar a la Administración Distrital los incrementos necesarios en la tarifa al usuario (TU) con base en los estudios que realice, o en su lugar, del monto de recursos que debe trasladar la Administración Distrital para cubrir plenamente el diferencial tarifario y evitar que el FET quede ilíquido.

Calculo de la tarifa técnica. La tarifa técnica se calcula mediante la aplicación de la siguiente formula: 


$$
T T_{S M P}=\frac{\left[\left(T T_{T M} \times P P_{T M}\right)-\sum D \operatorname{ctos} T M-R T T M_{i}\right]+\left(\sum_{i} R T_{i}\right)+\left(\sum_{i} R Z O N A_{i}\right)+(R S I R C I)+R M F+R A+R R+R F_{S T P P}+R P}{\left(1-\% G_{S T P P}\right) \times P P_{S T P P}}
$$

La citada formula, indica que la tarifa técnica del SITP $\left(\mathrm{TT}_{\text {SITP }}\right)$ es el resultado de multiplicar la tarifa técnica de Transmilenio $\left(\mathrm{TT}_{\mathrm{TM}}\right)$ por el número de pasajes pagos de Transmilenio $\left(\mathrm{PP}_{\mathrm{TM}}\right)$ restando la sumatoria de los descuentos de Transmilenio (DctosTM) y el recaudo de los buses troncales de Transmilenio $\left(\mathrm{RT}_{\mathrm{TM}}\right)$. Hasta aquí está calculado el monto de la tarifa necesaria para pagar los costos de operación de los agentes del subsistema Transmilenio (SbTM), el cual se adecúa a los contratos de la Fase I y II.

El resto de la formula introduce las variables propias del componente integrado o componente zonal (SITP) que consiste en adicionar la sumatoria de recaudo troncal (RT), compuesto por el dinero recogido por la fase III de Transmilenio (Troncales $10^{a}$ y Calle 26), más la sumatoria del recaudo zonal (RZONA) integrado por los recursos obtenidos por la prestación de servicio zonales, más la remuneración que le corresponde al concesionario del Sistema Integrado de Recaudo, Comunicación e Integración SIRCI (RSIRCI), más la remuneración correspondiente al modo férreo (RMF) cuando éste se incorpore, más la remuneración a de los buses de alimentación (RA), más la remuneración al concesionario del recaudo (RR) -respecto del subsistema TM, pues dicho rubro en el SITP es cobrado por el SIRCI-, más la remuneración de la fiducia $\left(\mathrm{RF}_{\mathrm{SITP}}\right)$ encargada de administrar los recursos del SITP que entran al sistema, más la remuneración destinada a la inversión en la infraestructura del sistema (RP), como compra de terrenos, adecuación de parqueaderos y talleres, etc. La anterior sumatoria, debe dividirse de lo que resulte de la resta de uno por el porcentaje de remuneración del ente gestor del SITP (\% $\left.\mathrm{G}_{\text {SITP }}\right)$, que corresponde a la entidad pública Transmilenio S.A. (TMSA), multiplicado por los pasajes pagos del SITP $\left(\mathrm{PP}_{\mathrm{SITP}}\right)$.

Problemas sobre algunas variables de la estructuración tarifaria. Examinado el diseño tarifario, se advierte que si bien en abstracto no se presentan mayores inconvenientes, dado que la formula integra los costos de operación del sistema, el problema recae sobre algunas de las variables que componen la formula, pues la remuneración de los agentes privados se fundamenta en algunos costos sobredimensionados, desproporcionados y en algunos casos inexistentes, los cuales impactan significativamente el cálculo de los costos finales, haciendo de Transmilenio y el SITP un sistema de transporte oneroso, que en su afán por asegurar la remuneración integral a los operadores, de la 
totalidad de los costos, termina sacrificando el principio de costeabilidad, generando tarifas que no se adecuan a la capacidad de pago de los usuarios, aspecto que se explicará en detalle en el Capítulo III.

Tarifa integrada. Finalmente, y teniendo en cuenta que el sistema integrado presta diferentes servicios (troncales, zonales, alimentadores), cada uno con cobro diferenciado, los transbordos, entendidos como el traslado que se hace de un tipo de servicio a otro, tendrán un cobro inferior a la tarifa plena del servicio que se aborde, este esquema será válido exclusivamente para usuarios con tarjeta personalizada, los demás usuarios deberán pagar la tarifa plena del servicio al cual transborden. La regla de transbordos será válida en una ventana de tiempo determinado que fije la administración, que inicialmente será de 75 minutos contados a partir de la primera validación. Por fuera de este lapso de tiempo, el usuario al momento de utilizar nuevamente algún servicio, deberá pagar la tarifa plena del servicio empleado, y se iniciará un nuevo ciclo de transbordo tal y como lo estableció la cláusula 68 (Contrato Concesión SITP, 2010).

\subsubsection{Disposición y Destinación de los Recursos Generados por el Sistema. Tabla No. 5.}

\begin{tabular}{|l|}
\hline \multicolumn{3}{|c|}{ Contrato TM } \\
\hline CLAUSULA 73.- DISPOSICIÓN Y \\
DESTINACION ESPECIFICA DE LOS \\
RECURSOS GENERADOS POR EL \\
SISTEMA
\end{tabular}

Los ingresos totales producidos por la explotación de la actividad de transporte masivo de pasajeros en el Sistema TransMilenio, serán utilizados para los siguientes fines:

73.1 La conformación de un fondo que se denominará "Fondo Principal", cuya finalidad será: (i) La distribución de las participaciones a las que tienen derecho tanto el CONCESIONARIO como los demás concesionarios coexistentes y operadores de la alimentación troncal, por su participación en el Sistema TransMilenio.

(ii) La cancelación del valor de la remuneración que el CONCESIONARIO se

\section{Contrato SITP}

CLÁUSULA 52. DISPOSICIÓN Y DESTINACIÓN ESPECÍFICA DE LOS RECURSOS GENERADOS POR EL SISTEMA

La totalidad de los flujos de dinero producidos por la explotación de la actividad de transporte masivo de pasajeros en el Sistema Integrado de Transporte Público de BogotáSITP, y de los aportes de recursos públicos en caso de presentarse, ingresarán al Patrimonio Autónomo del Sistema, el cual estará constituido por los siguientes fondos:

\subsection{Fondo o Cuenta Recaudadora -}

CR 52.1.1. En esta cuenta se acumulan los recursos recaudados por venta (carga) de unidades de transporte. (...) 52.1.3. De la cuenta recaudadora egresan recursos para remunerar a los operadores del Sistema, fiducia, y Ente Gestor. (...)

\subsection{Fondo Principal SITP - FP SITP}

52.4.1. A este fondo ingresa el equivalente a la Tarifa Técnica del SITP por las validaciones de entrada con cobro efectivo al SITP (TT SITP x PP SITP), monto destinado a remunerar a los agentes 
encuentra obligado a pagar periódicamente al Gestor por los derechos que le confiere la concesión, en los términos previstos en la cláusula 14 del presente contrato, y (iii) La cancelación de la comisión causada por la administración fiduciaria de los recursos que ingresen al Fondo Principal, en los términos y condiciones previstos en el contrato de fiducia mercantil que forma parte del presente contrato, suscrito por el CONCESIONARIO para los efectos previstos en el presente contrato.

Este fondo se conformará de manera permanente y continua, con la parte de los ingresos producidos por la aplicación del valor de la tarifa técnica al número de pasajeros pagos del Sistema.

73.2 La conformación de un fondo que se denominará "Fondo de Contingencias" cuya finalidad será (i) la cobertura de contingencias específicas relacionadas con la estructura de la tarifa al usuario, que puedan poner en riesgo la estabilidad y viabilidad del Sistema TransMilenio, (ii) la acumulación de recursos que permitan la implementación de estrategias que fomenten el uso del Sistema.

Este fondo se conformará e incrementará en el tiempo, de manera permanente y continua, con la diferencia positiva existente entre la tarifa al usuario y la tarifa técnica, multiplicada por el número de pasajeros pagos del Sistema, y los rendimientos generados por los recursos de los fondos del patrimonio autónomo. (EFT). del SITP, incluyendo los agentes del SbTM.

52.4.2. Los agentes del SbTM tendrán prioridad en pago (...)

\subsection{Fondo de Estabilización Tarifaria SITP - FET.}

52.5.1. A este fondo ingresa la diferencia positiva entre: TU y TT, y egresa la diferencia negativa de dicha formulación. Esta dinámica corresponde a su utilización como fondo de estabilización tarifaria, y permite que los niveles de Tarifa al Usuario permanezcan estables en el tiempo, a pesar de la variabilidad que pueda tener la TT SITP.

52.5.2. El fondo se alimenta de los rendimientos financieros de CR, FCU, y los recursos que sean trasladados desde el Fondo de Contingencias del SbTM (FC TM). 52.6.4 Este fondo también se alimentará con los recursos que se obtengan por concepto de multas descontadas al CONCESIONARIO, de conformidad con la cláusula 132 del presente contrato.

\section{CLÁUSULA 54. CONDICIONES PARA LA DISPOSICIÓN DE RECURSOS DEL FONDO DE ESTABILIZACIÓN TARIFARIA - FET. (...)}

54.2. Los recursos acumulados en este fondo únicamente se emplearan para diferir en el tiempo el incremento en la Tarifa al Usuario del Sistema, cubriendo la diferencia positiva entre lo que debe remunerarse a los agentes SITP y los ingresos recaudados correspondientes a las validaciones de entrada al SITP.

TRANSMILENIO S.A. deberá realizar una adecuada planeación en el diseño del esquema de Tarifa al Usuario del SITP (tarifas diferenciales y cobros por transbordo) y en conjunto con la Secretaría Distrital de Movilidad y la Administración Distrital planear su fijación y ajuste, así como la temporalidad y monto de los recursos que deban trasladarse del presupuesto Distrital al FET, de tal forma que se garantice que siempre existan recursos suficientes para cubrir la diferencia positiva entre lo que debe remunerarse a los agentes SITP y los ingresos recaudados correspondientes a las validaciones de entrada al SITP. (Énfasis fuera de texto).

Fuente: Elaboración propia a partir de (Contrato Concesión SITP, 2010) y (Transmilenio S.A., 2001). 
Definidos los ingresos del sistema, el paso siguiente dentro de la economía de las concesiones examinadas consiste en la disposición y destinación de los recursos generados, los cuales son manejados -en su totalidad- mediante un patrimonio autónomo que es administrado por una Fiducia, quien es uno de los agentes privados del sistema, cuya principal obligación es administrar y distribuir los recursos, frente a lo cual recibe su correspondiente contraprestación económica. En los contratos de TM. El patrimonio autónomo cuenta con un fondo principal, donde el agente recaudador consigna los recursos obtenidos por el sistema diariamente, los cuales son distribuidos a los agentes atendiendo sus derechos de participación. Adicionalmente, se conformó un fondo denominado "Fondo de Contingencias" cuya finalidad es garantizar: i) la cobertura de contingencias específicas relacionadas con la estructura de la tarifa al usuario, que puedan poner en riesgo la estabilidad y viabilidad del Sistema TransMilenio; y, ii) la acumulación de recursos que permitan la implementación de estrategias que fomenten el uso del Sistema. En los contratos del SITP. Se mantiene la estructura originaria que funciona a partir de un Patrimonio Autónomo del Sistema, que maneja la totalidad de los flujos de dinero producidos por la explotación de la actividad de transporte masivo de pasajeros en el Sistema integrado de Transporte Público de Bogotá - SITP, así como los aportes de recursos públicos en caso de presentarse.

Este Patrimonio Autónomo está conformado por una serie de fondos o cuentas separadas atendiendo la destinación específica de los recursos, dentro de los cuales se encuentran los siguientes: i) Fondo o Cuenta Recaudadora. En esta cuenta se acumulan los recursos recaudados por venta (carga) de unidades de transporte. A esta cuenta entran los recursos en bruto. ii) Fondo Principal SITP - FP SITP. A este fondo ingresa el equivalente a la Tarifa Técnica del SITP por las validaciones de entrada con cobro efectivo al SITP (TT SITP x PP SITP). Es decir, de la cuenta recaudadora salen los recursos necesarios para cubrir los costos de operación representados en la tarifa técnica (TT), y son consignados en este fondo principal. iii) Fondo de Estabilización Tarifaria SITP - FET. A este fondo ingresa la diferencia positiva entre: TU y TT, y egresa la diferencia negativa de dicha formulación. "Esta dinámica (...) permite que los niveles de Tarifa al Usuario permanezcan estables en el tiempo, a pesar de la variabilidad que pueda tener la TT SITP", como lo dispone la cláusula 52.5 (Contrato Concesión SITP, 2010). Este fondo hace las veces del Fondo de Contingencias de las concesiones TM, pero su naturaleza varió pues en un principio fue concebido como mecanismo de garantía ante los imprevistos que pudieran afectar la sostenibilidad del sistema. El nuevo fondo tiene 
como propósito principal mantener estable la tarifa ante las fluctuaciones de costos que puedan sobrevenir, para efectos de mantener fija la tarifa al usuario por ciertos periodos de tiempo.

Obligación de Transmilenio S.A. El ente gestor del sistema TMSA, tiene como una de sus obligaciones realizar una planeación adecuada sobre el esquema tarifario (tarifas diferenciales y cobros por transbordo), fijar su temporalidad y el monto de los recursos públicos que deberán trasladarse de las arcas del Distrito al fondo para mantener la sostenibilidad del sistema. En síntesis, la distribución de los recursos se encuentra a cargo de la Entidad Fiduciaria adjudicataria de la administración del Patrimonio Autónomo al que ingresan todos los recursos del sistema. En su interior, dicho Patrimonio Autónomo se encuentra dividido por cuentas o fondos con destinación específica. Tanto la distribución, como el manejo de los recursos están reglados por los contratos de concesión. Los Derechos de participación de los agentes del sistema obedecen a reglas especiales, como se verá a continuación.

\begin{tabular}{|c|c|}
\hline \multicolumn{2}{|c|}{ 2.2.1.5. Derechos de Participación del Concesionario. Tabla No. 6.} \\
\hline Contrato TM & Contrato SITP \\
\hline $\begin{array}{l}\text { CLAUSULA 78.- PARTICIPACION } \\
\text { DEL CONCESIONARIO } \\
\text { El CONCESIONARIO obtendrá a título } \\
\text { de participación en los beneficios } \\
\text { económicos derivados de la explotación } \\
\text { comercial del Sistema durante el término } \\
\text { de vigencia del presente contrato, un } \\
\text { valor que estará determinado en función } \\
\text { de los kilómetros recorridos } \\
\text { efectivamente, de acuerdo con las } \\
\text { órdenes de servicio de operación } \\
\text { impartidas por TRANSMILENIO S.A., } \\
\text { por cada uno de los vehículos que se } \\
\text { encuentren vinculados a la operación del } \\
\text { Sistema, restringido al nivel de ingresos } \\
\text { generados por los pasajeros pagos. }\end{array}$ & 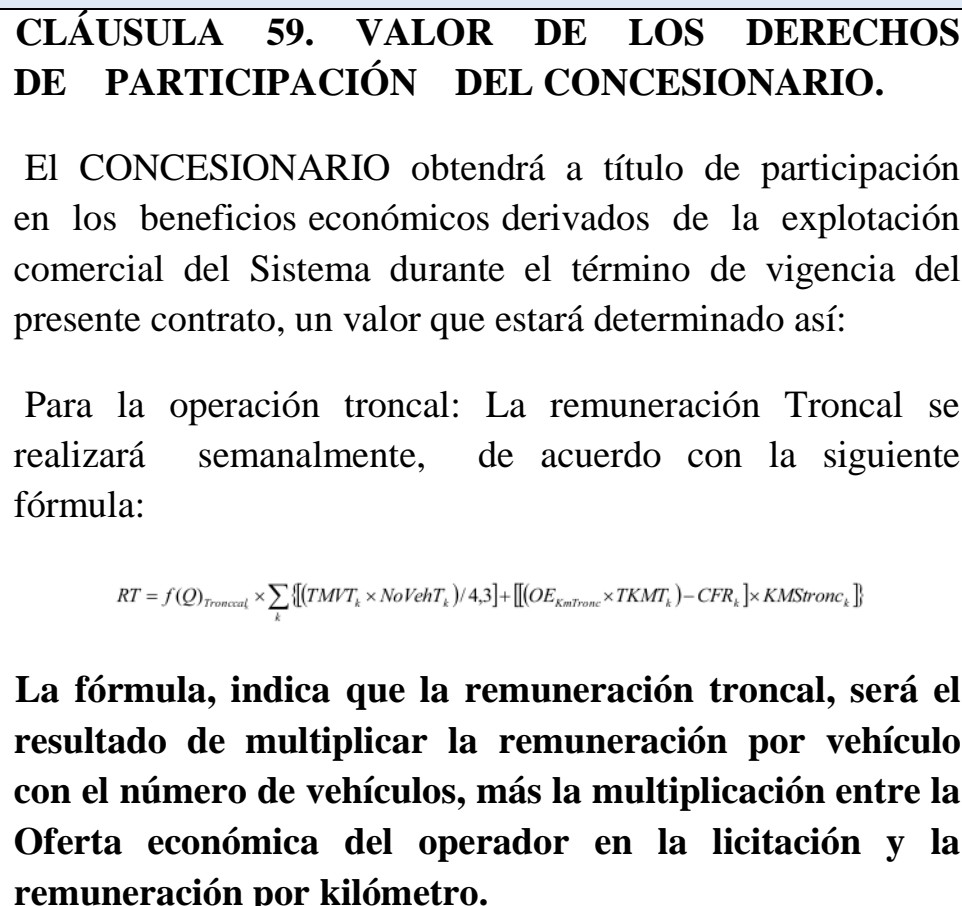 \\
\hline
\end{tabular}

Fuente: Elaboración propia a partir de (Contrato Concesión SITP, 2010) y (Transmilenio S.A., 2001). 
La participación de los concesionarios, consistente en la suma de dinero que le corresponde a cada uno, estará definida por los kilómetros efectivamente recorridos por los operadores, respecto de cada vehículo que se encuentre vinculado a la operación. En ese sentido, es pertinente anotar que en las licitaciones públicas los participantes entraron en la puja con un costo por kilómetro, y el valor con el que participaron y ganaron la licitación, con sus respectivos ajustes, es el que se pagan a los operadores atendiendo el número de kilómetros programados y efectivamente recorridos. Ahora bien, en cuanto al resto de los agentes del sistema, sus derechos de participación son asignados por el ente gestor, quien bajo las reglas previstas en los contratos de concesión realiza la distribución de los recursos, atendiendo los derechos de participación que corresponde a cada operador. Sobre este particular, resultan bastante ilustrativos los datos suministrados por los informes de gestión elaborados por Transmilenio S.A., los cuales serán examinados en el Capítulo III.

\subsubsection{Renegociación de los Contratos.}

Causas de la renegociación. En el documento de análisis para la modificación de los contratos (Transmilenio, 2013) se encuentra que la motivación principal del mismo, obedece a la necesidad de adecuar los contratos de concesión de las fases I y II de TM a las actuales condiciones de los contratos de concesión del SITP. En dicho documento se hace referencia a los principales problemas que se identificaron al cabo de 10 años de aplicación de las Fases I y II, y que requieren de cambios significativos para efectos de lograr la integración del sistema de transporte (Análisis para la posible negociacion y/o modificacion de los contratos de concesion para la Fase I y Fase II del sistema Transmilenio, 2013). La integración tarifaria entre TM y el SITP, que supone una unidad de medida que sirva para la utilización de todos los servicios de transporte, lo que a su vez implica modificaciones en la remuneración de los agentes del sistema, son algunos aspectos que no eran previsibles cuando se abrieron los procesos de licitación pública de TM Fases I y II (No. TMSA-0042009), lo que condujo a TMSA a modificar los contratos de concesión, “con el propósito de garantizar la operación del SITP, en un marco de sostenibilidad financiera, y un nivel de tarifa técnica del SITP que refleje los costos de operación y eficiencias del sistema", tal y como quedó consignado en el estudio elaborado para tal fin (2013). 


\subsubsection{Modificaciones principales de los contratos de Concesión Fase I y Fase II.}

Las modificaciones efectuadas en el 2013, introdujeron principalmente las modificaciones que se relacionan a continuación: i) Eliminación del Índice de Pasajeros por Kilómetro (IPK). La eliminación de esta variable (que se calcula como el cociente entre la totalidad de los pasajeros movilizados en el mes y la totalidad de los kilómetros recorridos durante un mes en todo el sistema troncal), dentro de la formula tarifaria es uno de los aspectos centrales de la modificación contractual bajo examen. Frente este aspecto, reconoce Transmilenio que esta modificación tarifaria no afectará el equilibrio contractual, ni cambia los incentivos de los operadores, "por el contrario busca reconocer el costo por $\mathrm{Km}$ inicialmente licitado y eliminar los efectos de la volatilidad den la demanda que ocasiona la entrada del SITP en la remuneración, con lo cual se elimina el riesgo de demanda que perciben los concesionario" (Transmilenio, 2013). Según el análisis técnico de TMSA la integración con el SITP altera este índice por 3 razones: 1) Introducción de buses biarticulados, que dentro del componente troncal corresponderán al 80\% del nuevo parque automotor para los servicios troncales, estos buses están en capacidad de manejar mayor número de pasajeros por viaje, "y por lo tanto la relación de pasajeros transportado por km recorridos aumenta". Según los estudios de Transmilenio, el IPK es un indicador que se calibra en función de la capacidad de los buses, y si la capacidad se modifica, es "incorrecto desde el punto de vista técnico, continuar con el mismo parámetro" (2013). 2) La integración tarifaria del SITP, incrementará necesariamente la demanda de los corredores de TM, pues "los pasajeros tendrán mayores incentivos para usar las rutas troncales, pues no se cobrará tarifas plenas, sino fracciones menores por transbordo", situación que hará que los usuarios respondan a los nuevos sistemas de precios intentando optimizar sus rutas, aumentando considerablemente la demanda en las troncales. 3) Mayor demanda por reconfiguración de rutas en el marco del SITP, los estudios elaborados por el ente Gestor indican que habrá un mayor flujo de pasajeros hacia TM, "lo cual es positivo desde el punto de vista de la eficiencia económica" (Transmilenio, 2013).

ii) Eliminación del Fondo de Contingencias. Se unificará dicho fondo en el FET creado por los contratos del SITP. La función del Fondo de Contingencias FC, consistía en mantener estable la tarifa del usuario TU de Transmilenio, para que esta no fuera a verse afectada por las continuas fluctuaciones que pudieran presentarse respecto de la tarifa técnica TT. Con la entrada del SITP se crea el Fondo de Estabilización Tarifaria FET, que tiene las mismas funciones del FC, lo que motivo a que dentro de la 
renegociación se incluyera la eliminación del FC para que solamente quedara funcionando el FET, en adelante encargado de dicha tarea. Frente a este punto es válido anotar que el Distrito en la renegociación mantiene el compromiso de pago extendido, que en la práctica constituye una garantía suscrita por el Distrito con la que se compromete a velar por que el FET siempre cuente con los recursos necesarios para solventar los gastos del SITP, cuando la TU no sea suficiente para cubrir la TT. El Distrito deberá garantizar la existencia de fondos, asegurando las correspondientes partidas presupuestales, en caso de ser necesarias, para mantener la sostenibilidad financiera del sistema. iii)

Incremento de la vida útil de los buses. La vida útil de los buses del sistema, que en los contratos de las Fases I y II fue convenida hasta que los articulados que componen la flota cumpliera $850.000 \mathrm{~km}$ o 10 años, fue aumentada hasta 1.240.000, incrementando cerca de $400.000 \mathrm{~km}$ de vida útil por bus. Esta concesión unilateral a favor de los operadores constituye otra gabela a los agentes encargados de la operación, concebida para lograr contar con su consentimiento para implementar la modificación contractual planteada, tal y como lo reconoció el propio ente gestor (2013). Este aspecto, será objeto de análisis en el Capítulo III.

\subsection{La Tarifa como Límite al Acceso al Servicio de Transporte.}

Una vez expuesto el funcionamiento del sistema de transporte urbano en Bogotá, e identificada la estructura económica que le sirve de sustento, se estudiará si la tarifa que hoy existe atiende a la capacidad de pago de los usuarios, para lo cual resulta necesario examinar las condiciones socioeconómicas de los habitantes de la capital, con el fin de tener un panorama claro, amplio y profundo para determinar si la tarifa constituye o no una restricción al acceso al servicio de transporte.

\subsubsection{Aspectos Socioeconómicos de Bogotá.}

Según los datos suministrados por la Secretaría Distrital de Planeación, en Bogotá para el año 2009 el 84\% de la población está ubicada en los estratos bajos 1, 2 y 3, siendo el estrato 2 (bajo) el más cuantioso con $38.6 \%$, seguido del estrato 3 (medio-bajo) con $36.7 \%$, y el estrato 1 (bajo-bajo) que alcanza $8.8 \%$, mientras que los estratos 5 y 6 tienen una población tan pequeña que sumados apenas representan el 3.2\%, es decir, 422 mil personas (Planeación S. D., 2010, p. 10). Por su parte, según el 
estudio realizado por la Secretaria de Hacienda del Distrito (2006), el 40\% de todos los ingresos que se generan en Bogotá queda en manos de apenas el 7\% de su población (491 mil personas); aspecto que no presenta mayor variación, pues para el 2009 "el 10\% de la población más rica de la Ciudad estaba recibiendo el 38.8\% del ingreso total” (Planeación S. D., 2009). Así mismo, las diferencias que se presentan de una localidad a otra son enormes, por ejemplo localidades como Teusaquillo y Usaquén presentan las menores incidencias de pobreza con un 6,4\% y 14,5\% respectivamente, mientras que Ciudad Bolívar con $56.5 \%$ y Usme con $51.6 \%$ son las que cuentan con mayor incidencia de pobreza (Planeación S. D., 2009), encontrando ciertas zonas de Usme, donde el ingreso per cápita es de 183 mil pesos mensuales.

Ahora bien, la última encuesta de ingresos y gatos elaborada por el DANE (2007) arrojó que solamente un 8,5\% de los bogotanos declara ganar más de cuatro (4) salarios mínimos legales al mes; mientras que el $60 \%$ de los hogares dijo tener ingresos disponibles inferiores a dos (2) salarios mínimos de la época: menos de 800 mil pesos (DANE D. N., Encuesta de Ingresos y Gastos, 2007). Y de esa inmensidad de ingresos bajos, las familias de escasos recursos destinan el $65 \%$ del gasto de los hogares para cubrir alimentación, salud, educación y vivienda. De ahí que, el 46\% de la población de Bogotá tiene la percepción de ser pobre, y de un total de 1.978 .528 hogares "el 24\% (474.021 hogares) afirman que sus ingresos no alcanzan para cubrir los gastos mínimos, el 56,5\% (1.118.395 hogares) dicen que sus ingresos solo alcanzan para cubrir los gastos mínimos” y solamente el 19,5\% (385.916 hogares) reportan que sus ingresos cubren más que los gastos mínimos (Planeación S. D., 2009). Pero no solamente las situaciones de escases y de necesidades básicas insatisfechas llaman la atención, la intensa desigualdad hace del problema algo absolutamente crítico, basta con saber que el 10\% más rico de la ciudad, recibe ingresos per cápita que son, en promedio, 50 veces más altos que los del 10\% más pobre; y mientras los hogares de menores recursos tienen que destinar el 30\% de sus ingresos a lo más básico: la comida, en los más ricos ese rubro les consume apenas el 12\% (Planeación S. D., 2009). Precisamente por eso, Bogotá ostenta el deshonroso título de ser la tercera ciudad más desigual, del tercer país más desigual del mundo, con un índice de Gini de 0,64 donde 1 es la desigualdad total (Suarez, 2010).

En ese orden de ideas, las familias que habitan en la capital, que i) pertenecen casi en un 50\% a los estratos 1 y 2 (bajo-bajo y bajo), ii) con un estrato 3 (medio bajo) que alcanza el 35\%, iii) donde el 
60\% de los hogares obtienen ingresos menores a 2 smmlv, y iv) el $56 \%$ afirma tener ingresos únicamente para cubrir sus gastos, mientras que el $24 \%$ afirma no tener ingresos suficientes ni siquiera para cubrir sus gastos básicos, son familias que se resienten por las altas tarifas, y resultan bastante susceptibles a cualquier alza de precios, situación que pone en evidencia que toda variación en los costos de los servicios públicos esenciales, afecta sensiblemente la economía familiar bogotana. En desarrollo de lo anterior, en seguida se examinarán las condiciones económicas específicas en materia del transporte urbano en Bogotá, para efectos de tener una noción mucho más precisa sobre las grandes limitaciones de acceso que encuentra un porcentaje muy significativo de la población capitalina (más del 50\%), quienes por el contexto socioeconómico en el que se desenvuelven, resultan afectados por las altas tarifas del servicio de transporte.

\subsubsection{La Realidad Económica en materia de Transporte Urbano en Bogotá.}

Como quedó visto, Bogotá ha vivido un importante cambio en materia de transporte urbano, primero con la entrada de TM que comenzó a operar desde el año 2000 y ahora con la implementación del SITP (2013), sistema que si bien generó avances relevantes en materia de movilidad, tales como construcción de estaciones, organización de rutas, establecimiento de carriles exclusivos para el transporte público, mejora del equipamiento urbano, entre otras, también produjo impactos negativos en materia de acceso al servicio. En efecto, cuando el Sistema TM comenzó, la tarifa se fijó en \$800, la cual era mucho menor que el sistema de Transporte Público Colectivo TPC, sin embargo, el costo de la tarifa fue incrementando paulatinamente y hoy supera con creces la tarifa del TPC, a relación de \$1.700 contra \$1.400. Según el informe de gestión de la Secretaria de Movilidad y TMSA (2012) “el $80.5 \%$ de los usuarios del Sistema reside en viviendas de estratos 2 y 3 (36,81\% y 43,69\% respectivamente). Las personas del estrato 4, con el 9,14\% se movilizan más en el Sistema que las personas del estrato $1(7,21 \%)$ y las personas que residen en viviendas de estratos 5 y 6 corresponden al 3,15\% (Movilidad, 2012). De lo anterior se puede concluir, que la mayoría de usuarios pertenece al estrato 3 (medio-bajo), seguidos de las personas de estrato 2 (bajo), siendo este estrato el de mayor proporción en la ciudad, lo que ponen en evidencia que por sus condiciones económicas encuentran en las tarifas serias limitaciones que impiden su acceso, y toda variación de precios resulta afectando a éstas familias de manera significativa. Las personas de estrato 1 (bajo-bajo) tampoco acceden en la 
proporción que correspondería atendiendo el porcentaje de población que lo compone, en parte porque -como quedó demostrado- sus ingresos insuficientes les impiden pagar el costo de la tarifa a pesar de que tienen la necesidad de transportarse. Lo anterior, explica por qué el $42 \%$ de los usuarios consideran que la tarifa de TM es alta o exagerada, más del doble de los usuarios que consideran que la tarifa del TPC es alta o exagerada (20\%) (Encuesta de percepción ciudadana, 2013). De ahí que el 13\% de los usuarios, considere que el problema principal de TM es el costo, que ocupó el tercer lugar después del hacinamiento y la inseguridad.

Así las cosas, puede concluirse que ciertos hogares se ven excluidos de este sistema de transporte a causa de las altas tarifas, mientras que otros hogares, no teniendo una opción distinta de movilidad se ven obligados a afectar seriamente su economía familiar por la necesidad de utilizar este servicio a pesar de su alto costo. En 2004, un hogar bogotano gastaba en promedio $\$ 304.100$ en transporte y comunicaciones, lo que equivale a $\$ 84.229$ por persona por ambos servicios. En 2007 , un hogar radicado en la capital, gasta en promedio $10 \%$ de sus recursos únicamente en transporte, porcentaje considerable si se le compara con lo que se gastan las familias en salud (1.8\%) o en educación (3.5\%) (DANE, 2007), y que se torna más intenso en los estratos bajos, quienes destinan cerca del $14 \%$ de su ingreso a movilizarse (Alcaldía Mayor B. , 2011). Así mismo, el impacto de las restricciones que genera el costo de la tarifa puede dimensionarse al examinar el comportamiento de los subsidios implementados en 2013 por el Distrito para los adultos mayores, a quienes se les subsidio tan solo \$200 de la tarifa, lo que representó un incremento de $219 \%$ en el uso de servicios troncales, y de $1.573 \%$ en el servicio zonal de (Transmilenio, 2013)

Pero la anterior situación se torna mucho más dramática con los precios actuales del Transmilenio (\$1.700), puesto que una familia promedio compuesta por 3,9 personas, puede gastarse únicamente en transporte, la suma de $\$ 280.000$ pesos al mes; cerca de $\$ 70.000$ por persona, lo que sin duda resulta insostenible para las familias de escasos recursos (estratos 1 y 2). Las cuantiosas sumas de dinero que deben gastarse los hogares para acceder al servicio público de transporte, permiten evidenciar que las tarifas constituyen una barrera, muchas veces infranqueable, para el acceso de una parte considerable de la población, situación que se explica porque "la elasticidad del gasto de transporte es cercana a la unidad: 1.0153, lo que indica que este gasto se aumenta o reduce en las mismas proporciones en que se mueva el ingreso de los hogares" (Hacienda, 2006), lo que en otras 
palabras quiere decir, que si se reducen los ingresos, se sacrifica los gastos en materia de transporte, a pesar de su carácter esencial. Basta comparar ese gasto en transporte de $\$ 280.000$ por familia, con el monto del salario mínimo actual que es de $\$ 616.000$, lo que representa el $45 \%$ del salario, situación que hace palidecer el auxilio de transporte que para el 2014 se fijó en $\$ 72.000$ (Decreto 3069 , 2013). Frente a lo anterior y teniendo en cuenta que cerca de la mitad de la población se encuentra en condiciones de pobreza, algunos de los cuales devengan el salario mínimo o mucho menos, resulta palmario que tales segmentos poblacionales no tiene la posibilidad de destinar sus escasos recursos para el uso de un servicio esencial, ya que tiene como prioridad atender necesidades aún más básicas como alimentación, vivienda y servicios públicos domiciliarios. En efecto, el alza en las tarifas del Transmilenio, que desde sus comienzos hasta el 2011 había incrementado 19\%, restando la inflación, desconoce de manera directa la capacidad de pago de un gran porcentaje de los capitalinos (Galeano, 2012). A pesar de los altos costos de Transmilenio, atendiendo que cerca del 50\% de la población en Bogotá pertenece a los estratos bajos (1 y 2), dicha población contaba con la posibilidad de movilizarse mediante el TPC, buses, busetas y colectivos, que no solamente son más baratos, sino que guardan la posibilidad de poder negociar la tarifa directamente con los conductores, logrando acceder al servicio por un precio mucho menor a los $\$ 1.400$ establecidos, práctica social bastante utilizada principalmente en las zonas periféricas de la ciudad.

Sin embargo, con la implementación del SITP y la correspondiente integración tarifaria expuesta en el acápite anterior, las limitaciones de acceso por aspectos económicos (costo de la tarifa) se tornan aún más fuertes. Sin duda el SITP trae aspectos positivos en tanto desarrolla un sistema de transporte multimodal, conformado por varias formas de transporte que se articulan a fin de tener una cobertura mayor, bajo un esquema mucho más organizado. No obstante, dichos avances se ven opacados por la imposibilidad efectiva de acceder al servicio de buena parte de la población, ya que la tarifa plena de dicho sistema de Transporte, en principio quedará en \$2000, si se suma el pasaje de Transmilenio $\$ 1.700$ y el cobro del transbordo \$300 (Alcaldía Mayor, 2012), teniendo en cuenta que la lógica del sistema genera la necesidad de hacer transbordo, el cual afecta en mayor medida a las personas que viven en la periferia (en su mayoría estratos 1 y 2 ), pues debido a las distancias y al esquema de transporte, tendrán que utilizar varios servicios para llegar a su destino final. Al volver a hacer las cuentas, de cuanto tendría que gastarse una familia promedio compuesta por 3,9 personas, con el funcionamiento en pleno del SITP, y el pago de una tarifa integrada de $\$ 2.000$ por trayecto, la suma 
asciende a $\$ 320.000$, es decir el $51 \%$ de un salario mínimo, lo que equivale a un costo por persona de $\$ 80.000$, suma que representa un aumento de la tarifa de transporte del orden del $17.65 \%$, mientras que el auxilio de transporte que es de $\$ 72.000$ solo aumentó $2.13 \%$ para el 2014, es decir, $\$ 1.500-$ menos

de un pasaje-, y el salario mínimo aumentó tan solo el 4.5\% (\$616.000), frente a un IPC de casi dos puntos (1.94\%). Más grave resulta la situación, si se considera que las personas de escasos recursos, (estratos 1 y 2) ya no van a contar con la posibilidad de tener una alternativa con el TPC, ya que este se integrará y hará parte del SITP, el cual maneja el recaudo como hoy lo hace el Transmilenio, impidiendo así la posibilidad de negociar la tarifa con el conductor, o de obtener descuentos por grupos.

\subsubsection{La Tarifa como restricción al acceso real y efectivo al Servicio de Transporte.}

Luego entonces, si la tarifa del TPC Bogotano ya era alta, y sobretodo inequitativa, haciendo de Bogotá "la cuarta ciudad del mundo con el transporte menos asequible para la quinta parte más pobre de sus población”, y donde además, cerca de 800.000 personas en promedio recorren 33 cuadras a pie para llegar a su lugar de trabajo o estudio, y otras 33 de regreso, se evidencia una situación sumamente crítica (Carty, 2006). Y si a lo anterior se le agrega que, "los más pobres terminan destinando el 28\% de su ingreso en transporte público”, se puede concluir con entera certeza, que la tarifa constituye hoy día, una poderosa restricción para el uso efectivo de un servicio fundamental como lo es el servicio público de transporte, en un mundo donde "el ingreso condiciona la capacidad de movilidad, y a su vez, la capacidad de movilidad condiciona el ingreso" (Carty, 2006). Y es que precisamente, si la ciudadanía no puede movilizarse de manera eficiente, las posibilidades de incrementar su ingreso, e incluso conseguirlo se reducen, afectando no solo la economía de las familias, sino de la sociedad en general. Ahora bien, la limitación de acceso representada por las altas tarifas, se deriva del esquema económico de los contratos de concesión, que debido a la estructuración tarifaria y a la distribución de costos y beneficios incorporada en las concesiones, imponen la necesidad de establecer tarifas que afectan a la población puesto que desconocen su capacidad de pago, con el único propósito de garantizar los derechos de los operadores privados, en perjuicio de los derechos de acceso, tanto individuales como colectivos, reconocidos por el sistema constitucional. Las serias limitaciones de acceso identificadas, ameritan una revisión minuciosa de la regulación del servicio de transporte público, bajo un enfoque económico y de derechos con el fin de establecer la 
conveniencia y eficiencia de la regulación examinada, aspecto que será objeto de estudio en el Capítulo III de la presente investigación.

\subsection{Conclusiones Capítulo II.}

En síntesis, se puede colegir que si bien la implementación de Transmilenio y del SITP en Bogotá significó un avance importante en materia de movilidad, debido a que organizó y modernizó el transporte, el mismo ha demostrado grandes falencias que conducen a concluir -incluso antes de su cabal implementación-, que resultará insuficiente para satisfacer las necesidades de una ciudad del tamaño y las características socioeconómicas de la Capital de Colombia, particularmente en términos de acceso. Ahora bien, tanto Transmilenio como SITP son operados por agentes privados, siendo TMSA la entidad pública que actúa como ente gestor, y se encarga de velar por la efectiva prestación del servicio en los términos y bajo la regulación dispuesta en los contratos de concesión. De ahí la importancia de examinar dichos contratos, toda vez que en ellos se encuentra el marco regulatorio y las reglas de juego con las que opera el sistema. Como núcleo de las referidas concesiones se encuentra el esquema económico que constituye la base sobre la que se sustenta la prestación del servicio de transporte. Así, luego de abordar el estudio minucioso de las principales cláusulas económicas tanto de los contratos iniciales de TM (fases I y II), como de los contratos del SITP, se exponen de manera comparativa 5 grupos de cláusulas de principal importancia, a saber: i) el marco económico constituido por los principios que deben guiar la prestación del servicio; ii) las cláusulas que regulan los ingresos del sistema; iii) las relativas al cálculo y definición de la Tarifa Técnica y la Tarifa al Usuario; iv) las cláusulas que establecen la disposición y distribución de los recursos del sistema; y, finalmente v) las cláusulas que prevén la participación de los agentes del sistema en los ingresos operacionales obtenidos por la prestación del servicio. Visto el detalle de las principales cláusulas que conforman el esquema económico de los contratos de concesión tanto de TM como del SITP, se identifican principios rectores, como son el principio de costeabilidad que establece que la tarifa que se cobre al público debe observar la capacidad de pago de los usuarios, aspecto medular dentro del estudio que se adelanta, pues se evidencia que las altas tarifas impiden el acceso real y efectivo de segmentos considerables de la población, en tanto no se adecuan a su capacidad de pago, lo que constituye una infracción al referido principio rector. Así mismo, se incorpora el principio de la sostenibilidad del 
sistema, que a partir de las concesiones SITP y las renegociaciones dejó de ser auto-sostenible, lo que implica que por regla general podrá acudirse a recursos externos para su mantenimiento. En consecuencia, la fuente principal de recursos, constituida por los recaudos obtenidos por la prestación del servicio, al ser insuficiente tiene que ser completada con recursos externos provenientes del Distrito, debido a los costos crecientes del sistema y la insuficiencia del recaudo para cubrirlos. En otras palabras, el Distrito tiene que mantener altas tarifas para cubrir los altos costos que se aseguran vía tarifa, que restringen el acceso a segmentos considerables de la ciudadanía, y a su vez destinar cuantiosas sumas de dinero para subsidiar las altísimas utilidades a los operadores privados, logrando la "sostenibilidad" a costa de subsidios y en perjuicio del acceso.

Justamente, la estructuración de la tarifa cobrada al público, obedece a una estructuración técnica, Tarifa Técnica, que está integrada por la totalidad de los costos de operación, incluyendo los costos de capital, los cuales llevan insertas tanto las utilidades de los operadores, como la depreciación económica de su inversión. Esa estructuración tarifaria constituye el aspecto central de la economía del contrato, pues es allí donde se definen los costos que deberán ser remunerados, dentro de los cuales se evidencian algunas variables sobredimensionadas, algunas que deberían ajustarse atendiendo las realidades del sistema, y otras incluso inexistentes, inconsistencias sobre las que se realizará un análisis concreto en Capítulo III de la presente investigación. Es pertinente hacer alusión al Acuerdo de Pago Extendido, que es la garantía mediante la cual, el Distrito -a través de recursos públicosasegura a los operadores privados el pago de la totalidad de los costos de operación del sistema, en caso de que el recaudo resulte insuficiente, hipótesis que constituye la regla general. Dicha garantía traslada todo el riesgo del negocio al erario público distrital, quien debe garantizar las partidas presupuestales necesarias para responder por los costos crecientes del sistema. Ahora bien, la distribución de las utilidades a los operadores privados se realiza según las cláusulas contractuales que regulan los derechos de participación de los agentes del sistema, aspecto que constituye el otro elemento esencial de la economía de tales concesiones. Por otra parte, en el 2013 la Alcaldía Mayor decidió firmar con los operadores privados una renegociación de los contratos, con el propósito de adecuar las concesiones de Transmilenio (fases I y II) a las nuevas estipulaciones de las concesiones del SITP. Los cambios estructurales que se efectuaron fueron 2, así: i) la eliminación de la variable del Índice de Pasajeros por Kilómetro IPK, la cual tenía en cuenta para la remuneración de los operadores el número de pasajeros transportado en un kilómetro, dicha medida torna los costos de 
operación insensibles a la demanda del sistema, que con el SIPT se incrementará exponencialmente, impidiendo que las eficiencias derivadas del aumento significativo de la demanda y la reducción de costos que esto implica, sean trasladadas a la TT, evitando la reducción de las tarifas al público. ii) El segundo cambio, consistió en el aumento de la vida útil de los buses del sistema (Fases I y II) el cual paso de $850.000 \mathrm{~km}$ o 10 años, a 1.240.000, incrementando cerca de $400.000 \mathrm{~km}$ de vida útil por bus.

Ahora bien, todo lo anterior se produce en el contexto de una ciudad con una realidad socioeconómica sumamente compleja, pues las familias que habitan en la capital, i) pertenecen casi en un $50 \%$ a los estratos 1 y 2 (bajo-bajo y bajo), ii) con un estrato 3 (medio bajo) que alcanza el 35\%, iii) donde el $60 \%$ de los hogares obtienen ingresos menores a 2 smmlv, y iv) el $56 \%$ afirma tener ingresos únicamente para cubrir sus gastos, mientras que el $24 \%$ afirma no tener ingresos suficientes ni siquiera para cubrir sus gastos básicos. Lo anterior demuestra que un alto porcentaje de familias en Bogotá (más del 50\%) se ven afectadas por las altas tarifas, y resultan bastante susceptibles a cualquier alza de precios, situación que pone en evidencia que toda variación en los costos de los servicios públicos esenciales, afecta sensiblemente la economía familiar bogotana.

Es así como, en 2007 un hogar radicado en la capital, gasta en promedio 10.0\% de sus recursos únicamente en transporte, porcentaje considerable si se le compara con lo que se gastan las familias en salud (1.8\%) o en educación (3.5\%) (DANE, 2007), y que se torna más intenso en los estratos bajos, quienes destinan cerca del 14\% de su ingreso a movilizarse (Alcaldía Mayor B. , 2011). Pero la anterior situación se torna mucho más dramática sí a los precios actuales del Transmilenio (\$1.700), se suma el cobro del transbordo \$300 derivado de la integración con el SITP (Alcaldía Mayor, 2012), quedando la tarifa plena en $\$ 2000$, teniendo en cuenta que la lógica del sistema genera la necesidad de hacer transbordo, el cual afecta en mayor medida a las personas que viven en la periferia (en su mayoría estratos 1 y 2); lo que quiere decir que una familia promedio compuesta por 3,9 personas, puede gastarse únicamente en transporte, la suma a $\$ 320.000$ al mes, lo que equivale a un costo por persona de \$80.000, monto que representa un aumento de la tarifa de transporte del orden del $17.65 \%$, mientras que el auxilio de transporte que es de $\$ 72.000$ solo aumentó $2.13 \%$ para el 2014, es decir, $\$ 1.500$-menos de un pasaje-, y el salario mínimo aumentó tan solo el 4.5\% (\$616.000), frente a un IPC de casi dos puntos (1.94\%). Las cuantiosas sumas de dinero que deben gastarse los hogares para acceder al servicio público de transporte, permiten evidenciar que las tarifas constituyen una barrera, 
muchas veces infranqueable, para el acceso de una parte considerable de la población -cerca del 50\%-, situación que se explica porque "la elasticidad del gasto de transporte es cercana a la unidad: 1.0153, lo que indica que este gasto se aumenta o reduce en las mismas proporciones en que se mueva el ingreso de los hogares" (Hacienda, 2006), lo que en otras palabras quiere decir, que si se reducen los ingresos, se sacrifica los gastos en materia de transporte, a pesar de su carácter esencial, en un mundo donde "el ingreso condiciona la capacidad de movilidad, y a su vez, la capacidad de movilidad condiciona el ingreso" (Carty, 2006).

Bajo tales consideraciones, se puede concluir en primer lugar que las tarifas son el resultado de las clausulas económicas de los contratos de concesión, en particular de la estructuración tarifaria y de la distribución de costos y beneficios. En segundo lugar, y una vez examinada la realidad socioeconómica de Bogotá, se evidencia que las tarifas son altas o exageradas atendiendo la capacidad de pago promedio de la ciudadanía ( $82 \%$ pertenece a estratos 1, 2 y 3), lo que impide el acceso real y efectivo de segmentos considerables de la población, sobre todo los sectores más desfavorecidos (estratos 1 y 2), quienes o se ven excluidos del sistema de transporte y tienen que acudir a sustitutos (medios humanos, motos, etc.), o tienen que subirse sin pagar (70 mil usuarios diarios), o tienen que afectar seriamente sus economías familiares para acceder a un servicio esencial. En efecto, resulta tan sensible la demanda al costo del servicio, que solo con subsidiar $\$ 200$ a los adulto mayores, se incrementó $219 \%$ el uso de servicios troncales, y de $1.573 \%$ en el servicio zonal (Transmilenio, 2013). En tal sentido, no existe duda sobre las serias limitaciones que representa la tarifa para el acceso al servicio esencial de transporte público. Por lo tanto, en el Capítulo III de la presente investigación, mediante la aplicación de las herramientas del Análisis Económico del Derecho AED, se realizará un análisis económico sobre la regulación del servicio de transporte, en especial sobre la estructuración tarifaria y la distribución de costos y beneficios, a fin de establecer cuáles son las causas de las altas tarifas y buscar alternativas para adecuarlas a la capacidad de pago promedio de los ciudadanos. 


\section{CAPÍTULO III.}

\section{ANÁLISIS ECONÓMICO DE LA REGULACIÓN DEL SERVICIO DE TRANSPORTE EN BOGOTÁ, CASO TRANSMILENIO Y SITP.}

Hasta este momento, se ha efectuado un análisis sobre las normas económicas constitucionales y la regulación en materia de servicios públicos, aspectos que integran el marco jurídico iusfundamental que gobierna estas especiales prestaciones. Así mismo, se realizó un examen al funcionamiento tanto operativo, como económico del sistema de transporte en Bogotá, del cual se derivan altas tarifas, que atendiendo al contexto socioeconómico de la Capital, terminan restringiendo de manera ostensible el acceso a un servicio público esencial a segmentos significativos de la población, generando un conflicto entre la regulación -que para este caso se expresa a través de contratos de concesión- y los derechos de los ciudadanos a movilizarse y a acceder a los servicios públicos esenciales como el transporte, derechos que se deben asegurar a toda la colectividad. En desarrollo de lo anterior, en el presente capítulo se realizará un análisis sobre la regulación en materia de transporte, para lo cual se acudirá a algunos conceptos y metodologías implementados por el denominado Análisis Económico del Derecho (en adelante AED), movimiento académico que ha introducido nuevos elementos provenientes de las ciencias económicas para analizar tanto normas, como problemas jurídicos, desde nuevas valoraciones propias de esa área del conocimiento. En ese orden de ideas, dentro del presente Capítulo III se tratarán 3 puntos centrales, así: i) se realizará una aproximación al AED, sus fundamentos y utilidades; ii) luego se examinarán los estudios efectuados sobre la Economía del Sistema de Transporte de Bogotá; y iii) finalmente se realizará el Análisis Económico sobre la regulación del servicio de transporte de la capital, con el fin de establecer si los "arreglos institucionales" que configuran la regulación, afectan o no los derechos al acceso al servicio de transporte público, que constituye el objetivo principal de la presente investigación.

\subsection{El AED como Herramienta para Resolver Conflictos de Derechos.}

Siguiendo al profesor Márquez Escobar (2005), "la economia es el estudio de la interacción de la acción de los agentes y de los modos de controlar dicha acción para lograr una asignación optima o eficiente de los recursos escasos" (pág. 31). Esta ciencia social, encaminada a establecer por qué los 
humanos toman ciertas decisiones y no otras, desarrolló su estructura argumentantativa convirtiendose en un área especifica del conocimiento, que con el tiempo comenzaría a encontrar espacios comunes con la ciencia jurídica, encargada del estudio de las normas y principios jurídicos que intervienen el comportamiento humano (Palacios, 2009). En consecuencia, el encuentro entre ambas disciplinas era inevitable, en la medida que como indica Marquez "la existencia de normas simplemente indica que hay unos limites artificiales (sean consensuales o dictatoriales) a la acción humana deliberada" (pág. 32), luego entonces, para entender por qué se toman ciertas decisiones, uno de los elementos a tener en cuenta será la norma juridica, que necesariamente afecta, positiva o negativamente, la toma deliberada de decisiones.

Pero la interacción entre Derecho y Economía no es unívoca ni unilateral, pues las normas jurídicas son el reflejo de unos intereses y unas decisiones económicas, donde los agentes dentro de un mercado, desplegan diferentes tipos de comportamientos, para que las reglas de juego resulten favorables a sus intereses, permitiendo maximizar los beneficios particulares de los individuos. En ese sentido, es pertinente la cita que hace el profesor Leguizamo (2007) de Engels, quien sobre la relación entre economía y derecho manifiesta que "no es que la situación económica sea la causa, en el sentido de ser el único agente activo y que todo lo demás no sea sino un resultado pasivo. Se trata más bien de una acción y reacción mutuas, sobre la base de la necesidad económica que, en último término, se impone siempre". En otras palabras, si bien ambas ciencias se interconectan, la producción normativa siempre estará supeditada a un trasfondo económico, del cual no se puede desligar. En efecto, el derecho es producto de un determinado contexto (político, social, cultural), que en lo fundamental se estructura a partir de las relaciones económicas que se presentan en un determinado momento histórico. El derecho entonces, será una forma de regular la realidad, y por lo tanto terminará configurando ciertos aspectos de ésta, pero dicha realidad, producida en lo fundamental por las interacciones económicas que se presenten y por las fuerzas de los distintos agentes en disputa, es la que principalmente configura y produce el derecho. En consecuencia, la conexión entre el derecho y la economía debe ser entendida como una relación dialéctica en donde ambas disciplinas se nutren y contradicen mutuamente, pero donde las fuerzas económicas prevalentes en una determinada sociedad, terminan apoderándose de los aparatos de producción normativa, y por lo tanto, acaban diseñando el derecho de conformidad a sus intereses. 


\subsubsection{El Análisis Económico del Derecho.}

Ahora bien, las intimas relaciones entre ambas áreas del conocimiento, demuestran una estrecha conexión, cada una como factor que influye los análisis de la otra, sin embargo es hasta el siglo XIX, cuando se comienza a esbozar lo que más adelante se conocería como Análisis Económico del Derecho, AED, que podría definirse como "la aplicación de la teoria económica y los métodos econometricos para examinar la formación, estructura, proceso y el impacto de la ley y las instituciones legales" (Marquez, p. 41). Tras la aparición de los primero escritos durante la decada de los 60, donde Ronald Coase, Henry Simons y Aaron Director, abordaron el estudio de la ley, bajo la metodología y los conceptos económicos, muchas serian las corrientes que basadas en el análisis económico, estudiarian problemas jurídicos, antes de orbita exclusiva de la lógica jurídica.

Corrientes como la Escuela de Chicago, la Nueva Economía Institucional, la Escuela de la Elección Pública, irían enrriqueciendo el AED como paradigma de investigación, complementando los vacios existentes (Amador, 2012). La aplicación del AED conducirá sin duda a resultados jurídicos direccionados desde los modelos económicos a partir de los cuales se aborde el asunto, evidenciando una vez más, y de manera directa y frontal, que son las interacciones económicas entre los agentes, en los distintos escenarios en los que se encuentran, las que definen la realidad a partir de las luchas incesantes de las fuerzas económicas, y es el derecho el que vendrá a configurar, organizar y producir normas jurídicas, a partir de los resultados de esas interminables disputas. En síntesis, el AED tal y como lo señala el profesor Gaspar Ariño (2003) responde a una necesidad cada vez más latente en las sociedades contemporáneas, que consiste en tomar en consideración los grandes conflictos de intereses que se producen en la vida social, "no solo desde una perspectiva principalista, a la que tan acostumbrados estamos los juristas tradicionales, sino consecuencial: ¿Cuáles son las consecuencias económicas y sociales- que producen las decisiones jurídicas legislativas o judiciales?” (p. 74).

\subsubsection{Tipos de Análisis Económico del Derecho.}

Richard Posner, uno de los más prolíficos impulsores del AED, señala que el enfoque económico del derecho tiene dos ramas, que en su concepto darán surgimiento a la economía como un campo 
distinto del conocimiento en el siglo XVII, que son "el análisis económico de las leyes que regulan los mercados explícitos, y el análisis económico de las leyes que regulan el comportamiento ajeno a mercado" (Usos y Abusos de la Teoría Económica en el Derecho, 2000). Ejemplos de los primeros (mercados explícitos), son los análisis económicos elaborados sobre la regulación en materia de derecho de la competencia, la empresa, la responsabilidad, etc., en la que existe una clara relación del objeto de estudio con los mercados y el proceso económico. Por otra parte, ejemplos de los análisis económicos de leyes que regulan comportamientos ajenos a mercado, son los estudios adelantados sobre instituciones como el matrimonio, la adopción, los delitos, e incluso sobre el amor, aspectos que no guardan un vínculo directo con la actividad económica, pero que han sido objeto de su análisis, dentro de los que sobresalen los estudios realizados por Gary Becker, situación que ha sido objeto de múltiples críticas, que ven en dichos intentos una apuesta imperialista del análisis económico.

Ahora bien, el mismo Posner, indica que existe otra distinción importante del AED, que lo divide entre el análisis económico normativo y el positivo, es decir, "entre el uso del análisis económico para argumentar que debe ser y el uso de éste para explicar que es, que ha sido o bien para predecir que será" (2000, p. 69). En efecto, Posner sostiene que gran parte de los intentos de aplicar el enfoque económico en el Derecho, se han ocupado de cómo debería ser la regulación (AED normativo) y cuál sería el sistema legal ideal en un área del Derecho, situación que no considera óptima, pues primero debe entenderse el sistema legal existente, y comprender económicamente cómo funciona la regulación vigente (positivo), para identificar las ineficiencias, y realizar las adecuaciones necesarias que permitan superarlas, en lugar de construir modelos ideales muchas veces inaplicables. Justamente, Posner concluye que uno de los grandes aportes de las nuevas obras del AED (positivas) "es que el análisis económico puede ser útil para diseñar reformas del sistema jurídico" (El Enfoque Económico del Derecho, 2011). Posner, con el objeto de sistematizar las distintas expresiones del movimiento del AED, efectúa otra distinción, entre el AED que estudia el comportamiento regulado y aquel que estudia el comportamiento regulatorio. En ese sentido, "el economista puede estudiar una actividad regulada por el sistema legal o puede estudiar la actividad regulatoria del sistema" (2000, p. 68). Ejemplo de la primera, será un análisis económico sobre el carbón, el petróleo o los servicios públicos, actividades que son objeto de regulación; por otra parte, el análisis económico podrá versar sobre la eficiencia del sistema legal que regula la explotación económica del carbón, el petróleo o los servicios públicos. 
En línea con lo expuesto por Posner, la presente tesis se podría clasificar como un AED positivo que recae sobre el comportamiento regulatorio de un mercado explícito, en tanto que el mismo se efectúa sobre la regulación en materia del servicio de transporte, contenida en los contratos de concesión, que constituyen el marco legal que gobierna la prestación actual de dicho servicio público. Precisamente, la presente investigación no tiene como propósito definir cuál sería la regulación ideal, por el contrario tiene como finalidad analizar la regulación que existe, a fin de identificar sus problemas y establecer criterios mediante los cuales se pueda lograr una regulación más eficiente. Así mismo, si bien se examinan aspectos económicos de la prestación del servicio de transporte público (objeto regulado), el mismo se aborda por ser una expresión material de la regulación, que permite obtener evidencia empírica sobre su funcionamiento, no obstante, el análisis económico y la crítica se concentra en el sistema regulatorio, en especial, en las cláusulas económicas de los contratos de concesión, aspecto que se desarrollará en el tercer punto del presente capítulo.

\subsubsection{Utilidades del Análisis Económico del Derecho.}

Una vez revisado el origen, el concepto, los fundamentos en torno al AED, se puede concluir anticipadamente - en palabras de Posner- que "la aplicación de la economía al derecho es algo más que la traducción de la sabiduría tradicional de los académicos del derecho a una jerga diferente” (2000, p. 89) cargada de tecnicismos económicos. A continuación, se resaltarán las principales utilidades de la aplicación de la teoría económica en el derecho tanto en términos generales, como para el caso concreto relacionado la regulación del servicio de transporte público.

Utilidades Generales. Bajo la egida de la teoría de la argumentación jurídica, según la cual se considera que "una de las actividades centrales de los juristas es argumentar, esto es, presentar razones que justifiquen una serie de decisiones que se toman en diversas actividades", y presentar "razones de apoyo a una determinada interpretación" (Cruz Parcero, 2006), es indudable que AED mediante la introducción de algunos de los principales conceptos y metodologías de la economía, enriquece ampliamente la tradición jurídica argumentativa, otorgando nuevas razones, de considerable peso, para justificar la elección de una decisión destinada a resolver un problema jurídico, e incluyendo dentro de la valoración normativa, el estudio de las consecuencias y los impactos económicos, en términos de costos, lo que permite fortalecer el catálogo de consideraciones y de razones a partir de las cuales se fundamenta una decisión jurídica. Adicionalmente, el análisis jurídico se limitaba a discutir sobre la 
justicia, la validez y la eficacia de las normas, pero la teoría económica del derecho ha permitido demostrar que la regulación no solo responde a los criterios clásicos de valoración normativa, sino que, por el contrario, está sujeta a las fuerzas económicas existentes y su influencia.

Precisamente, examinar el derecho utilizando los lentes de la economía permite concluir lo afirmado por Gaspar Ariño (2003), en el sentido que a cada sistema económico le corresponde un determinado sistema legal. En ese orden de ideas, "el sistema legal asigna derechos, obligaciones, deberes, responsabilidades, privilegios, etc., a las personas" mediante "el derecho, la regulación y la constitución" (Cooter), fundamentado principalmente en el orden económico que impere en un determinado momento histórico. Lo anterior explica, entre otras cosas, por qué la distribución de derechos y beneficios dentro del capitalismo financiero que existe en la actualidad, tienda a favorecer a los agentes financieros (bancos, fondos de pensiones, comisionistas de bolsa), quienes logran intervenir en el diseño del sistema legal. De la misma manera, la prevalencia aún vigente de los postulados económicos neoliberales, explica por qué buena parte de los estudios que aplican el AED, se fundamenta principalmente en las posturas de la teoría económica clásica o liberal. En otras palabras, el AED permite evidenciar de manera directa, que el sistema legal se adecua a las necesidades de las fuerzas económicas que logren hacer prevalecer sus intereses. Como un elemento adicional para corroborar lo afirmado, puede observarse como las recientes crisis financieras generadas en las cunas del Capitalismo, han dado muestras del resquebrajamiento de la estructura económica vigente, generando por resultado serios cuestionamientos a los paradigmas económicos defendidos por los exponentes contemporáneos del liberalismo económico (Suarez, 2010), situación que ha obligado a realizar planteamientos económicos desde otras perspectivas, y desde nuevas escuelas, que comprendan el fenómeno económico desde una dimensión más amplia, fundamentados en variables macroeconómicas, que presten atención a las consecuencias sociales y vean más allá del simple comportamiento egoísta e individual.

Utilidad del AED para la presente investigación. La necesidad de acudir al AED para examinar el objeto de investigación, se da por las siguientes razones: i) por que la regulación del servicio de transporte, revestida de tecnicismo y complejidad ha impedido realizar análisis profundos sobre las problemáticas principales del servicio de transporte. En efecto, las innumerables criticas apuntan a diferentes diagnósticos sobre los problemas de la movilidad, sin embargo, el AED 
suministra datos extrajurídicos (estadísticos, económicos, cuantitativos) a partir de los cuales se puede abordar el estudio crítico sobre la economía de los contratos, en particular sobre la estructuración tarifaria y la distribución de costos y beneficios, aspectos medulares de los que se derivan los problemas estructurales del sistema de transporte. ii) Adicionalmente, el conjunto de derechos que se encuentra en interacción en materia del servicio de transporte, genera conflictos entre los distintos intereses protegidos por el sistema constitucional, como por ejemplo la tensión que existe entre el derecho de los ciudadanos al acceso a un servicio esencial como lo es el transporte público y los derechos a la libre competencia de los agentes privados encargados de su operación. En términos abstractos, dicho conflicto debería resolverse a favor de los ciudadanos y usuarios -por la prevalencia del interés general-, sin embargo, abordar el debate jurídico desde una perspectiva eminentemente de derechos, resulta insuficiente, pues el discurso prevalente y los valores sociales imperantes otorgan rango superior a bienes jurídicos como la protección de los inversionistas, la inversión extranjera, la seguridad jurídica, las alianzas público privadas, la prestación de servicios por particulares, la ineficiencia estatal en el suministro de los mismos, aspectos que inclinan la balanza a favor del modelo de transporte actual y que se oponen abiertamente a todo tipo de modificación estructural, lo que conduce inexorablemente a fundamentar las necesidades de modificación integrando argumentos provenientes tanto desde la dimensión jurídica, como desde la dimensión económica, pues en la actualidad el debate de derechos pasa por el debate económico. iii) Finalmente, es pertinente anotar que, el sistema jurídico colombiano asegura la igualdad material, el principio de solidaridad, la prevalencia del interés general sobre el particular, pero dichas máximas debe ser llenadas por aspectos concretos expresados en cifras, números, datos cuantitativos, que permitan evidenciar que en efecto hay unos interés colectivos e individuales reales, que cuentan con un sustrato material, y que están siendo efectivamente lesionados por unos intereses particulares y por una regulación específica, la cual se debe cambiar para hacer prevalecer los imperativos constitucionales.

\subsection{Estudios sobre la Economía del Sistema de Transporte de Bogotá.}

Luego de estudiar los fundamentos, la lógica y la utilidad del AED para afrontar el objeto de estudio, es necesario examinar lo dicho por la comunidad académica sobre la aplicación del enfoque económico en materia de regulación del servicio público de transporte. Al efectuar la búsqueda de las 
fuentes para estructurar el Estado del Arte de ésta investigación, se encontraron distintos y muy interesantes estudios que examinan el servicio de transporte, desde una perspectiva de eficiencia, con algunas relaciones sobre asuntos de distribución y de equidad, pero otorgándole mayor realce al enfoque económico. A continuación, se expondrán brevemente los principales hallazgos, con el objeto de dar a conocer cuál es el estado actual de la discusión en torno a la eficiencia de la regulación del servicio de transporte público.

\subsubsection{El servicio público y la regulación del Medio de Transporte. (Posner).}

Uno de los principales estudios que aplican el enfoque económico del derecho sobre la regulación en materia de transporte, es el elaborado por Posner en el Capítulo XII de su obra Análisis Económico del Derecho (2013). En dicho estudio, Posner, a partir del concepto de monopolio natural según el cual "un monopolista natural es una empresa que tiene economías de escala netas en todo el conjunto de su producción viable" (p. 556), explica que dicho fenómeno bajo ciertas condiciones puede ser el procedimiento más barato para la organización de una industria. No obstante, el monopolio natural plantea tres problemas que ameritan regulación: i) Fijación de precios, ii) la entrada en el mercado, y iii) dificultad para elaborar una estructura de precios eficiente. Par dar solución a los referidos problemas derivados del monopolio natural, la respuesta habitual de la ley es la regulación de los servicio púbicos, dentro de los cuales - destaca Posner- "los casos del medio de transporte de pasajeros de carga y de las empresas de comunicaciones" (p. 559). Este tipo de regulación, se fundamenta en 3 elementos "primarios": 1) el control de la ganancia (las tarifas de la empresa regulada no deberán exceder el nivel necesario para permitir que la empresa cubra sus costo de servicio, incluido un rendimiento razonable sobre el capital invertido); 2) control de la entrada (una empresa no podrá proveer un servicio regulado sin obtener primero, de la dependencia reguladora, un certificado de conveniencia y necesidad públicas); y 3) control de la estructura de precios (la empresa no podrá discriminar en sus tarifas) (Posner R. A., 2013). Identificados los controles, Posner procede a verificar si dichas medidas resuelven los problemas del monopolio natural planteados.

Control de ganancias y el problema del rendimiento razonable. Existe un método tradicional para calcular la tarifa de los servicios públicos. Consiste en que el ente regulador selecciona un año 
reciente y representativo de la compañía que presta los servicios y computa los cotos totales de la empresa para proveer en ese año el servicio regulado, menos todos los cotos de capital. La entidad reguladora añade al costo del servicio un rendimiento razonable sobre el capital invertido (la deuda a largo plazo más el capital social). El componente de rendimiento, que según Posner es el asunto principal, "se determina multiplicando la base tarifaria de la compañía - una estimación del valor de los activos de capital empleados por la compañía para prestar el servicio regulado- por la tasa de rendimiento razonable de la compañía. Esta última es un promedio ponderado de la tasa de interés a largo plazo más la tasa de rendimiento para los accionistas que la dependencia considere apropiada en vista del riesgo de la inversión y la tasa de rendimiento disfrutada por los accionistas de las empresas comparables" (EFT). Establecer los costos del servicio en un año de prueba no presenta mayores inconvenientes, aunque "algunas ganancias monopólicas pueden ocultarse en rubros del gasto reales como sueldos y las prestación de los administradores”. El verdadero problema consiste en saber cuál debe ser el monto de los rendimientos. Precisamente, se ha dicho que "la garantía constitucional de la compensación justa por las expropiaciones gubernamentales faculta a los accionistas de un servicio público a recibir un rendimiento justo de su inversión” (EFT) (p. 562). Pero, ¿cómo determinar cuál es el rendimiento "justo”? esa la cuestión que preocupo largo tiempo a los tribunales y a los jurisconsultos, quienes se preguntaban "si la base tarifaria debería medirse por el costo original depreciado de los activos de capital de la empresa o por su costo de reposición". La respuesta a este interrogante es de vital importancia, sobre todo si se tienen en cuenta la variable de la inflación, pues en los periodos de inflación prolongada, “el costo de reposición de un activo de capital de larga vida puede exceder grandemente al costo original del activo, de modo que el empleo del costo de reposición facultaría a la compañía a recibir una tasa de rendimiento mucho mayor, lo que a su vez se traduciría en tarifas más altas” (p. 561).

Posner explica que la elección sobre qué tipo de costos se deben incluir en la tarifa, si los costos originales o los costos de reposición, no es univoca y dependerá de diferentes variables. Señala que el costo de reposición no es siempre la norma económica correcta, razón por la cual será necesario analizar si los activos de capital de una industria (por ejemplo, las vías ferroviarias, las locomotoras y las terminales) se deben reemplazar completamente, lo que ameritaría utilizar los costos de reposición, o si por el contrario solo se requerirá reemplazar un porcentaje de dichos activos (por ejemplo solo las locomotoras), frente a lo cual sería correcto partir de los costos originales. En tal sentido, si los 
principales activos no serán reemplazados en su totalidad, "debido a la declinación del demanda del producto de la industria, el cobro de un precio basado en los costos de reposición solo impediría la utilización plena de la capacidad existente", generando mayores tarifas. En ese sentido, si los costos han bajado, las tarifas corrientes serán demasiado elevadas, y ante unas tarifas así, los consumidores se verán abocados a comprar productos sustitutos "cuya producción es efectivamente más costosa para la sociedad". En sentido contrario, en caso que las tarifas resulten demasiado bajas, "los consumidores se alejaran de los productos sustitutos cuya producción es menor para la sociedad; de nuevo se desperdiciaran recursos” (p. 564). Tal es la importancia de contar con una regulación correcta al momento de estructurar las tarifas. Ahora bien, resulta necesario tener claro que la regulación de servicios públicos tiene importantes efectos colaterales, pues "en la medida en que alcance su objetivo formal de determinar el precio del servicio público sobre la base de cierta tasa de ganancia sobre el costo, reducirá el incentivo de la empresa para minimizar sus costos”, protegiendo de esta manera la calidad y la prestación del servicio público. En caso de lograr establecer una tarifa que asegure costos y una tasa "justa" de rendimiento -aspecto que constituye el objetivo principal de la regulación según Posner-, los clientes obtendrán el beneficio de cualesquiera disminuciones inesperadas de los costos y, por lo tanto, debieran soportar la carga de cualesquiera aumentos inesperado de los costos. Bajo tales consideraciones, "el verdadero empresario -quien asume el riesgo- es el consumidor antes que el productor. Pero si, debido a la demora reguladora o a otros factores, la empresa de servicio público puede quedarse con las ganancias accidentales, lo mismo debería ocurrir con las perdidas accidentales" (p. 567).

\section{La demanda de regulación. La intervención al servicio de los intereses de la industria}

regulada. Posner, luego de examinar la regulación en materia de transporte, arriba a una de sus principales conclusiones en la materia, al indicar que, siendo la regulación de los servicios públicos un método para regular las ganancias de los operadores, la forma como permite conservar "deliberadamente estructuras tarifarias ineficientes", y "la frecuencia con la que se ha impuesto en industrias naturalmente competitivas y en que se ha empleado también para desalentar la competencia en industrias que tienen algunas características de monopolio natural”, generan serios cuestionamiento sobre el verdadero propósito de la regulación de las empresas de servicio públicos. Al respecto, sentencia Posner "quizá sea la regulación más bien un producto, muy semejante a otros productos excepcionales proveídos por el gobierno, demandado por grupos políticos eficaces y es a ellos a los 
que se les provee". En este punto, Posner identifica una paradoja, pues en buena parte de su obra se ha esforzado por explicar que el derecho común, el derecho producido por los jueces, es un sistema diseñado para promover la eficiencia, un sistema que por esencia y por naturaleza lleva inserto en su lógica la búsqueda de las soluciones más eficientes. En contraste, al emplear el análisis económico para evaluar la regulación en materia de servicios públicos, los resultados encontrados conducen a "refutar la concepción de que otra rama del derecho, la regulación de los servicio públicos, persigue la eficiencia con la misma consistencia" (p. 581) por el contrario, la regulación pareciera perseguir un objetivo totalmente contrario.

\subsubsection{Impactos Económicos de Transmilenio.}

Una evaluación económica del sistema Transmilenio. La aplicación de la teoría económica sobre la regulación en materia de transporte, no solo ha sido efectuada por grande académicos como Posner, en el caso colombiano, son varios los estudios en los que aplicando el enfoque económico se ha realizado una valoración sobre el funcionamiento del sistema de transporte. Al respecto, se destaca el estudio elaborado por Echeverry, Ibáñez y Moya (2005) en el que se efectúa un análisis de CostoBeneficio sobre la decisión Política de implementar el Sistema Transmilenio. El análisis de Echeverry et al. parte de identificar las fallas de mercado derivadas del sistema de transporte público colectivo (tradicional) TPC, las cuales se tradujeron en "ineficiencias en la provisión del servicio, exceso de buses, congestión, altas tasas de accidentalidad, contaminación auditiva y ambiental y tiempos de viaje excesivamente altos" (p. 68). El impacto de Transmilenio sobre la calidad de vida de los

Bogotanos. Beneficios. Luego de examinar las variables consideradas como principales, Echeverry et al. indican que "TM mejoró significativamente las condiciones de viaje para sus usuarios y limitó las externalidades de congestión en los corredores por los que opera”. El estudio señala que los tiempos de viaje de los usuarios del nuevo sistema cayeron $32 \%$, lo que a su vez mejoró la velocidad promedio de los vehículos en Bogotá, presentándose un incremento de 16.8 millas/hora a 20 millas/hora, el porcentaje de usuarios que se demoraban más de una hora viajando desde su casa al trabajo disminuyó de $23 \%$ a 17\%, "la emisión de material particulado (PM-10) cayó en 9\% en las áreas de la ciudad aledañas a los corredores TM, y la accidentalidad disminuyó 90\%” (p. 74). Perjuicios. No obstante lo anterior, los beneficios no se distribuyeron equitativamente a toda la población, y la reducción en 
tiempos de viaje y contaminación solo beneficiaron a los usuarios de TM, y lo que ocurrió fue un fenómeno de desplazamiento, pues en los corredores donde no se implementó TM, "se intensificaron las externalidades de congestión, incremento en tiempos de viaje, contaminación y tasas de accidentalidad, generando un traslado de externalidades, no su eliminación” (p. 74). Esto, según Echeverry et al. se originó en buena medida porque los contratos de concesión estipulaban que los operadores de TM debían comprar y chatarrizar los buses que anteriormente operaban por los corredores de TM, y únicamente 1.410 de los 6.080 de dicho parque automotor fueron efectivamente chatarrizados, lo que generó que 4.670 vehículos fueran relocalizados, produciéndose el fenómeno del desplazamiento de las externalidades. Lo anterior, concluyó el análisis, debe ser parte del análisis, pues no solo se debe calcular los beneficios para los usuarios de TM, sino también las pérdidas de utilidad que la implementación de dicho servicio generó para los usuarios del sistema tradicional.

Resultados del Análisis Costo Beneficio. Para hacer un análisis sobre la inversión de la ciudad en el nuevo sistema de transporte, se debe hacer una valoración tanto de las ganancias como de las pérdidas de bienestar ocasionadas por la introducción de TM. Echeverry et al, analiza quien ganó y quien perdió en la primera fase del sistema, arribando a las siguientes conclusiones: i) Desde la perspectiva de la producción, los operadores de los buses del TM obtuvieron beneficios, mientras que los dueños de los vehículos chatarrizados dejaron de percibir los ingresos producidor por sus buses. "el excedente del productor de los operadores de los vehículos de TM, medido como el ingreso neto de la operación de TM, representa ganancias de bienestar. Por su parte, el ingreso que las firmas dejaron de percibir por la chatarrización de sus buses representa pérdidas en bienestar. ii) Desde la dimensión de la demanda, el análisis costo beneficio elaborado por Echeverry et al, examino los tiempos de viaje para los usuarios del sistema tradicional y los de TM, frente a lo cual se indicó que "un indicador apropiado para valorar estos cambios es la disponibilidad a apagar por mejoras en el tiempo de viaje. Este valor se define como la tasa marginal de sustitución entre el tiempo de viaje y el costo monetario. iii) Así mismo, en el análisis costo beneficio de la referencia se tuvo en cuenta los cambios en los niveles de contaminación de material particulado (PM 10) en los corredores de la ciudad, lo cual, debido a la baja chatarrización, ocasionó una relocalización de los buses del sistema tradicional hacia los corredores no cubiertos por TM, los cuales experimentaron un aumento de los niveles de contaminación. iv) El último de los impactos examinados por Echeverry et al en su estudio, analizó la variable de la accidentalidad, en particular, los beneficios asociados con la reducción en el número de 
accidentes fatales en los corredores de TM. Ahora bien, al calcular las diferentes variables, examinando solamente los impactos en los corredores de TM, los resultados son positivos para TM, pues los beneficios son superiores que los costos arrojando como beneficios netos la suma de US \$3.7 millones. Sin embargo, al introducir las externalidades producidas en los corredores del sistema tradicional, el resultado es contrari o, y los beneficios son negativos e iguales a US \$8 millones.

\section{Cinco Cuestionamientos y una recomendación a los autores del artículo "Una evaluación} económica del Sistema Transmilenio". Las críticas a un Análisis Costo Beneficio que arrojaba resultados en contra del nuevo sistema de transporte, no se hicieron esperar, y el profesor Ardila Gómez (2005) se encargó de exponerlas, señalando que la evaluación hecha por Echeverry et al (2005) es sesgada y que los autores sobrestimaron los costos y subestimaron los beneficios, por lo que el referido profesor procedió a recalcular la evaluación, encontrando que TM fue un proyecto positivo para la sociedad colombiana.

\subsubsection{Estudios sobre las Tarifas del Transporte Público en Bogotá.}

\section{La auto-sostenibilidad del sistema de transporte público masivo Transmilenio en Bogotá.}

En el estudio elaborado por González et al. (2006) se efectuó un análisis sobre la auto-sostenibilidad del sistema de transporte, que como se vio, era uno de los criterios económicos que regían los primeros contratos de concesión. Lo principal de la evaluación de González, es que al revisar el modelo económico del sistema de transporte, desde la perspectiva de su auto-sostenibilidad, evalúa aspectos concretos sobre la estructuración de algunos costos que componen la tarifa, aspecto de particular importancia para la presente investigación. Señala el estudio de González et al., que la forma de financiación del sistema, dependerá del valor y la prioridad que la sociedad le otorgue al servicio de transporte. En el caso de Bogotá, siguiendo la regla general, el sistema masivo de transporte se estructuró a partir de subsidios dirigidos a cubrir los costos de infraestructura, que fueron asumidos por la Nación y el Distrito mediante "recursos que provienen de las tasas y de los impuestos y que permiten compensar el desequilibrio ocasionado por unos costos mayores que las tarifas" (p. 11). En efecto, al Transporte público no le son aplicables las normas de competencia perfecta, pues los 
ingresos obtenidos por su prestación no guardan equilibrio con sus costos totales, de ahí la necesidad a recurrir a recursos externos provenientes de subsidios.

A partir de lo anterior, el mentado principio de auto-sostenibilidad, protagonista en las concesiones de TM, resulta estrictamente microeconómico, y significa que la operación del sistema debe ser autónoma en sus flujos y funcionar financieramente como un negocio privado. Desde esa concepción, la tarifa se considerará eficiente si "garantiza la sostenibilidad de la operación además de una rentabilidad razonable". Pero no bastará con que sea eficiente, según el principio económico de la costeabilidad, aún vigente en las concesiones del SITP, la tarifa debe ser equitativa, y lo será "si respeta la capacidad de pago de los usuarios, según su nivel socioeconómico" (p. 12) (EFT). En el mismo sentido, y teniendo en cuenta que el servicio de transporte público es un bien "cuasi público", debería estar "disponible para todos los consumidores, nadie debería ser excluido, independientemente de que pague o no pague", sin embargo, medidas en ese sentido que partan de un bien público puro, “generan rivalidad, que se expresa en congestión y apiñamiento". Por su parte, "una política de precios que solo busque la ganancia máxima termina reflejándose en tarifas altas con efectos negativos sobre la distribución del ingreso" (p. 13). Ahora bien, luego de examinar los aspectos generales de la autosostenibilidad, el estudio de González et al. (2006) se concentra en la asignación de ingresos otorgada al único agente público del sistema, al ente Gestor TMSA, cuya participación en los ingresos del sistema de transporte, no se fijó en función de sus costos, ni mucho menos teniendo en cuenta su rentabilidad financiera como ocurrió respecto de los operadores privados, por el contrario, se estableció un ingreso fijo, lo que ha generado déficit financiero del TMSA que afecta su sostenibilidad. Lo anterior, pone en evidencia que la estructura para definir la participación tarifaria no es homogénea entre los diferentes agentes del sistema. TMSA, entidad pública, es la encargada de planear, gestionar y controlar el sistema y su remuneración corresponde a un porcentaje fijo de ingresos por venta de pasajes equivalente "al 3\% y 4\% para las fases I y II, respectivamente. De acuerdo con el estudio de estructuración del Sistema TM, realizado por Capital Corp la empresa gestora debería recibir un porcentaje estimado en el 7\%" (p. 18). En ese sentido, para superar tal situación otorgando mayores recursos a TMSA, tendría que obtenerse esos recursos bien del aumento de las tarifas, o bien de disminuir los ingresos de los operadores. Finaliza González et al. recomendando que la formula tarifaria debe ser dinámica, y revisada cada cinco años, debido a que existen factores que cambian de 
manera significativa a lo largo del tiempo, "entre ellos el costo del capital, las tasas de interés y de rentabilidad, los costos de los insumos, el cambio tecnológico y la administración del sistema” (p. 35).

\subsubsection{Pronunciamientos Institucionales sobre la Regulación.}

Organismos de Control. Los análisis efectuados sobre los contratos de concesión que regulan la prestación del servicio de transporte, no solo han provenido de la academia, existen importantes estudios institucionales, que se han ocupado de manera seria y profunda de los problemas derivados del modelo económico de tales concesiones. Sobresale el Diagnóstico de la Contraloría de Bogotá (2007), en el que se examinaron los resultados financieros de la empresa pública Transmilenio S.A. El informe presentado por la Contraloría Distrital (2007), afirmó que la inequidad del sistema se originaba en parte, por la distribución de costos y beneficios. Pues en caso de que los ingresos resulten insuficientes, se acude al Fondo de Contingencias, de donde se han obtenidos recursos por la suma de \$12.645 para pagar el faltante a los operadores; en contraste, en el periodo operativo hasta abril de 2006 donde los ingresos por cuenta de pasajes fueron superiores a los costos pactados con los operadores del sistema, se generaron ingresos adicionales o de productividad en la suma de $\$ 79.209$ millones, que fueron pagados en su totalidad a los operadores troncales (buses rojos), reportando para estos ingresos adicionales del $9.23 \%$ de los costos licitados, mientras que TMSA presentó pérdidas operacionales de \$60.585 durante el periodo 2001-2005 etapa operativa (Contraloría de Bogotá, 2007).

Pronunciamientos Judiciales. Por su parte, desde la jurisprudencia también se han realizado aproximaciones al problema aquí expuesto. En particular, existe un caso en el que el Tribunal Administrativo de Cundinamarca (Expediente: AP 03-2488, 2011), resolviendo una acción popular impetrada contra las concesiones de Transmilenio, realizó un estudio bastante pormenorizado sobre el modelo económico que fundamenta la regulación del servicio de transporte público. En el caso de la referencia, el Señor Oscar Orlando Roldán, presentó una acción popular contra el IDU, Transmilenio S.A. y los operadores concesionarios favorecidos por las licitaciones públicas, pues en su criterio, se desconocen los derechos colectivos del espacio público, el patrimonio público, derechos de la libre competencia y los derechos de los consumidores y usuarios. Sus fundamentos principales consisten, por una parte, en que la entrega en concesión de la vía pública, a operadores privados, constituye una 
privatización de un bien público; y por otra, que las condiciones económicas que se pactaron en los contratos de concesión, generan grandes desventajas para el ente público Transmilenio S.A., por lo cual se presenta un rompimiento al equilibrio contractual que amerita la correspondiente modificación de las condiciones contractuales, dirigidas a repartir de manera equitativa las cargas y los beneficios de la puesta en marcha del sistema de transporte.

El Tribunal al momento de abordar la acción popular, efectúa un completo y juicioso análisis sobre las concesiones de Transmilenio, en particular sobre las clausulas económicas sobre las cuales se erigen las mismas, encontrando lo siguiente: i) se pregunta el Tribunal si puede hablarse de autosostenibilidad del sistema, cuando la falta de recursos se tiene que atender aumentando la tarifa, trasladando los costos a los usuarios, a lo que responde que "en el escenario donde las dificultades económicas son trasladadas al usuario, y la carga obligacional a la empresa pública gestora, cualquier negocio es sostenible" (p. 60); ii) en tal sentido, si la auto-sostenibilidad del sistema ya es dudosa, al examinarse el funcionamiento de TMSA, dicho principio no supera análisis, pues evidencia el Tribunal que "desde un inicio fue sacrificada su participación en la renta del negocio", lo que demuestra que al momento de la distribución de la remuneración "no existió proporción entre el porcentaje de participación de cada extremo negocial, y las obligaciones asumidas por los mismos";

Finalmente, el Tribunal considera que es un despropósito que las labores de recaudo hayan sido asumidas por otro operador, que recibe mayor participación que el mismo TMSA, a pesar de la desproporción de las cargas entre uno y otro. Dichas funciones han debido ser asumidas de manera directa por los operadores del servicio, como "tendrían que hacerlo en cualquier otro negocio", otorgando la participación asignada al agente recaudador a TMSA. Concluye el Tribunal, asegurando que es necesario "proteger el derecho colectivo de defensa de los consumidores y usuarios, para que pueda la empresa prestar un servicio adecuado de planificación y control que propenda en beneficio del sistema de transporte" (p. 70). Pero, de la misma manera, que también evite que potencialmente se incrementen las tarifas "en desmedro obviamente de los usuarios del sistema, lo que indiscutiblemente puede ocasionar un problema social de importancia mayúscula, pues toca el bolsillo de las clases menos favorecidas" (p. 71). En consecuencia, "se ordena a TRANSMILENIO S.A., que en el término perentorio de tres (3) meses proceda a modificar de manera concertada o si no es posible de forma unilateral los contratos de concesión celebrados para la operación del Sistema Transmilenio, en la 
forma señalada en la motiva, de tal manera que TRANSMILENIO S.A. alcance un mayor porcentaje de ingresos y de esta forma se de prevalencia al interés" (p. 75). Dicha decisión fue impugnada, y el recurso está en trámite (enero 2015).

Conclusiones Análisis económicos sobre el Sistema de Transporte. El funcionamiento del Sistema de transporte de Bogotá, ha interesado a la academia y se ha venido abordando desde diferentes ópticas, análisis efectuados desde la ingeniería, desde la economía, desde el derecho y los organismos de control, dan cuenta de la importancia y necesidad de examinar la estructuración tarifaria y el modelo económico que sirve de sustento a la regulación del servicio de transporte. Los estudios han arrojado resultados diferentes, algunos consideran que la rentabilidad social del sistema supera los problemas financieros del ente gestor, y que los beneficios son superiores a los costos debido a los avances en organización, estructura, tiempos de viaje y calidad del servicio, mientras que otros estudios señalan que a pesar de las mejoras, las deudas en bienestar social siguen vigentes. Lo relevante de la aproximación efectuada sobre los análisis económicos que existen sobre el objeto de la investigación, es que permite tener un panorama amplio sobre el estado de la discusión y proporciona mayores herramientas, criterios y experiencias para entrar a realizar el análisis costos beneficio sobre la regulación del servicio de transporte, que constituye el propósitos central del este trabajo.

\subsection{Análisis Económico sobre la Regulación del Servicio de Transporte Público. Caso Transmilenio y SITP.}

\subsubsection{Herramientas y fundamentos del AED que se aplican al objeto de investigación.}

Antes de efectuar el Análisis Económico sobre la regulación del servicio de transporte, lo primero es señalar que el AED lejos de ser un bloque dogmático cerrado y claramente delimitado, constituye un conjunto de herramientas que enriquecen la valoración jurídica que se efectúa sobre un problema determinado. En ese sentido, el AED es una "metodología incluyente" que examina el sistema jurídico "a partir de herramientas y supuestos de microeconomía y de economía de bienestar" (Pinzón, 2010). Así las cosas, el AED que se efectúa en la presente investigación parte de 3 fundamentos principales, así: i) en primer lugar el denominado Teorema de Coase constituye el 
paradigma que guía el análisis, seguido de un concepto de eficiencia que reconoce el impacto social de la regulación; ii) por otra parte, el análisis se cimienta en dos de los fundamentos esenciales la Nueva Economía Institucional NEI, cuales son, la importancia de los costos de transacción y la asignación de los derechos de propiedad; y, iii) finalmente, se utilizará la herramienta económica de las externalidades negativas, para efectos de realizar una valoración completa sobre la regulación del servicio de transporte. A continuación se expondrá la esencia del Teorema de Coase y el concepto de eficiencia utilizado dentro de la presente investigación, para luego proceder con el análisis, en apartados independientes, de los costos de transacción, la asignación de derechos de propiedad, y las externalidades negativas.

\subsubsection{El Teorema de Coase.}

Uno de los hitos fundacionales del AED es el escrito elaborado por el juez y profesor de derecho Ronald Coase, quien en 1960 publicó en el periódico Journal and Law and Economics un artículo titulado "el problema del costo social". En su escrito, Coase analiza distintos problemas que habían tenido que abordar los tribunales judiciales principalmente de Inglaterra, relacionados con la responsabilidad por los daños producidos, a partir de los cuales concluía que "pareciera entonces deseable que las cortes comprendieran las consecuencias económicas de sus decisiones y pudieran, en la medida en que esto sea posible, sin crear demasiada incertidumbre acerca de la posición legal en sí misma, tomarlas en cuenta cuando adoptaran sus decisiones" (Coase, 2000, p. 530) (EFT). Tal conclusión, se convertiría en el paradigma que abriría la puerta al movimiento académico que utilizaría el enfoque económico para analizar el Derecho. El llamamiento de Coase, se fundamentaba en una idea central, posteriormente denominada teorema de Coase, según el cual, contrario a lo expuesto por la escuela neoclásica, en el mundo siempre hay costos de transacción, entendidos como los costos de negociación, de información, de ejecución, etc, que se generan más allá de los costos de producción (capital, tierra, trabajo) y los cuales no son tenidos en cuenta. El teorema de Coase, supone que ante la existencia de costos de transacción, no se termina logrando de manera natural la asignación más eficiente de los derechos, situación que legitima la posible intervención del sistema legal, para efectuar una redistribución eficiente de los mismos. En ese sentido, las leyes, y los jueces al momento de aplicar la ley, deberán optar por la asignación más eficiente de los costos de transacción con el fin de lograr la redistribución más eficiente de los derechos. 
El problema radica entonces, en definir si el beneficio que se deriva de reasignar los costos y redistribuir los derechos es mayor que la perdida que se genera por no hacerlo. Por ejemplo, en términos de daños, será necesario "decidir si el beneficio que se deriva de prevenir el daño es mayor que la perdida que tendría lugar para otros sujetos y relaciones sociales como resultado de interrumpir la acción que causa el daño" (Kitch, 2000, p. 58). Es decir que el juez o la ley tendrá que determinar si es más costoso prevenir el daño, o repararlo. Lo anterior quiere decir, tal y como lo afirma Coase que “en un mundo en el que existen costos cuando se reasignan los derechos, los tribunales, en los casos de molestias [o de reparación de daños], están tomando decisiones sobre un problema económico y determinando como se emplearán los recursos", teniendo en cuenta que "un ordenamiento de los derechos puede ocasionar un valor mayor de la producción que cualquier otro" (Coase, 2000, p. 526). Para efectos de lograr determinar si es más costoso redistribuir derechos que no hacerlo, Coase propone que así como los economistas utilizan un enfoque de costos de oportunidad cuando analizan la empresa, "comparando los ingresos obtenidos de una combinación de factores con otros usos alternativos", de la misma manera los tribunales deberían utilizar este enfoque para analizar problemas de política económica y "comparar el producto total obtenido mediante arreglos sociales alternativos" (p. 553). Es decir, que al momento de establecer una posible intervención judicial, se deberá definir que "arreglos sociales" - entendidos como formas de redistribución de derechos- se pueden efectuar para resolver una determinada cuestión, y luego comparar ese reordenamiento de derechos con otros posibles, para efectos de tomar la decisión más beneficiosa, esto es, la decisión más eficiente. Así, Coase concluye su tesis indicando que:

"sería deseable que las únicas acciones desarrolladas fueran aquellas en las que lo que se ganase valiera más que lo que se perdiese. Pero al elegir entre arreglos sociales (...), debemos tener en mente que un cambio del sistema existente que conduzca a un mejoramiento en algunas decisiones puede muy bien conducir a un empeoramiento en otras, situación que hace necesario que la elección de los “arreglos sociales" para la solución de los problemas económicos, se efectúe de tal manera que tenga en cuenta los efectos que dichos arreglos pueden generar en las diferentes esferas de la vida. Al diseñar $\boldsymbol{y}$ elegir entre arreglos sociales debemos considerar el efecto total. Este es el cambio de enfoque que estoy proponiendo" (Coase, 2000, p. 555). (EFT).

Aplicar el Teorema de Coase para la presente investigación, consiste en valorar los costos totales derivados de la regulación del servicio de transporte, no solo los costos operativos, sino también los 
costos de transacción y las externalidades producidas, con el propósito de establecer si los arreglos institucionales expresados en los contratos de concesión, dados los efectos totales que producen, son los más eficientes y los más beneficiosos para la colectividad, o si por el contrario resulta necesario efectuar un reajuste en la regulación en aras de asegurar su eficiencia, equidad y adecuación a los mandatos constitucionales que todo arreglo institucional debe proteger.

El fundamento de la eficiencia. El concepto de eficiencia, tal y como lo explica el profesor Cooter (2000), generalmente está relacionado con la ausencia de desperdicio. "Los economistas han perfeccionado este concepto, pero el significado principal para ellos es "sin desperdicio de dinero"" (p. 133). "El desperdicio es, por ende, una irracionalidad que debe erradicarse del derecho y la política" (p. 139). La eficiencia, también se ha entendido como la obtención del máximo posible de beneficio maximización del beneficio- con los menores costos posibles. Actualmente, los impulsores del AED, manifiestan que "la eficiencia es una propiedad deseable de la ley, tal como lo nutritivo es una propiedad deseable de los alimentos" (Cooter, p. 133), reconociendo, que la eficiencia corresponde a un juicio de valor, tal como la justicia y la equidad, otorgándole de esta manera un valor significativo tanto para los legisladores, como para la sociedad en general, que tendrá un peso de bastante importancia al momento de hacer políticas públicas y de expedir normas jurídicas. Así entonces, la eficiencia se recomienda y la ineficiencia se condena en la ley, en la economía, y en los demás ámbitos de la vida, erigiéndose como un valor social contemporáneo, que hace parte del orden institucional vigente.

Ahora bien, tal y como lo sostiene el profesor Morales de Setién (2011) "el hecho de que los economistas y los juristas dedicados al análisis del derecho escojan la eficiencia como forma de valoración de los resultados de las conductas, no significa que la realidad tenga que ser necesariamente eficiente o que la eficiencia sea siempre deseable" (p. 47). En efecto, habrá asuntos donde otros juicios de valor como la equidad o la libertad prevalezcan sobre la eficiencia al momento de seleccionar la solución para un determinado problema, "sin embargo, en sociedades en las que se ha escogido el libre mercado como forma de organización de la economía es difícil separarse de la eficiencia como criterio de valoración de los resultados de su funcionamiento" (p. 47). Ahora bien, resulta imperativo señalar que la forma de determinar la eficiencia de una medida, de una norma o de un comportamiento no es univoca, pues dicho concepto económico, ha sido centro de distintos debates, 
y su contenido varía atendiendo métodos, conceptos y las corrientes económicas desde las cuales se defina. En efecto, se han desarrollado algunos conceptos de eficiencia como la Eficiencia de Pareto Potencial o Eficiencia Kaldor-Hicks que señala que "cuando se toma una determinada medida legal: la situación de algunos sujetos empeorará y la de otros mejorará", pero la medida resultará eficiente "si las ganancias de unos compensen las de otros” (Morales de Setién, p. 49).

\subsubsection{El concepto de eficiencia para el presente trabajo.}

Teniendo en cuenta que la eficiencia no es un criterio unívoco, ni a-histórico (González, 2006), y por el contrario es un criterio que puede ser llenado por contenidos distintos, en el presente trabajo se considera que la Eficiencia no puede examinarse de manera aislada, solo bajo consideraciones microeconómicas que tengan en cuenta exclusivamente el funcionamiento de las firmas que prestan el servicio de transporte. Siguiendo a Coase, el "arreglo institucional" que se disponga para regular el servicio de transporte, debe tener en cuenta todos los efectos que produzca más allá del comportamiento de las firmas, incluyendo dentro de la valoración aspectos macroeconómicos como el impacto social, las externalidades negativas que puedan presentarse, los costos de transacción, la funcionalidad del servicio de transporte para el progreso y el desarrollo de la sociedad en su conjunto, la accesibilidad al servicio, la congestión que produce el sistema entendido como un todo, los costos públicos (subsidios), y la asignación de los costos y beneficios. Sobre este punto, es fundamental referir el segundo principio de Rawls (2006), el principio de la diferencia, según el cual "las desigualdades sociales y económicas deben resolverse de modo tal que: resulten en el mayor beneficio de los miembros menos aventajados de la sociedad”. Bajo tal criterio, la asignación más eficiente de costos y beneficios del sistema de transporte, en aras de concretar los Mandatos Constitucionales definidos por el sistema jurídico vigente, debería asegurar el acceso al servicio esencial de transporte a los menos aventajados de la sociedad. En ese sentido, el criterio adoptado en el presente trabajo es el de eficiencia macroeconómica, o eficiencia social, que no solo tiene en cuenta la rentabilidad de las firmas que intervienen en una actividad, sino que examina la rentabilidad social, que comprende las utilidades tanto de las firmas como de los usuarios, y adicionalmente los impactos que tanto unas como otras puedan generar. La eficiencia entonces no se limita a examinar la máxima optimización de los recursos, sino también incorpora la mejor asignación de los mismos (distribución), partiendo de la base de que el "mayor beneficio" debe resultar para "los menos aventajados de la sociedad" (Rawls, 2006). 


\subsubsection{Los aportes de la Nueva Economía Institucional el caso concreto.}

Para la escuela de la Nueva Economía Institucional NEI, las instituciones son el eje fundamental para el desarrollo económico y social en la medida que ellas "definen y limitan el conjunto de elecciones de los individuos, (...) evitándonos tener que pensar en los procesos y decisiones rutinarias ayudándonos a resolver los conflictos y contradicciones propias de la interacción humana". Para Douglas North (1993) padre de la NEI, las instituciones "son las reglas de juego de una sociedad, son las limitaciones ideadas por el hombre que dan forma a la interacción humana", dando origen a través del tiempo a un Orden Social, compuesto por instituciones formales (sistema legal, economía) e informales (cultura, costumbres) a partir de las cuales se reduce la incertidumbre de los agentes y se eliminan costos de transacción. En ese sentido, la regulación en materia de transporte bajo los lentes de la NEI es entendida como una institución formal en la medida que corresponde a las reglas de juego que aplican para la prestación de servicios públicos. Los contratos de concesión a su vez son una institución de nivel medio, a través de la cual se hace viable el funcionamiento del mercado del transporte urbano de pasajeros, que permite eliminar la incertidumbre frente a las necesidades de prestar éste servicio. En efecto, la regulación y en particular los contratos de concesión definen y limitan el conjunto de elecciones que se deben realizar, pues ante la necesidad de que las autoridades públicas garanticen un servicio público dicha institución indica que se puede acudir a un particular para que este opere el servicio a cambio de una remuneración.

La NEI se edificó sobre tres pilares teóricos, que son: Costos de Transacción, Asignación de Derechos de Propiedad y Contrato Imperfecto. Para la presente investigación únicamente se hará referencia a los dos primeros.

\subsubsection{La Estructuración Tarifaria o de los Costos de Transacción.}

La NEI define los costos de transacción como aquellos costos en los que incurre un agente para llevar a cabo una negociación. En efecto, al momento de realizar una interaccion económica los agentes no cuentan por ejemplo con toda la información, y acceder a ella demanda unos gastos que deben ser tenidos en cuenta al momento de realizar la valoración total de la operación. Es decir, que para calcular los costos de una determinada actividad no es suficiente contabilizar los costos de 
producción (capital, tierra, trabajo), resulta inxorable incorporar los costos que permiten la operatividad del mercado (negociación, ejecución). Según Douglass North los costos de trasacción serán menores en la medida que existan instituciones eficientes que los reduzcan. La literatura económica ha reconocido tres tipos de costos de transacción, así: i) Costos de información o acceso a un mercado; ii) Costos de negociación y decisión; y, iii) Costos de vigilancia y ejecución.

A continuación, se procederá a examinar una serie de variables que componen la estructura tarifaria que contemplan los contratos de concesión del servicio de transporte, las cuales analizadas a la luz del concepto de costos de transacción, permitirán dar cuenta de una serie de ineficiencias generadas por la regulación que gobierna la prestación de dicho servicio.

Principios de la Regulación. No obstante lo anterior, antes de realizar el análisis sobre la estructuración tarifaria, es necesario reiterar que la regulación del servicio de transporte se edifica sobre unos principios económicos que deben iluminar la aplicación de las normas que rigen la materia. Así, en los contratos de concesión de TM (2001) y SITP (2010), se hace referencia a los principos de

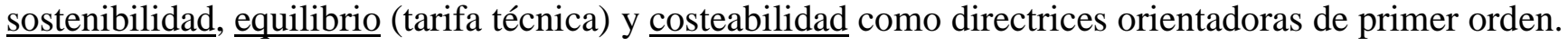
Por su parte, el Plan Maestro de Movilidad (2006), indica que el desarrollo del Sistema Masivo tiene como finalidad el "aumento de la productividad y competitividad" y "mejorar la accesibilidad y conectividad de los sectores perifericos y rurales de la ciudad” (pág. 7), así como garantizar los derechos "al trabajo, a la dignidad humana y a la libre cinculación por el territorio" (pág. 10), mientras que el COMPES 3260 (2003) establece que las tarifas deberán responder a la estructura de costos "sin que ello eleve el nivel actual de gasto en transporte público de los usuarios" (pag. 23). Teniendo en cuenta que los anteriores principios hacen parte del marco de interpretación de la regulación del transporte, se procederá con la revisión crítica de la estructuración tarifaria.

\subsubsection{Altas Tarifas de Acceso.}

Al comparar las tarifas del sistema de Transporte de Bogotá (TM \$1.700 y TM más SITP \$2.000), con sistemas de transporte de otras ciudades latinoamericanas -incluso con sistemas más avanzados tipo Metro-, se advierten los altos costos de las tarifas que se cobran a los usuarios en Bogotá (Tabla No. 7). Justamente, las únicas ciudades que superan las tarifas de la capital de Colombia 
en América Latina son "los sistemas BRT de Sao Paulo (0,48 por ciento más), Curitiba (0,41), León en México (0,33) y Santiago de Chile (0,31 por ciento)" (Cuellar, 2012), teniendo en cuenta que las ciudades de Brasil incluyen la tarifa de acceso al metro. Los altos costos de las tarifas que se cobran al público, tienen su origen en varios factores, que serán objeto de estudio. En primer lugar, es necesario indicar que las altas tarifas no comienzan con la implementación de TM, pues el TPC para la época de los años 90, ya venía en una tendencia de incremento de sus tarifas. Este fenómeno se debe, como lo explican con suficiencia Echeverry et al. (2005) a la estructura operativa del sistema, donde las empresas afiliadoras -quienes obtenían las licencias de las rutas- tenían como principal incentivo afiliar buses, pues del canon de afiliación derivaban sus ganancias, lo que condujo a un incremento exponencial en la entrada de vehículos, haciendo que sus dueños, para poder mantener la renta del negocio, presionaran continuamente al regulador para que aumentara las tarifas, llevándolas por encima de los niveles de eficiencia, (Evans, 1987).

En consecuencia, las altas tarifas del TPC se tomaron como punto de partida para estructurar las tarifas de TM y posteriormente del SITP. Pero la influencia sería en ambos sentidos, pues las Tarifas de TM -que iniciaron por debajo de las tarifas del TPC-, comenzaron a aumentar de manera relevante al punto de superarlas, y luego presionaron su incremento. Esto se explica porque la única competencia de TM era el TPC, que por su precio resultaba más competitivo para el importante segmento de usuarios que basan su decisión de consumo en el costo antes que en la calidad o en los tiempos de viaje. El aumento de la tarifa del TPC fruto de la presión de TM, generó una afectación directa a los usuarios cautivos del TPC que verían un aumento de precio del pasaje sin una mejoría significativa del servicio, lo que significó otra externalidad negativa de TM en términos globales, pues su implementación arrastró consigo la tarifa del transporte colectivo generando más costos sociales frente a un mismo servicio. Con la implementación del SITP, si bien hay una organización en la operación y un mejoramiento de los buses que prestan el servicio, lo que representa avances al inicio -como ocurrió con TM- la calidad del mismo no muestra mayor mejoría y, por el contrario, produce serios impactos en el acceso, pues el SITP genera la necesidad de hacer transbordo con respecto a rutas que antes se solucionaban con un solo vehículo, lo que implica un mayor costo para los usuarios, aumentando en términos reales la tarifa. 
Tabla No. 7. Comparativo de Tarifas.

\begin{tabular}{|c|c|c|c|}
\hline $\begin{array}{c}\text { SISTEMA DE } \\
\text { TRANSPORTE }\end{array}$ & $\begin{array}{c}\text { TARIFA } \\
\text { (MONEDA } \\
\text { NACIONAL) }\end{array}$ & $\begin{array}{c}\text { TARIFA } \\
\text { (DOLARES) }\end{array}$ & $\begin{array}{c}\text { TARIFA } \\
\text { (PESOS COL.) }\end{array}$ \\
\hline Metro de Lima & 1.50 & 0,5227 & $\$ 1.042$ \\
\hline Metro Ciudad de México & 5.00 & 0,3775 & $\$ 753$ \\
\hline Metro de Buenos Aires & 4.50 & 0,5337 & $\$ 1.065$ \\
\hline Trole de Quito & 0.25 & 0.25 & $\$ 498$ \\
\hline Metro de Caracas & 1.50 & 0,3490 & $\$ 696$ \\
\hline TranSantiago (BRT) & 700 & 1,1900 & $\$ 2.325$ \\
\hline Transmilenio (BRT) Bogotá & 1700 & 0,8500 & $\$ 1.700$ \\
\hline
\end{tabular}

Fuente: Elaboración propia a partir de datos obtenidos de páginas web oficiales de los sistemas de transporte consultados.

La consecuencia directa de las altas tarifas, tal y como lo expone Posner (2013), es que generan incentivos a los usuarios para que compren sustitutos, cuya producción puede generar mayores costos para la sociedad. En el caso del transporte público en Bogotá, debido a las altas tarifas, el hacinamiento y los largos tiempos de espera que hoy produce TM, los usuarios se han desplazado a buscar sustitutos como por ejemplo las motocicletas, cuya venta se ha multiplicado por 4 en los últimos 10 años alcanzando las 660.000 unidades en 2013, cifra que duplicó la comercialización de carros (Martinez, 2014), mejorando la calidad de vida de algunas familias, pero generando impactos sociales como mayor congestión, contaminación y accidentalidad (cerca de $42 \%$ de los accidentes de tránsito del país implican una moto), lo que demuestra la importancia de contar con una regulación correcta de la tarifa, que responda no solo a los costos de operación, sino que tenga en cuenta la capacidad de pago de los usuarios. Así las cosas, las altas tarifas en buena medida se deben a importantes costos de negociación e información que no se tuvieron en cuenta, pues los operadores privados de TM, justificaron sus costos de operación a partir de tarifas que ya venían sobredimensionadas desde el TPC. Así mismo, el poder de negociación de los agentes privados se impuso al momento de establecer los costos de operación del sistema.

\subsubsection{Prima de Riesgo Sobrestimada.}

Es pertinente aclarar que las altas tarifas del TM no solo fueron heredadas del TPC, al momento de la celebración de los contratos de concesión, cuando se definió la estructura tarifaría y la canasta de 
costos que se debía cubrir vía tarifa, existían unas condiciones macroeconómicas sumamente difíciles, que aumentaban la percepción negativa del riesgo por parte de los operadores privados, lo que condujo a que la valoración de los costos fijos, como el valor de la flota, (que comprenden: i) depreciación, ii) seguros, iii) remuneración del capital invertido, que ya incluye una rentabilidad "razonable"), se calculará efectuando proyecciones costosas, tasas de interés altísimas, devaluaciones pronunciadas, entre otras (González, 2006). El resultado: los costos de reposición de la flota, que sumados corresponden al 26.8\% del valor de la tarifa técnica (Transmilenio S.A., 2001), se calculan a partir de valores sobredimensionados, que desbordan la realidad económica que se presentó.

En efecto, al realizar una comparación entre las condiciones macroeconómicas de la época en la que se celebraron las concesiones y los periodos sucesivos, se encuentra, por una parte, que tal y como lo describen González et al. (2006) se partía de "una caída del PIB del 4,2\% en 1999, la más profunda desde 1924, las tasas de interés eran superiores al 40\%, el desempleo era del 20,1\% y la devaluación del 23\%" (p. 19), sumado a la intensa volatilidad de los mercados financieros, aspectos que aumentaban significativamente los riesgos. Por el contrario, las condiciones macroeconómicas de inicios de los años 2000 hasta hoy, son bastante diferentes, pues pasado el decrecimiento económico de 1999, y debido al auge de los precios del petróleo y otros comodities, una mayor demanda de materia primas de China y a unas condiciones internacionales favorables (Suarez, 2009), el PIB presentaría crecimientos sostenidos alcanzando picos como los vistos en 2006 (6,7\%) y 2007 (6,9\%), arrojando un PIB promedio de 4,4\% en los últimos 3 años (Pib, 2014); de la misma manera, hoy no se presenta devaluación del peso colombiano, en contraste, la moneda nacional se ha venido revaluando de manera considerable, en lo que va corrido de 2014 alcanzó el 4,34\%, mientras que para 2012 fue del 9\% (Peso colombiano, 2013). La tasa de interés también presentó cambios significativos, pues en 2014 se situó en 3,5\% (Banco de la República, 2014) y el promedio de los últimos 10 años ha sido de 8,1\% (Banco Mundial, 2014), cifra distante de la que se presentó al momento de hacer la estructuración de costos del nuevo sistema de transporte. Las inmensas variaciones macroeconómicas que se presentaron en los años sucesivos a la suscripción de las concesiones, sin que se pactaran mecanismos para revaluar o ajustar los costos asignados al riesgo, incrementaron exponencialmente las tarifas, a favor de los operadores y en perjuicio del sistema de transporte y de los usuarios. 
Pero la estructuración tarifaria, no solo favoreció a los operadores al tener en cuenta la totalidad de los riesgos del capital y asegurarlos mediante asignaciones de valores superlativos; no siendo suficiente garantía lo anterior, el riesgo de la demanda, que por naturaleza corresponde a los operadores del negocio - puesto que es uno de los elementos de su esencia-, fue asignado a los recursos públicos, tal y como se evidencia a partir de la incorporación de 2 mecanismos complementarios, así: i) en primer lugar la estructuración tarifaria señaló que existiría una tarifa técnica TT y una tarifa de usuario TU, garantizando a través de la primera, absolutamente todos los costos de operación, y en caso que los ingresos reportados por la TU resultaran insuficientes, se tomarían los recursos del Fondo de Contingencias FC, ahora Fondo de Estabilización Tarifaria FET tras la implementación del SITP; ii) en caso que los recursos que existan en el FC o en el FET sean insuficientes para el pago de la TT, el Distrito, a través de la empresa TMSA suscribió un $\underline{\text { Acuerdo de Pago Extendido, }}$ mediante el cual compromete los recursos públicos que sean necesarios para pagar la totalidad de los costos de operación contenidos en la TT, incluyendo la sobrevalorada remuneración del capital. Es decir, que el riesgo principal del servicio de transporte público (la demanda), fue asignado en su totalidad a la entidad pública, y de manera indirecta a todos los ciudadanos. Lo anterior, es corroborado por los datos que indican que los agentes privados no han sido afectados negativamente por el riesgo de la demanda, pues ésta ha mostrado una tendencia creciente del orden del 30.85\% anual hasta el 2004 (Gonzalez Borrero, 2006), tendencia que se ha mantenido (con excepción del 2010 que presentó 15\%), alcanzando incrementos del 49\% en 2005, y del 17\% en 2011 (Andi, 2011) y que logrará niveles nunca antes vistos con la implementación del SITP, pues el antiguo TPC alimentará los servicios troncales de TM. En ese sentido, tanto el incremento constante de la demanda, como los mecanismos instituidos en las concesiones para resguardar del riesgo a los operadores, explican el por qué ninguno de los agentes privados ha tenido problemas financieros a casusa de la asociación directa entre ingresos y costos, mientras que las pérdidas del ente gestor y el monto de los subsidios -como se verá más adelante- han venido en constante aumento.

Así las cosas, la canasta de costos que corresponde a la definición de los insumos y costos de operación, la cual está definida contractualmente (que incluye los siguientes ítems: costos variables: combustibles, neumáticos, lubricantes, mantenimiento , salarios, y costos fijos: gastos administrativos, seguros de la flota, depreciación y remuneración sobre el capital invertido), se calculó -partiendo de la buena fe- bajo "supuestos pesimistas", que buscando la manera de reducir la mayor parte de los riesgos 
de los operadores, terminaron asignando costos -principalmente de capital- sobrevalorados. De la misma manera, llama la atención que la canasta de costos se ajusta a las variaciones que presente el IPC, mientras que frente al valor asignado a los riesgos de capital, no se diseñó mecanismo alguno para efectuar los ajustes necesarios, atendiendo las variaciones macroeconómicas, que efectivamente se presentaron. Es decir, se ajustan los costos pero no se ajusta el cálculo ni la distribución del riesgo. En consecuencia, la información económica y financiera que se tiene hoy, permite concluir que los costos de operación durante los últimos 14 años han sido menores que los de la canasta de costos definida en los contratos, lo que demuestra la incorrecta y desequilibrada estructuración tarifaria, que generó sobrecostos de riesgo del orden de 15\% (González, 2006), que condujeron a inflar la tarifa a favor de los operadores, y en perjuicio de los usuarios que se han visto excluidos del servicio y han acudido a productos sustitutos, incrementando costos sociales y el desperdicio de recursos valiosos, situación que no ha podido corregirse debido a que no se incluyeron mecanismos de ajuste dentro de los contratos de concesión.

Lo anteriormente expuesto es un típico ejemplo de costos de información, pues el Distrito calculó la prima de riesgo, sin tener información cierta sobre el comportamiento macroeconómico del país en la década posterior a la celebración de los contratos. Adicionalmente, las proyecciones estimadas, marcadamente pesimistas, no se presentaron, situación que resultó a favor de los operadores quienes se vieron favorecidos por las condiciones generales de la economía. Ahora bien, en este punto también se configura un costo de negociación, pues el Ente Público no ha introducido dentro de los contratos mecanismos de ajuste que impida que a través de la prima de riesgo terminen generándose tarifas que no atienden a la capacidad de pago de los usuarios.

Sistema de Costos Crecientes. Los estudios adelantados por TMSA (2013), se han ocupado de examinar la evolución de los costos de operación del Sistema, particularmente evaluando las ponderaciones del Subsistema Transmilenio, que para el periodo comprendido entre enero de $2011 \mathrm{y}$ agosto de 2013 ha arrojado un crecimiento del 10,77\%, porcentaje por encima del IPC acumulado del periodo. Por su parte, desde sus comienzos hasta el 2011 el alza en las tarifas del Transmilenio, ha incrementado 19\%, restando la inflación (Galeano, 2012), lo que da un incremento total aproximado de 29,77\% del valor de la tarifa. Estas significativas alzas, son producidas por el aumento de los costos de operación del sistema, lo que permite concluir que se trata de un sistema de costos crecientes. La 
situación no se detiene, y por el contrario se agudiza, pues con la implementación del SITP se incrementaron los costos operacionales en un 53\% (\$39.028,11 millones). Debido a esta situación el Ente Gestor TMSA recomendó a la Administración Distrital la implementación de incrementos sucesivos de las tarifas a los usuarios (2013).

Se tiene entonces un sistema de transporte inusual, pues ante el incremento de la demanda, no se logran reducir costos de operación; por el contrario se tiene un aumento constante en costos operativos, que no logran ser cubiertos por los ingresos del sistema. Sin embargo, los ingresos de los operadores no dejan de crecer, por ejemplo en el 2012 los ingresos operacionales de las zonas del SITP que habían iniciado operaciones ascendieron a \$37.967 millones; de enero a septiembre de 2013 tales ingresos suman \$247.087 millones, reportando un crecimiento de 6.5 veces en tan solo 9 meses (Transmilenio, 2013). Así mismo, para el periodo de 2013, el operador del SIRCI (encargado del recaudo, control y la información) presentó una variación considerable pues paso de tener ingresos operacionales por $\$ 615$ millones a \$52.106 millones. Por su parte, el operador de San Cristóbal obtuvo ingresos por \$45.539 millones de enero a septiembre de 2013, el operador de Usaquén \$19.631 millones, y el de Engativá \$40.006 siendo los operadores que más aumentaron sus ingresos de operación (Transmilenio, 2013). Es decir, la demanda aumenta, las tarifas aumentan, los ingresos de los operadores aumentan, pero los ingresos totales del sistema no alcanzan, precisamente porque TM y SITP son sistemas de costos crecientes, aspecto que afecta seriamente el acceso de los usuarios. Al respecto, resultan ilustrativos los datos aportados por el comportamiento del Fondo de Estabilización tarifaria. Según el informe de gestión 2013, el comportamiento del FET cada mes tuvo que cubrir un monto mayor por la diferencia entre la tarifa técnica y la tarifa al usuario, situación que es atribuida por el Ente Gestor a la implementación del SITP, por lo cual ha tenido un egreso promedio neto semanal de $\$ 9.181,38$ millones. La Tabla No. 8 pone en evidencia el comportamiento del FET, en comparación con el Fondo de Contingencias de Transmilenio (FC) (Transmilenio, 2013, p. 110).

Respecto del Fondo de Contingencias FC, se observa que los montos que ha tenido que entrar a cubrir oscilan entre los $\$ 11.000$ y los $\$ 13.000$ millones, a pesar de que Transmilenio se encuentra en funcionamiento desde el año 2001, situación que demuestra que los costos del subsistema Transmilenio han sido crecientes y el recaudo obtenido por la validaciones (entradas al sistema) a resultado insuficiente, a pesar del incremento de la demanda, teniéndose que acudir a recursos externos 
(públicos) para garantizar el mantenimiento y la sostenibilidad del sistema, convirtiendo una práctica excepcional (subsidios) en elemento esencial del funcionamiento ordinario de las concesiones del servicio de transporte. La situación descrita, constituye un ejemplo de los costos de ejecución, pues los mecanismos regulatorios diseñados no han permitido reducir los costos del sistema, los cuales a pesar del aumento de la demanda, no han parado de crecer, tanto como las ganancias de los operadores, y el déficit de los recursos públicos, lo que pone en evidencia la ineficiencia regulatoria.

Tabla No. 8. Comparativo de Egresos FET vs FC.

\begin{tabular}{|l|c|l|c|}
\hline \multicolumn{4}{|c|}{ EGRESOS FONDOS } \\
\hline \multicolumn{2}{|c|}{$\begin{array}{c}\text { FONDO ESTABILIZACIÓN } \\
\text { TARIFARIA }\end{array}$} & FONDO DE CONTINGENCIAS \\
\hline \multicolumn{1}{|c|}{ MES } & 8,35013 & \multicolumn{1}{c|}{ MES } & AÑo 2013 \\
\hline ENERO & 9,855 & FEBRERO & 12,729 \\
\hline FEBRERO & 11,995 & MARZO & 13,277 \\
\hline MARZO & 18,690 & ABRIL & 11,684 \\
\hline ABRIL & 25,721 & MAYO & 13,158 \\
\hline MAYO & 22,796 & JUNIO & 6,301 \\
\hline JUNIO & 25,091 & JULIO & 6,640 \\
\hline JULIO & 33,389 & AGOSTO & 8,670 \\
\hline AGOSTO & 29,544 & SEPTIEMBRE & 6,196 \\
\hline SEPTIEMBRE & 40,154 & OCTUBRE & 4,240 \\
\hline OCTUBRE & 34,921 & NOVIEMBRE & 2,142 \\
\hline NOVIEMBRE & 36,726 & DICIEMBRE & 3,090 \\
\hline DICIEMBRE & & & \\
\hline
\end{tabular}

Fuente: Transmilenio S.A. (Informe de Gestión, 2013, pág. 110).

\subsubsection{Altos Costos Públicos. Subsidios.}

El hecho que la Tarifa Técnica TT sea superior a la Tarifa cobrada al Usuario TU, significa que los ingresos del sistema no alcanzan para cubrir los costos de operación, razón por la cual el Distrito en virtud del acuerdo de pago extendido, ha tenido que girar recursos públicos para que el sistema siga funcionando y para garantizar todos los costos reconocidos a los operadores. Por ejemplo, al cierre de los estado financieros de 2013, Transmilenio reporto ingresos operacionales por valor de $\$ 114.009$ millones, de los cuales $\$ 74.009$ millones corresponden a ventas de servicios y $\$ 40.000$ millones a

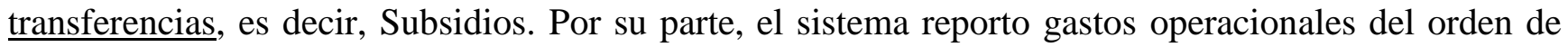
\$112.314 millones, lo que generó finalmente una utilidad operacional que asciende a la suma de $\$ 1.695$ millones. Lo anterior quiere decir, que los recursos públicos incorporados a través de subsidios 
son los que garantizan las utilidades operacionales que son repartidas entre los operadores. Esto ha hecho que los ingresos no operacionales, provenientes de las transferencias del Distrito Capital, hayan presentado un crecimiento del 299\%, (\$404.872 millones) para respaldar la política tarifaria del Sistema Transmilenio (2013), lo que significa que el sistema de transporte el doblemente caro, pues se ha venido aumentando el costo tanto de las tarifas al público, como de los subsidios que demanda el sistema para su operación.

No obstante, los recursos públicos no solo se han trasladado al sistema de transporte para subvencionar su operación, también se han destinado grandes partidas presupuestales para superar las barreras de accesibilidad financiera del sistema, subsidiando dos grupos poblacionales: i) los discapacitados, quienes en 2013 se les otorgaron 7.273 tarjetas especiales con descuentos, lo que generó un incremento en los subsidios que pasaron de \$6.098.000 millones a \$82.059.000 millones, en solo un año; ii) los otros beneficiados de los subsidios fueron los adultos mayores, quienes cuentan con una tarifa especial para acceder al transporte público, el costo de este beneficio asciende a la suma de \$9.350.489.093 millones. Esto indica que la regulación, en lugar de asegurar el aprovisionamiento de un servicio público accesible, genera la necesidad de invertir cuantiosas sumas de dinero para que ciertos segmentos vulnerables de la población puedan acceder al servicio, lo que aumenta los costos públicos. En conclusión, los costos crecientes de operación del sistema demandan millonarios recursos públicos, no solo para asegurar su funcionamiento, sino también para garantizar las utilidades de los operadores. Pero el problema de los costos crecientes no para allí, pues estos presionan las tarifas hacia arriba, aumentando las barreras de acceso, y generando la necesidad de enormes subsidios para permitir el acceso únicamente de ciertos grupos poblacionales vulnerables - no todos-, lo que conduce a un aumento considerable del gasto público.

Ahora bien, es preciso señalar que en ciertas ocasiones puede resultar legítimo que el Estado deba subsidiar ciertas actividades para el logro de sus objetivos sociales, no obstante, la existencia del subsidio no será legitima si la renta del negocio garantiza los costos de operación del contrato y del servicio, lo que ocurre en el presente caso, "donde como se ha podido establecer se obtiene una renta suficiente para cubrir la totalidad de los costos del servicio y la contraprestación o retribución del contratista en punto de no perdida" (Tribunal Administrativo de Cundinamarca, p. 63), e incluso generando significativas utilidades, que como se evidencia rayan al punto de resultar abiertamente desequilibradas. En efecto, quedo demostrado que se trata de un negocio rentable, "por tanto se presenta una manifiesta incongruencia entre las rentas o porcentajes distribuidos y las 
cargas que correlativamente se adscribieron a los firmantes del contrato". Todo lo anterior, pone en evidencia que el sistema de transporte de Bogotá no es sostenible, pues requiere de inmensos recursos externos, que generan enormes costos públicos, con el propósito principal de asegurar cuantiosas utilidades privadas. Esos costos que han surgido en la etapa de ejecución no fueron contemplados al inicio, y su presencia encarece la prestación del servicio, y pone en entredicho tanto su sostenimiento, como los derechos de participación de los privados.

\subsubsection{Desconocimiento de las economías de escala.}

Por otra parte, el crecimiento constante de los costos operativos, desconoce totalmente el principio de las economías de escala, que se presentó como uno de los argumentos principales para entregar la operación del sistema a un puñado de empresas y legitimar, por vía de la regulación, un oligopolio que supuestamente bajaría sus costos con el aumento de la demanda, ante la reducción de costos fijos, y costos de transacción. Las economías a escala se dan cuando hay un aumento en la escala de la producción, y los costos por unidad disminuyen, es decir, cuando el costo medio de una unidad baja a medida que aumenta su producción, para el caso del servicio de transporte, las economías de escala se producen cuando la incorporación de un nuevo usuario no incrementa significativamente el costo medio, logrando una estabilización de costos óptima (Amador Cabra, 2011). Analizado lo anterior, la pregunta que surge es ¿cómo un sistema que tiene una mayor demanda -originada por la integración total del servicio de transporte-, que aumenta considerablemente sus ingresos, $y$ donde la competencia ha sido regulada al punto de constituir en la práctica zonas de explotación exclusiva, no logra reducir sus costos de operación? Al respecto, lo primero es señalar que el aumento de la demanda, incide en los costos de operación, pues la tarifa técnica se ve afectada por el número de pasajeros transportados. Esto se explica con el Índice de Pasajeros por Kilómetro IPK, que es un indicador que mide la eficiencia operacional del sistema, ya que sirve para saber cuántos pasajeros se están transportando por un km recorrido. Entre más pasajeros por $\mathrm{km}$ se transporten, los costos totales se distribuyen entre más usuarios, haciendo que la demanda tenga un impacto en los costos. Así, en las concesiones de fase I y II de TM, si se transportaban menos de 4.75 pasajeros por km (IPK mínimo), se incurría en pérdidas que serían asumían por los operadores, pero si por el contrario se transportaban más de 5.80 pasajeros por km (IPK máximo), las ganancias 
eran de los operadores. No obstante, el IPK nunca bajo de 5.1, generando que no hubieran perdidas y sí muchas ganancias para los agentes privados.

Para comprender el impacto de esta variable, es importante traer a colación el análisis hecho por Suárez (2012), en el que hace un comparativo entre la variación que presentó TM de 2008 a 2011. En 2008 cada bus rojo llevó al año 932.789 pasajeros, mientras que en el 2011 transportó 1'220.402. Por su parte, la flota paso de 1.074 en 2008 a 1.290 en 2011. Tales variaciones, en ese periodo de 4 años, representan un aumento de buses tan solo del 20\%, mientras que el número de pasajeros por bus incrementó 57\%. En contraste, los kilómetros recorridos permanecieron "prácticamente invariables", pues se mantuvieron entre 250 y 260 por día. Lo anterior quiere decir, que los costos no aumentaron significativamente, pues se recorrieron los mismos kilómetros y los buses adicionales no se comparan con el incremento -bastante considerable- del número de pasajeros, luego entonces, por lo menos los costos fijos (valor de la flota, seguros, depreciación, etc.), divididos en mayor número de pasajeros deberían disminuir, y con ellos la tarifa. Sin embargo, los operadores del sistema enfocándose en optimizar el IPK, para aumentarlo por encima del 5.8 máximo, y de esta manera apropiarse de los mayores ingresos generados por km, y por el alza constante de la tarifa, sin importar el hacinamiento consiguieron incrementar sus beneficios, tal y como lo reflejan sus estados financieros, ya que en el periodo examinado, pasaron de tener utilidades operacionales de $\$ 84.009$ millones a $\$ 104.477$ millones, "la utilidad neta se comportó con progresiones positivas y la rentabilidad sobre el patrimonio oscila entre el 17\% y el 20\%", pero lo más notorio es el crecimiento del patrimonio, "que pasó de \$196.972 millones a \$325.446 millones, ¡80\% más!” (Suárez, 2012). Bajo tales consideraciones, salta a la vista que tal y como se diseñó el IPK, las eficiencia generadas por el incremento de la demanda y las economías de escala no se transmiten a los usuarios, vía tarifa, sino que son absorbidas en su totalidad por los operadores, quienes aumentan sus ingresos tanto como aumenta el hacinamiento en los buses.

Ahora bien, el nefasto diseño del IPK, que en la práctica trasladó todo el riesgo del negocio al ente público, TMSA, mientras que los beneficios los asignó a los operadores, a más de incentivar el sobrecupo y el hacinamiento en los buses, fue eliminado en la renegociación de los contratos (2013). $\mathrm{Al}$ respecto, TMSA afirmó que "la TT se moverá con los costos de los insumos (CT), pero será completamente insensible a la demanda" (p. 24). Sumado a lo anterior, y con el objetivo de adecuar los 
Contratos TM fase I y II con el SITP, se incorporó la figura de los costos medios, que consiste en un pago por bus mes, asociado al resultado de $\mathrm{km}$ programados y efectivamente recorridos por la tarifa troncal ofertada por cada uno de los diferentes operadores. En síntesis, se eliminó el IPK y se pasó al costo medio por bus, aspecto que no soluciona el problema de las economías de escala, pues no se parte del costo real del servicio (costo marginal), que corresponde al costo de transportar a una persona, sino al costo medio por bus. Precisamente, al examinar los costos medios de la demanda, se tiene que cuando era de 3.057.087, el costo medio llegada a $\$ 350$, mientras que cuando al demanda aumento a 24.600.739 el costo medio desciende a \$69, bajando de manera importante. Sin embargo, la nueva medida no atiende al costo medio de la demanda, sino al costo medio del bus, lo que significa que los beneficios producidos por transportar más personas, que podrían ser trasladados a los usuarios, continúan siendo apropiados por los operadores, quienes internalizaran de manera exclusiva las eficiencias derivadas de la integración. En ese sentido, la eliminación del cuestionado IPK no garantiza de ninguna manera que las economías de escala, derivadas del incremento de la producción (transporte de pasajeros), se traduzcan en menores tarifas, pues con la implantación de la medida del costo medio, la TT -como lo afirmó TM- queda totalmente insensible a la demanda, asignando en la práctica las eficiencias obtenidas por el aumento de la producción, única y exclusivamente a los operadores. La situación descrita, representa un costo altísimo de negociación, pues uno de los fundamentos sobre los cuales se tomó la decisión de implementar TM, fue lograr economías a escala, aspecto que si bien se presentó, no fue asignado a los usuarios y fue apropiado en su totalidad por los operadores privados, quienes impusieron su poder de negociación.

\subsubsection{Renegociación de los Contratos (2013).}

Aumento de Vida Útil de los Buses. Como se vio al momento de examinar la renegociación de los contratos (2013), una de las más importantes modificaciones fue el aumento de la vida útil de los buses del sistema, que paso de $850.000 \mathrm{~km}$ o 10 años, a $1.240 .000 \mathrm{~km}$, incrementando cerca de $400.000 \mathrm{~km}$ de vida útil por bus. Esta medida no solo afecta la seguridad de los usuarios, pues se incrementan las posibilidades de accidentalidad, sino que a su vez afecta la calidad del servicio pues impide la incorporación de nueva flota, que como se tenía previsto estaría compuesta principalmente por biarticulados a través de los cuales se puede atender el significativo incremento de la demanda producido por la implementación del SITP. Pero no solo la calidad se ve afectada y el riesgo de 
accidentalidad aumentado, esta modificación contractual tiene serios impactos en dos temas trascendentales: fase de reversión y estructura tarifaria.

Al respecto, el aumento de la vida útil de los buses, afecta el patrimonio público pues los contratos tienen cláusulas de reversión, las cuales en la práctica terminan siendo cabalmente desconocidas por vía del aumento de la vida útil, pues con el nuevo kilometraje concedido carecería de sentido la entrega de estos buses cuando no tendrán ninguna posibilidad técnica para prestar el servicio. En efecto, los contratos de concesión fueron estructurados a partir de tres fases principales. La fase pre operativa en la que se adelantaron todas las acciones necesarias para la entrada en funcionamiento del sistema; ii) la fase operativa, compuesta por el inicio de operaciones y la efectiva ejecución en la prestación del servicio; y, iii) la fase de reversión, en la que se haría entrega de todos los activos operacionales afectados a la prestación del servicio, cuya naturaleza permita su reversión. Es así como en los contratos de concesión se pactó la entrega de los vehículos, los cuales tendrían que ser revertidos cuando la flota alcanzara los $850.000 \mathrm{~km}$, situación que daba un margen de tiempo para que dicho parque automotor pudiera ser utilizado por TMSA para la prestación del servicio, pues la vida útil técnica de dichos vehículos es de $1.400 .000 \mathrm{~km}$ (bajo el cumplimiento de ciertos parámetros de mantenimiento), pero con la modificación del kilometraje de vida útil contractual, en la que se pasa de $850.000 \mathrm{~km}$ a $1.240 .000 \mathrm{~km}$, la etapa de reversión, de la que hacían parte los vehículos es eliminada de facto, pues al momento de ser revertidos los automotores no podrán ser utilizados, ni alquilados, ni explotados por TMSA.

Pero lo más grave del aumento de la vida útil, consiste en que la formula tarifaria incluye la remuneración sobre el capital invertido (valor de vehículo nuevo) que corresponde al 15\% de la TT, y remuneración por la depreciación del vehículo que se fijó en 10\% de la TT, costos que al cabo de más de 10 años de funcionamiento del sistema, ya se encuentra totalmente amortizados, es decir, la inversión de los operadores para la adquisición de articulados y el costo de su depreciación, ya se pagaron en su totalidad. No obstante, dichos importes no fueron eliminados de la formula tarifaria, ni su porcentaje fue ajustado, lo cual significa que los usuarios seguimos pagando un rubro que ya se costeó de manera íntegra, pues el precio de los buses (capital invertido, intereses, depreciación), que como se demostró fue calculado con valores sobredimensionados, ya fue cancelado con el esfuerzo que por más de 10 años hicieron los usuarios de Transmilenio. 
En tal sentido, tras la renegociación de los contratos (2013), la canasta de costos a partir de la cual se define la tarifa técnica, ha debido reducirse mínimo en un $\mathbf{2 5 \%}$, contando solamente la reducción por el costo de la inversión (15\%) y el costo de la depreciación (10\%) que corresponde al valor de desgaste por el uso de los vehículos. Así las cosas, el aumento de vida útil de los buses, de entrada cuestionable por los efectos sobre la reversión, ha debido acompañarse de un reajuste tarifario del orden de los $\$ 450$ por pasaje, dejando la tarifa de TM en $\$ 1.250$, lo que sin duda hubiera significado un alivio para los usuarios en términos de acceso. En ese orden de ideas, el aumento de vida útil de los buses, genera grandes pérdidas sociales, en cuanto acceso, calidad y seguridad, y por otra parte produce grandes utilidades a los agentes privados quienes se están apropiando de $\$ 450$ de cada pasaje sin que exista causa para ello. Así, teniendo en cuenta que el promedio de pasajeros al día es de 2.154.961, multiplicado por el tiempo de prolongación de los contratos, que con base en los km recorridos al día se aumentaría en 4,38 años, la ganancia adicional y sin justa causa que por esta

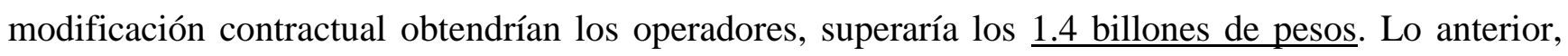
pone de manifiesto el descomunal poder de negociación acumulado por los operadores privados, quienes al momento de la asignación de costos y beneficios, logran satisfacer plenamente sus intereses, situación que resalta el agudo analisis de Douglass North quien señaló que "las instituciones no son creadas para ser eficientes socialmente, son hechas para servir los intereses de los que tienen mayor poder de negociación" (1993).

En conclusión, la estructuración tarifaria presenta cuantiosos sobrecostos derivados de una sobrestimación del riesgo, aspecto sobre el cual no se incorporó mecanismo alguno para lograr su ajuste a la realidad. Además, la tarifa -que de entrada resultó alta- no ha parado de crecer, a pesar de lograrse la reducción de costos de operación debido a las economías de escala y la menor densidad de la industria, debido a que las eficiencias generadas por los menores costos son apropiadas en su totalidad por los operadores, a quienes a pesar de los enormes privilegios, les otorgaron un aumento de la vida útil de los vehículos, sin realizar los ajustes tarifarios necesarios, haciendo que los bogotanos estén pagando cerca del $25 \%$ de la tarifa por unos costos que ya fueron cubiertos en su integridad.

La evaluación concreta de la estructuración tarifaria permite demostrar los inmensos costos de transacción derivados de la regulación existente, los cuales no fueron tenidos en cuenta al momento de la toma de decisiones, y explican los altísimos costos del servicio de transporte, y que ponen de 
manifiesto la inminente necesidad de reajustar el arreglo institucional con miras a superar las serias ineficiencias macroeconómicas de la regulación, y la profunda inequidad que propicia al asegurar cuantiosas utilidades a los operadores privados, e inmensos costos para los usuarios tanto a través de tarifas, como de impuestos.

\subsubsection{Asignación de Costos y Beneficios.}

La distribución de costos y beneficios es un aspecto fundamental en el desarrollo de cualquier mercado o actividad. Para comprender los efectos de dicha distribución la NEI desarrolló el concepto de los Derechos de propiedad. Los derechos de propiedad son entendidos como los derechos de un agente de usar activos valiosos. "Estos derechos definen la posición relativa de los actores en el mercado con respecto a la utilización de los recursos escasos, son determinantes del poder de negociación de los agentes (North, 1993). Es decir, que los derechos de propiedad corresponden a las prerrogativas que tienen los agentes que participan en un mercado determinado (utilidades, derechos de uso o explotación, derechos de participación), pero ¿Cómo se distribuyen tales derechos? La NEI considera que la distribución de los derechos de propiedad no necesariamente responde a consideraciones de eficiencia, y por el contrario está marcada por el poder político o de negociación de los agentes. En ese sentido, la asignación de los derechos de propiedad determina el sistema de costos y beneficios, y en consecuencia, los arreglos institucionales dependiendo de múltiples variables, pueden generar asignaciones incorrectas que produzcan daños e ineficiencias, o pueden producir asignaciones de derechos de propiedad que logre eficiencia y equidad.

Así las cosas, teniendo en cuenta que la distribución de derechos influye de manera directa en la distribución de ingresos y riqueza, y que dicha distribución responde a unos determinados intereses, se procederá a examinar el sistema de costos y beneficios contemplado en los contratos de concesión del servicio de transporte, para efectos de establecer si el arreglo institucional establecido en los contratos efectuó o no una asignación de derechos de propiedad correcta que asegure tanto la eficiencia como la equidad en la prestación del servicio.

\subsubsection{Derechos de Participación.}

Al examinar los derechos de participación que tienen los operadores sobre los recursos del sistema, de acuerdo a los datos proporcionados por los informes de gestión (2013), salta a la vista la 
desproporción entre las asignaciones otorgadas a los agentes privados y al ente gestor público. Precisamente, al revisar el informe contable se comprueba la forma de distribución de los recursos del Sistema, y el porcentaje que le corresponde a cada uno de los diferentes agentes que participan, tal y como se puede apreciar en las siguientes gráficas comparativas. En la Gráfica No. 3 "Distribución de recursos del sistema TM", sobresale la cuantiosa proporción asignada a los operadores troncales, quienes se llevan el $70 \%$ de los recursos de todo el sistema. Seguidos por los operadores de alimentación que participan con un 17\% de los ingresos, y por el agente recaudador que obtiene el 7\%, siendo la participación de la fiducia un monto marginal $(0,04 \%)$ en comparación con los demás. La sumatoria de la participación de los agentes privados (operadores troncales, alimentadores, recaudador y fiducia), representa el $94 \%$ de los recursos del sistema, correspondiéndole a la entidad pública Transmilenio S.A. solamente el $6 \%$ de los ingresos totales.

\section{Gráfica No. 3. Distribución de Recursos del Subsistema TM por Agente.}

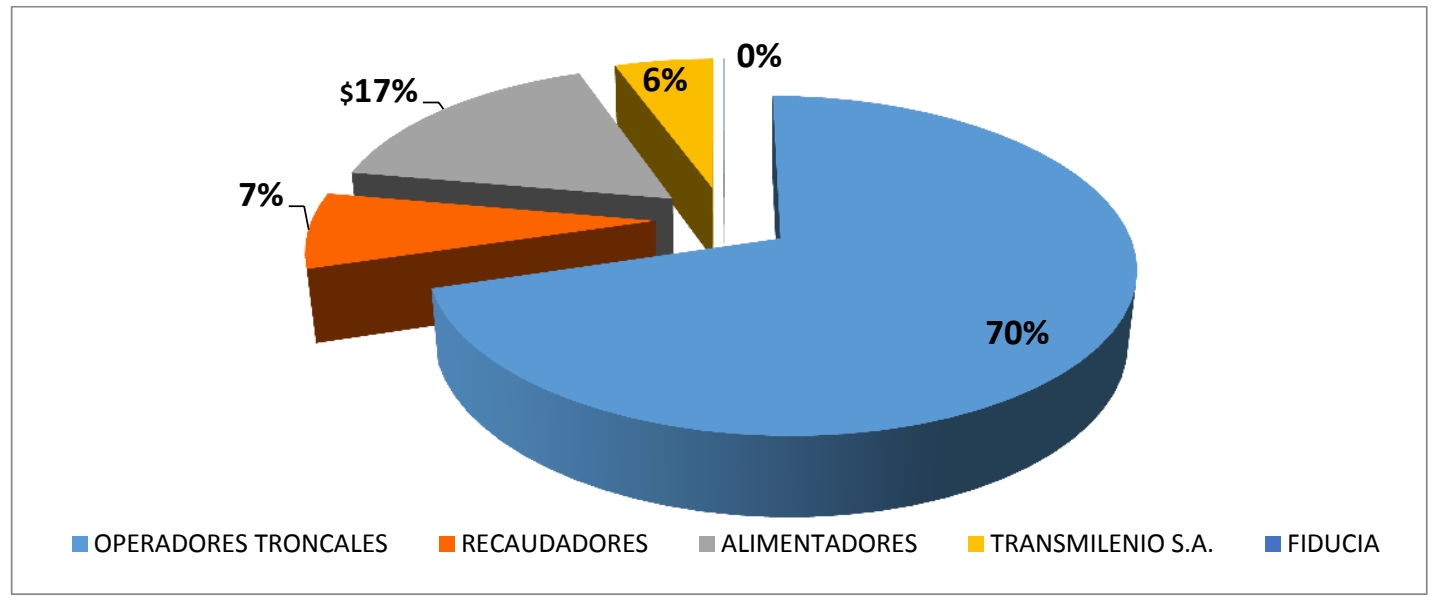

Fuente: Elaboración propia a partir de informe de gestión elaborado por Transmilenio S.A. (Informe de Gestión, 2013, pág. 123)

Por su parte, en la Gráfica No. 4 "Distribución de recursos dentro de las concesiones del SITP" se refleja una participación del 30\% asignada a los operadores zonales, encargados de las rutas que operan en cada una de las 13 zonas en las que se dividió Bogotá, seguidos por los operadores troncales, que son los encargados de las rutas de la Fase III de Transmilenio (10ma y 26) quienes participan con el 14\% de los recursos del sistema. Llama la atención el incremento de los derechos de participación otorgados al operador del recaudo (SIRCI), quien canaliza el 12\% de los ingresos. Pero sin duda la 
variación más importante se presenta en la distribución de dinero otorgada al Ente Gestor, Transmilenio S.A. quien vio reducida su participación con respecto a la otorgada en las concesiones de Transmilenio Fase I y II, pasando del $6 \%$ a un irrisorio $2 \%$.

Gráfica No. 4. Distribución de Recursos del SITP por Agente.

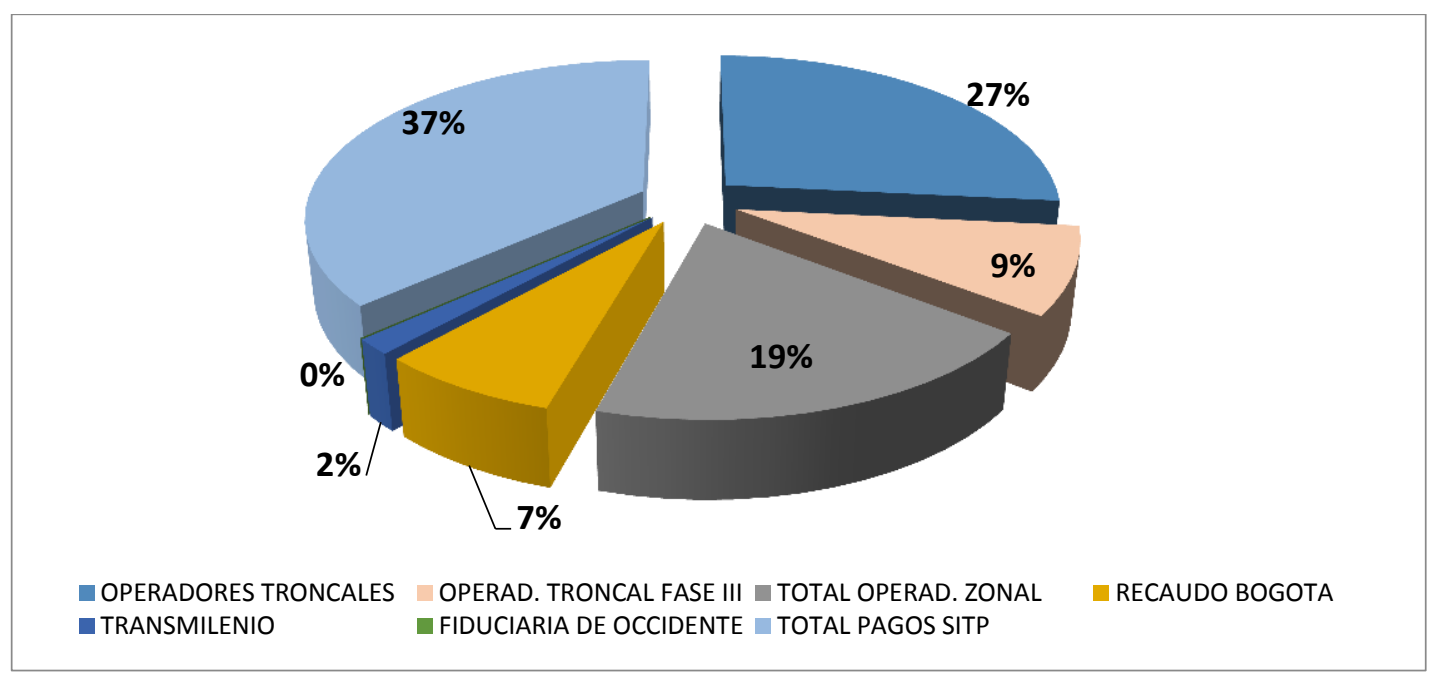

Fuente: Elaboración propia a partir de informe de gestión elaborado por Transmilenio S.A. (Informe de Gestión, 2013, pág. 124)

De acuerdo con este esquema de remuneración, a Transmilenio S.A., le corresponde una participación en los ingresos del sistema del $5.7 \%$ en TM y del 2\% en SITP, que solo le permite, en promedio, cubrir el $40 \%$ de sus costos operacionales, generándole un gran déficit al Distrito, que tiene que cubrir con recursos públicos, ya que los costos de operación de TM no se incluyen de manera explícita en la estructuración de la tarifa, la cual responde a garantizar exclusivamente el cubrimiento de los costos y la utilidad de los operadores (Galeano, 2012). En efecto, al momento de calcular la asignación de TMSA no se efectuó ningún análisis financiero, ni de sostenibilidad del ente gestor, y de ninguna manera se incluyó la forma de tener en cuenta las variaciones de costos en los que pudiera incurrir éste, otorgando una remuneración fija, que no permite recaudar lo necesario ni siquiera para su sostenimiento, aspecto que afecta la viabilidad financiera de TMSA, que continuamente demanda recursos públicos para su mantenimiento, lo que muestra que desde un comienzo la distribución estipulada en el contrato, distorsiono el equilibrio de las ecuaciones entre los ingresos y los gastos del 
sistema. Tal y como lo señaló la Contraloría de Bogotá (2007) TMSA presenta pérdidas operacionales de $\$ 68,275$ millones a 2007; y en adición, TMSA recibe $\$ 48.462$ millones a título de participación, mientras que incurre en gastos del orden de $\$ 116.737$ millones, por lo que solamente logra cubrir el $41.5 \%$ de sus costos.

Tampoco resulta proporcionado y equitativo, que las funciones del recaudo hayan sido asignadas a otro agente privado, distinto de los operadores troncales, quien participa con un porcentaje mayor que el Ente gestor (7\%), y solo tiene la función de recoger el dinero y consignarlo diariamente a la fiducia que maneja todos los recursos. Si bien el recaudo implica unos gastos de inversión, estos solo se efectúan al inicio, mientras se implementa la tecnología de las tarjetas inteligentes, lo que hace desproporcionada la asignación de la participación, no obstante lo más desproporcionado es el hecho de que las funciones de recaudo no sean asumidas directamente por los operadores, como sucede en la mayoría de sistemas de transporte del mundo, pues el recaudo del dinero, es uno de los elementos de la esencia de este tipo de negocios, por lo que su asignación a otro agente con su correspondientes derechos de participación evidencia la inequitativa y oportunista asignación de derechos dentro de las concesiones examinadas.

\subsubsection{Distribución de Funciones.}

Por su parte, al examinar las funciones que corresponden a cada uno de los agentes del sistema de transporte definidas en los contratos de concesión, la desproporción entre la asignación de las obligaciones de los agentes privados y el Ente Gestor resulta notoria, prueba incontrovertible de dicha desproporción es que TMSA solamente participa del 5.73\% de los ingresos del sistema TM y del 2\% en SITP, mientras que ostenta cargas como "LOS COSTOS DE FUNCIONAMIENTO Y OPERACIÓN PROPIOS, y los costos de aseo, vigilancia y mantenimiento del sistema; lo que evidentemente es desequilibrado" (Tribunal Administrativo de Cundinamarca, 2011, p. 60). Lo anterior se pone en evidencia en el Comparativo de Funciones Transmilenio S.A. vs. Operadores Privados (Tabla No. 9).

En ese sentido, TMSA ha venido asumiendo costos de: aseo, vigilancia y mantenimiento que contractualmente deben ser contratados por el Sistema Transmilenio por una cuantía de \$19.609 millones de pesos desde la entrada en operación del Sistema y hasta mayo de 2005, de los cuales, 
teniendo en cuenta la proporción de los ingresos recibidos por el Sistema durante el mismo periodo (\$929.882 millones de pesos), a TMSA, le correspondería únicamente la suma de \$911 millones y no los más de 19.000 que ha pagado (Contraloría de Bogotá, 2007) .

\section{Tabla No. 9. Comparativo de Funciones Transmilenio S.A. vs. Operadores Privados}

\begin{tabular}{|c|c|}
\hline Funciones de Transmilenio S.A. & Operadores Privados \\
\hline \multicolumn{2}{|l|}{ Infraestructura } \\
\hline $\begin{array}{l}\text { Distrito: } 40 \% \\
\text { Nación: } 60 \% \\
\text { (Mediante la Ley } 86 \text { de } 1989 \text { se creó la sobretasa } \\
\text { al precio de la gasolina, que se destinó a } \\
\text { inversiones en vías urbanas y a la implantación de } \\
\text { proyectos de transporte masivo de pasajeros). }\end{array}$ & Operadores privados: $0 \%$ \\
\hline \multicolumn{2}{|l|}{ Costos de Operación } \\
\hline $\begin{array}{l}\text {-Gestionar, administrar, controlar todo el } \\
\text { sistema de Transmilenio, fijar rutas, establecer } \\
\text { frecuencias, etc. } \\
\text {-Velar por la seguridad de las estaciones y } \\
\text { portales } \\
\text {-Velar por el aseo de las estaciones y portales } \\
\text {-Atender el mantenimiento de las estaciones } \\
\text {-Atender el mantenimiento de los parqueaderos } \\
\text {-Atender el Mantenimiento de las vías }\end{array}$ & $\begin{array}{l}\text { - Adquirir los buses que prestarían el servicio de } \\
\text { transporte, } \\
\text { - Adquirir equipos, maquinarias y herramientas } \\
\text { necesarias para el funcionamiento de los talleres; } \\
\text { - Atender el mantenimiento de los talleres. } \\
\text { (Los costos de operación son cubiertos en su } \\
\text { totalidad por la tarifa, que remunera por los costos } \\
\text { de capital: buses, intereses del capital invertido, } \\
\text { seguros, depreciación; costos fijos: empleados, } \\
\text { gastos de administración; costos variables: } \\
\text { combustible, aceites, neumáticos, etc. Vía tarifa ya } \\
\text { se reconoce una "justa" remuneración. }\end{array}$ \\
\hline \multicolumn{2}{|c|}{ Porcentaje de participación de los ingresos del sistema } \\
\hline $5,7 \%$ & $70,3 \%$ \\
\hline
\end{tabular}

Fuente: Elaboración propia a partir de (Contrato Concesión SITP, 2010), (Transmilenio S.A., 2001) y

(Tribunal Administrativo de Cundinamarca, 2011, p. 60). 


\subsubsection{Sistema Residual de participación.}

Pero sin duda, lo que más inequitativo y desproporcionado resulta de la distribución de costos y beneficios, es el sistema residual de participación contenido en los contratos, según el cual de la totalidad de los ingresos del sistema (operacionales y no operacionales), se paga primero los porcentajes fijos de TMSA y fiducia, luego se paga a los operadores de recaudo y de los alimentadores, y el dinero restante, sin importar su cantidad es asignado a los operadores troncales, independientemente de los costos en los que hayan incurrido. Dicha situación, ha generado que los operadores troncales reciban más ingresos que los costos operativos efectivamente causados, y dentro de los cuales ya se encuentra incorporada su "justa” remuneración. En efecto, al examinar los ingresos de los operadores de los buses rojos se encuentra que el valor de sus costos contractuales -según kilometraje recorrido y el costo por kilómetro licitado, ajustando mensualmente $\left(\mathrm{C}^{*} \mathrm{KM}\right)$ - es inferior a los ingresos recibidos. El sistema residual establecido en los contratos con los operadores, ha permitido que la remuneración haya sido ostensiblemente superior a los costos licitados, por encima del $11.5 \%$ adicional. Esta situación, hace que los operadores estén obteniendo una doble remuneración, pues por una parte reciben una "justa" retribución a título de utilidades, las cuales se encuentran insertas dentro de la canasta de costos y se garantizan vía tarifa, y por otra parte, gracias al sistema de distribución residual, se apropian de los excedentes de ingresos que queden luego de efectuar el pago al Ente Gestor y a la fiducia, los cuales solo son posibles gracias a los inmensos subsidios que gira el Distrito Capital. Una muestra más de los superlativos costos públicos y las cuantiosas utilidades privadas que genera la regulación del servicio de transporte público de Bogotá.

Lo anterior se ve reflejado en los resultados financieros de los diferentes agentes, por ejemplo, las empresas operadoras de los servicios troncales, eran dueñas de la tercera parte de sus activos, ahora lo son del 50\% y su endeudamiento disminuyó del 67\% al 40\% (Suárez, 2012). Para el 2012, las firmas SI 99, Express del Futuro, Conexión Móvil, S.O. Móviles, Transmasivo y Citimovil, que operan en las troncales de la Caracas, la NQS, la Calle 80, la Avenida Suba y la Autopista Norte (Fases I y II) presentaron significativas variaciones, mientras en 2011 sus ingresos fueron de $\$ 452.509$ millones, para 2012 sumaron $\$ 550.829$ millones, 22\% más (según datos suministrados por la Superintendencia de Transporte). En cuanto a las utilidades - antes del impuesto a la renta- para el 2011 fueron de $\$ 23.813$ millones y en 2012 ascendieron a la suma de $\$ 40.755$ millones, es decir, crecieron $71 \%$ 
(Suárez, 2012). En el caso de los alimentadores, sus resultados son inmejorables: ingresos, utilidades, márgenes, patrimonio, capital de trabajo y flujo de caja van en ascenso y la rentabilidad sobre el patrimonio supera el $40 \%$. En contraste con las alentadoras cifras del negocio que arrojan los estados financieros de los operadores privados, las cifras de TMSA palidecen, pues el ente gestor que ha sufrido caída en sus ingresos debido a la política tarifaria que subsidia horas valle ( $\$ 300$ por pasaje), registró para el 2012 pérdidas operacionales por \$7.800 millones, situación que demandó un partida presupuestal de la Secretaría Distrital de Hacienda del orden de \$165 mil millones para purgar el déficit, dinero que en buena parte terminó en las arcas de los operadores privados.

\subsubsection{Estructura de incentivos.}

La asignación de derechos de propiedad, reflejada en los derechos de participación, las obligaciones que deben atender los agentes y el sistema residual de participación, pone en evidencia que los agentes privados ejercieron su significativo poder de negociación al momento de configurar el sistema de costos y beneficios, pues lograron conseguir que el grueso de los costos fueran asumidos por los recursos públicos, y la mayor parte de beneficios fueran asignados a sus patrimonios, produciéndose un arreglo institucional incorrecto que no atiende ni a la equidad ni a la eficiencia en la prestación del servicio. Dicha situación, negativa para los intereses públicos, se ve agravada por la estructura de incentivos que se deriva de la mencionada asignación, toda vez que genera mala calidad en la prestación del servicio, pues se estimula que los operadores, en aras de optimizar sus utilidades disminuyan costos operativos a través de la disminución en la frecuencia de los buses, puesto que sus ingresos se encuentran asegurados por el sistema residual de participación, que implica que su pago se realiza independientemente de sus gastos de operación, razón por la cual, entre menos sean sus costos operativos mayor será su margen de utilidad.

Así mismo, la mala calidad del servicio y el alto costo para acceder a él, incentivan a los usuarios a buscar servicios sustitutos para solucionar sus necesidades de movilidad, situación que incrementa la congestión, los tiempos de desplazamiento y calidad de vida de la ciudadanía. A su vez, los costos para utilizar un sistema de mala calidad, afecta seriamente la economía familiar, lesionando por resultado los beneficios sociales que está llamado a asegurar el servicio de transporte público. En tal sentido, la estructura de incentivos producida por la asignación de derechos, es decir, por el sistema de distribución de costos y beneficios de ninguna manera logra los objetivos que debe observar la 
prestación de un servicio público de tal envergadura, como son los de suministrar un servicio de transporte bajo criterios de calidad, accesibilidad, capacidad de pago y sostenibilidad.

\subsubsection{Externalidades Negativas. Los Costos Ocultos del Sistema de Transporte de Bogotá.}

Luego de realizar un examen crítico sobre la regulación del servicio de transporte público en Bogotá, expresada en los contratos de concesión tanto de TM como del SITP, se puede concluir que la estructuración tarifaria es ineficiente e incorpora numerosos sobrecostos, sumado a importantes costos de transacción que produce, todo lo cual generan altísimas tarifas, que se erigen como una barrera al acceso real y efectivo de este servicio esencial. Así mismo, al revisar la distribución de costos y beneficios del sistema se pudo advertir la desproporción de sus asignaciones, a partir de las cuales se aseguran cuantiosas utilidades a los agentes privados, que demandan recursos externos, que son cubiertos a través de inmensos subsidios, lo que a su vez incrementa los costos públicos del sistema de transporte. En tal sentido, el modelo económico que sirve de fundamento de la regulación genera un transporte público caro para los ciudadanos (acceso) y sumamente costoso para la ciudad (sostenimiento). Hasta aquí, los temas examinados hacen parte de los costos visibles y directos derivados del sistema, sin embargo, dado el carácter esencial de la prestación objeto de estudio, los efectos e impactos de la regulación del servicio de transporte generan otros costos no tan visibles y directos, costos "ocultos" que -siguiendo la lógica planteada por Coase- necesariamente se deben tener en cuenta al momento de hacer una valoración total sobre el sistema de transporte seleccionado y las reglas que lo gobiernan. Estos "costos ocultos" corresponden al concepto económico de externalidades negativas, entendidas como aquellos efectos indirectos de una determinada actividad de producción, en este caso el transporte, que afectan otros agentes u otras actividades. A continuación se estudiarán las externalidades negativas o los “costos ocultos" de mayor impacto según los resultados arrojados por la presente investigación.

\subsubsection{Congestión Vehicular.}

Las altas tarifas no solo generan limitaciones al acceso real y efectivo al servicio esencial de transporte, a su vez conducen a los usuarios a buscar alternativas y formas sustitutas del servicio. En ese sentido, TM que ha sido muy caro para los estratos bajos y poco atractivo para los estratos altos, ha 
generado un incremento en el uso de sustitutos. Al respecto, resulta ilustrativo el caso de la motos, pues las personas que se movilizan en este medio de transporte pasaron de $4 \%$ a $7 \%$ (Reporte Anual de Movilidad, 2010), lo que explica que las ventas se hayan cuadruplicado alcanzando las 660.000 unidades en los últimos 10 años. Así mismo, las personas que utilizan modos humanos para transportarse (a pie o en bicicleta) hoy representan el 16\% de la población. El caso de los modos alternativos de transporte (denominados transporte pirata) también ha sido un fenómeno en ascenso, pues cada vez son más los vehículos particulares, motos o camionetas que establecen rutas no autorizadas para prestar el servicio. Si bien no existe una cifra exacta sobre la cantidad de los llamados “piratas", se tienen identificadas más de 15 zonas en la capital donde están establecidas, y se han impuesto más de 1.598 multas e inmovilizado cerca de 1.543 vehículos por esta razón (El Tiempo, 2009). El aumento de los vehículos particulares, que representan el 30\% de los viajes diarios de la ciudad, prácticamente se duplicó en 10 años, pasando de 600.000 vehículos en el año 2.000 a 1’150.000 en el 2010 (Alcaldía Mayor d. B., 2011).

El aumento en el uso de sustitutos tiene efectos sociales perjudiciales, pues más motos, carros y transporte alternativo en la vía aumenta la congestión y con ella los tiempos de viaje, afectando notablemente la calidad de vida de los ciudadanos. En efecto, si bien en un comienzo TM bajó los tiempos de viaje de sus usuarios, del año 2008 al 2009 pasó de 34,1 minutos en promedio a 39,2. El TPC también aumentó sus tiempos de viaje en 7,2 minutos y paso de un promedio de 23,4 km/h a 19,3 $\mathrm{km} / \mathrm{h}$, lo que a generado que el tiempo promedio de traslado en el transporte público sea de 67 minutos, es decir, que la gente en Bogotá "gasta 37 minutos por días por encima del tiempo del traslado normal que debe tener un usuario entre su casa y el trabajo" (El Tiempo, 2015) Por su parte, la velocidad promedio de los vehículos particulares también disminuyó de manera considerable, pasando de 30,4 km/h a 23,8 km/h (Alcaldía Mayor d. B., 2011). En síntesis, existe suficiente evidencia que demuestra que la regulación del servicio de transporte, en particular sus altas tarifas y el hacinamiento -generado en parte por los incentivos creados por la distribución de costos y beneficios-, han generado el aumento en el consumo de sustitutos, lo que produce externalidades negativas de amplio impacto, como el incremento ostensible de la congestión vehicular, aspecto que por resultado incrementa la contaminación, la accidentalidad, disminuye los tiempos de viaje y con ello la calidad de vida de los usuarios, sin mencionar la disminución en la productividad de la ciudad, ya que los bogotanos gastan alrededor de 7 millones de horas al año dentro de un bus, "un tiempo superior al 
promedio nacional, que es de 4 millones de horas" lo que significa que la congestión vehicular le cuesta al país “el 2 por ciento del PIB nacional” (El Tiempo, 2015).

\subsubsection{Calidad del Servicio.}

Pero si acceder al servicio de transporte es difícil por los grandes costos que requiere, una vez se puede hacer uso de él, se evidencian sus notables y crecientes fallas de calidad en la prestación del servicio. En efecto, la implementación de los sistemas de transporte masivo tienen como finalidad mejorar la movilidad en la ciudad para incrementar las oportunidades económicas, sociales y culturales de la ciudadanía y con ello mejorar su calidad de vida. Sin embargo, dichos objetivos son abiertamente desconocidos por las condiciones materiales en la que se presta el servicio de transporte. El hacinamiento de los buses ha venido en aumento, registrando un incremento de pasajeros por bus del 57\% en el periodo de 2008 a 2012. Dicha situación obedece a que TM es un sistema de mediana capacidad, que puede movilizar en promedio de 20.000 a 35.000 pasajeros/hora sentido, sin embargo TM transporta más de 45.000 pasajeros/hora sentido (Alcaldía Mayor d. B., 2011). Sumado a lo anterior, la asignación de costos y beneficios a través del sistema residual de distribución descrito líneas atrás, incentiva a los operadores a incurrir en menores costos de operación guardando en los parqueaderos buena parte de su parque automotor, pues entre menos gastos incurran mayor será su margen de utilidad, ya que como se advirtió no solo se pagan los gastos operativos generados, sino que del total de recursos del sistema (incluido subsidios) y una vez efectuados los pagos de TMSA y fiducia, el restante es distribuido entre los agentes privados independientemente de sus costos operativos. Así mismo, los operadores privados no tienen ningún incentivo para invertir en más buses, a pesar del aumento significativo de la demanda; por el contrario el Distrito en 2013 aumentó la vida útil de los buses que debían reemplazarse. Tal situación, de por sí grave, será peor cuando el SITP este en pleno funcionamiento, pues gran parte de los usuarios que antes no necesitaban TM, ahora tendrán que utilizarlo pues buena parte de las rutas del SITP funcionarán como alimentadores de TM.

Así mismo, la demora en los tiempos de espera de los buses, las inmensas filas para comprar los pasajes, y el hacinamiento en buses y estaciones, hacen que los tiempos totales de viaje aumenten, lo que afecta el bienestar y la calidad de vida de los usuarios, variables de singular importancia al momento de valorar el sistema de transporte, a pesar de que no funcionen a través de sistemas de 
precios. La percepción de la ciudadanía respalda lo afirmado, pues el 43,6\% considera que el problema principal de TM es el hacinamiento, seguido de la seguridad (17\%) y el costo (13\%). De igual forma, el 44\% de los ciudadanos considera que en el 2013 se aumentaron sus tiempos de viaje en TM, y solamente el $14 \%$ considera que sus tiempos mejoraron. En cuanto a la calidad del servicio el $32 \%$ de los usuarios considera que el servicio ha empeorado o empeorado mucho, mientras que las personas que consideran que ha mejorado bajaron del 22\% al 15\% (Encuesta de percepción ciudadana, 2013). Todo lo anterior explica por qué TM es el peor calificado de los medios de transporte, obteniendo un puntaje de tan solo 2,8 mientras que el TPC recibió 3,3 y la bicicleta 4,3 (Reporte Anual de Movilidad, 2010). En conclusión, la ineficiente regulación no incentiva la calidad, y por el contrario genera una ineficiente prestación del servicio, caracterizada por buses y estaciones que desbordan su capacidad -lo que facilita el aumento de robos e inseguridad-, tiempos largos de espera y la demora de los viajes, aspectos que afectan de manera notoria el bienestar de la ciudadanía y su calidad de vida.

\subsubsection{Monopolio.}

La regulación del servicio de transporte cambió significativamente con la implementación de TM y el SITP, pues la estructura de funcionamiento paso de 3 agentes (afiliadoras, dueños de los buses y administración) a solamente 2 (operadores y administración), de la misma manera la competencia en los corredores, conocida como "la guerra del centavo", paso a la competencia por los corredores, en el entendido que la disputa se trasladó a las licitaciones públicas mediante las cuales se asignan zonas de operación del servicio. Esta situación, condujo a la concentración de la propiedad en materia de transporte, pues las pequeñas y medianas empresas sucumbieron ante el poderío de los grandes grupos económicos del sector, quienes lograron hacerse de las concesiones. En la práctica, se constituyó un oligopolio por vía de la regulación, con el argumento de lograr mayor eficiencia y los beneficios de las economías de escala. No obstante, los objetivos positivos de entregarle la explotación del servicio de transporte a un puñado de empresa no se concretaron, las economías a escala fueron apropiadas por los operadores y las tarifas no han parado de crecer, haciendo de TM uno de los sistemas más caros de América Latina. En ese sentido, el arreglo institucional condujo a que el sistema funcionara bajo condiciones de monopolio, generando ineficiencias, sobrecostos y graves dificultades de acceso a un servicio público esencial. Aunado a lo anterior, y tal y como lo explica Posner (2013), las firmas 
encargadas de la operación se encuentran fuera del alcance de las leyes antimonopolio, pues la regulación termina legitimando y validando sus actuaciones.

\subsubsection{La captura del regulador.}

Las grandes ventajas obtenidas por los operadores, se explican en buena medida por un fenómeno conocido como la captura del regulador, una externalidad que ha incidido ampliamente en las ineficiencias expuestas en esta investigación. Al respecto, tal y como lo señala el profesor Gil Alzate (2009), en términos económicos el regulador no es necesariamente un "buen samaritano", se trata de un agente económico que opera bajo incentivos, es un maximizador racional, quien se puede ver incentivado a dirigir la regulación hacia los intereses del regulado "en busca de mayor apoyo político o de algún otro tipo de interés, sea o no patrimonial" (p. 103). La descripción anotada se adecua plenamente a lo sucedido en el caso del transporte en Bogotá, donde el gran poder acumulado por los grupos de interés que se adueñaron de las concesiones, logró tomarse al regulador, y con ello direccionar la regulación para asegurar sus intereses, lo que les permitió hacerse de "enormes volúmenes de capital económico y político" mediante el cual controlan el mercado del transporte (Echeverry, Ibañez, \& Moya, 2005), lo que explica por qué, a pesar de las protuberantes ineficiencias e inequidades, la regulación continúa otorgando beneficios a los operadores.

La captura del regulador en Bogotá, comenzó a evidenciarse antes, con las presiones para el incremento de las tarifas del TPC, pero se hace patente ahora, con las inmensas gabelas otorgadas a los operadores, tanto en los contratos iniciales - donde la falta de experiencia y la novedad del negocio permitieron amplia laxitud y beneficios a favor de los operadores-, como en los recientes contratos del SITP y la renegociación de 2013, donde a pesar de la experiencia adquirida y de las inmensas críticas sobre la estructuración tarifaria y la distribución de costos y beneficios, se aseguraron cuantiosas ventajas a los operadores, que están siendo investigadas por los órganos de control dada la magnitud de sus proporciones. En efecto, la prima de riesgo sobrevaluada, el sistema residual de distribución de ingresos, la existencia de un operador del recaudo, el irrisorio porcentaje asignado a TMSA, el aumento de vida útil de los buses, etc., son pruebas suficientes que demuestran la captura del regulador en Bogotá. No obstante, para evidenciar el grado de captura que existe, vale la pena referir un hecho político reciente -junio 2014- que causó gran revuelo, pues el alcalde de la capital nombro como 
gerente de TMSA - entidad encargada del control, la vigilancia y la gestión de los contratos- a Marco Tulio Gutiérrez, ex presidente de Conaltur, entidad que agremia a los grandes transportadores urbanos, y uno de los voceros principales de los operadores. En conclusión, el regulador del sistema de transporte en Bogotá TMSA, más que al servicio de los usuarios y del interés general, está a merced de los operadores privados y de sus intereses.

Bajo las anteriores consideraciones, salta a la vista el impacto indirecto que ha generado la regulación del servicio de transporte en aspectos fundamentales como congestión vehicular, accidentalidad, contaminación, falta de calidad del servicio, aumento en los tiempos de espera y desplazamiento, lo que genera estrés en la ciudadanía, inseguridad, falta de pertenencia ciudadana, externalidades que producen un amplio inconformismo social, que se expresa en intolerancia, falta de cultura ciudadana y en los más de 200 bloqueos al año que se presentan en TM a causa del descontento con la prestación del servicio, situación que explica por qué la movilidad es uno de los problemas principales de la ciudad que demanda soluciones estructurales de corto, mediano y largo plazo.

Cambio Institucional. Observada la incorrecta asignación de derechos efectuada por el sistema de distribución de costos y beneficios previsto en la regulación, identificadas las ineficiencias producidas por la estructuración tarifaria derivadas de los elevados costos de transacción relacionados con la información, la negociación y la ejecución, y reconocida la existencia de onerosas externalidades negativas que han producido serios impactos sociales, se hace patente la necesidad de un cambio institucional, entendido como un reajuste a los arreglos sociales en materia de regulación del servicio de transporte, que permitan superar las ineficiencias económicas y las inequidades sociales producidas por los arreglos actuales, reestructuración que solo será posible si cuenta con el decidido apoyo de los actores afectados (agente público, agentes usuarios del servicio), únicos capaces de enfrentar a los grupos de poder privilegiados, quienes tienen la capacidad de "frenar la constitución de derechos de propiedad socialmente más eficientes en función de preservar sus intereses particulares" (North, 1993).

\subsection{Conclusiones del Capítulo III.}

El Análisis Económico del Derecho, efectuado sobre la regulación del servicio de transporte público, en particular sobre la economía de los contratos de concesión que gobiernan la prestación del 
servicio, demostró que el esquema económico implementado es ineficiente e inequitativo por las siguientes razones:

Estructuración tarifaria. 1) La Prima de Riesgo. El sobredimensionado valor asignado al riesgo, y los inmensos costos que dicho rubro generó, produjo sobrecostos en la remuneración del capital, los intereses de capital y la depreciación, del orden del 15\% por encima del valor real. En adición, a pesar del cambio significativo de las condiciones macroeconómicas, no se introdujeron mecanismos para ajustar las variables, y tales sobrecostos se continúan pagando. 2) Altos Costos Públicos. Los enormes sobrecostos operativos asegurados vía tarifa, hacen que los ingresos obtenidos del sistema sean insuficientes, lo que en virtud del acuerdo del pago extendido suscrito por el Distrito, requiere del incremento de los subsidios públicos, que a 2013 se habían incrementado 299\%, lo que hace que el sistema no solo sea caro para los usuarios (acceso) sino sumamente oneroso para la ciudad (sostenimiento), afectando tanto la economía de las familias, como las arcas públicas, solamente para asegurar multimillonarias ganancias a un puñado de firmas. 3) Apropiación de economías de escala. Así mismo, la eliminación de la variable del IPK y la incorporación de la remuneración por costos medios, torno los costos de operación insensibles a la demanda, lo que produjo que las eficiencias y los menores costos derivados del aumento exponencial de la demanda, fueran apropiados en su totalidad por los operadores privados, impidiendo el traslado de los menores costos a los usuarios. 4) La renegociación de los contratos. El aumento de vida útil de los buses, como una concesión unilateral a favor de los operadores, impide la incorporación de nueva flota, anula la efectividad de la etapa de reversión de los contrato, pero la crítica principal consiste en que no se acompañó con el ajuste tarifario pertinente, lo que significa que los costos de capital, que ya fueron cubiertos dentro del periodo de vida útil fijado en el contrato, ya no tendrían que pagarse durante el nuevo periodo de operación de los buses, pues tanto el capital, como los intereses, como la depreciación de la flota ya fue cubierta en su totalidad. En ese sentido, aumentar la vida útil de los buses dejó sin sustento los costos de capital, que ascienden al $26.8 \%$ del costo de la tarifa, importes que se han debido descontar de la tarifa, lo que significa que el costo al usuario ha debido bajar cerca de $\$ 450$ por pasaje, medida que genera grandes pérdidas sociales, en cuanto acceso, calidad y seguridad.

Distribución de Costos. La distribución entre los costos y lo beneficios resulta abiertamente desproporcionada e inequitativa por las siguientes razones: 1) La asignación otorgada a TM es fija y 
no se ajusta a sus costos de operación, en la medida que al momento de calcularse su participación se subestimaron sus costos, lo que explica que tan solo logra cubrir el $40 \%$ de sus gastos, incurriendo en déficit permanente que se soluciona mediante subsidios. 2) La distribución de funciones pone de manifiesto la desproporción e incorrecta asignación de costos y beneficios, pues otorga las mayores cargas al Ente Gestor TMSA, y concentra los beneficios en los operadores privados. 3) La existencia de un operador de recaudo, incrementa ostensiblemente los costos, pues se le asigna una participación incluso mayor que TMSA, del orden del 7\%, que no tiene razón de ser pues se encarga de una de las funciones propias del servicio y de sus operadores, como es recaudar el dinero. 4) El sistema residual de participación es una medida inequitativa y desproporcionada, pues permite que los excedentes de los recursos del sistema sean asignados a los operadores troncales, quienes están obteniendo más ingresos que los costos operativos en los que incurren y los cuales ya llevan incorporadas las “justas” utilidades por su labor. Así, los ingresos del sistema no alcanzan, por lo que se requiere de subsidios, los cuales son repartidos en primer lugar a TMSA, luego a fiducia, recaudador y alimentadores, y el resto de los recursos, independientemente de si el sistema se encuentra en déficit o no, es asignado a los operadores troncales en aplicación de las normas contractuales. 5) La distribución de costos y beneficios asignó el riesgo principal del negocio, la demanda, al ente gestor TMSA, aspecto que no tiene justificación técnica. 6) Utilidad por hacinamiento. (Estructura de incentivos) Sumado a lo anterior, a través de la variable del IPK generó estímulos para incrementar el número de personas por km, lo que generó sobrecupo en los buses, produciendo una relación directamente proporcional, a mayor hacinamiento mayor utilidad de los operadores. Tras la eliminación de dicha variable tampoco se introdujo ningún mecanismo que lograra asignar los menores costos derivados de una mayor demanda a los usuarios a través de la disminución de las tarifas.

Costos Ocultos. Los onerosos costos de las tarifas y la baja calidad del servicio hacen que los usuarios busquen sustitutos, incrementándose los medios de transporte humanos $16 \%$ y el uso de motos $7 \%$ y vehículos privados $30 \%$, lo que generado una serie de externalidades negativas como: 1) Aumento de congestión vehicular, y con ella la contaminación y los tiempos de viaje lo que genera grandes pérdidas sociales en trabajo, producción, educación y bienestar colectivo, más del 2\% del PIB nacional. Adicionalmente, las 2) perdidas en bienestar, el estrés, 3) la inseguridad, el hacinamiento tanto en estaciones como en buses, afectan seriamente la 4) calidad del servicio, y con ella la calidad 
de vida de los usuarios, finalidad última de un sistema de transporte. 5) Monopolio, por su parte la regulación incentivo la concentración de las firmas operadores, con el propósito de generar mayor rendimiento por economías a escala, lo cual no condujo a menores tarifas, y por el contrario, incremento considerablemente los ingresos de los operadores, quienes se volvieron más poderosos, haciendo valer su poder político y de negociación al momento de celebrar las renegociaciones de los contratos, lo que produjo que se presentara el denominado fenómeno de la 6) Toma del regulador.

Por las razones expuestas, el sistema de transporte de Bogotá únicamente puede ser considerado eficiente desde una perspectiva microeconómica, que examine solo el funcionamiento operativo de las firmas concesionarias quienes han obtenido inmensas ganancias, no obstante, al dar un paso hacia atrás y observar el sistema como un todo, se evidencian las enormes ineficiencias en términos de acceso, costos públicos, protección de derechos, asignación de recursos, lo que hace de la regulación de TM y SITP, un arreglo institucional de baja rentabilidad social, que genera inmensas perdidas colectivas y enormes costos de oportunidad.

Respuesta a la pregunta de investigación. Por todo lo anterior, luego de efectuar un análisis crítico sobre la regulación del servicio de transporte, se puede señalar que las cláusulas económicas de los contratos de concesión Sí constituyen un límite al acceso real y efectivo del servicio esencial de transporte por parte de un segmento considerable de la población, en la medida que las variables incorporadas dentro de los costos del servicio, algunas sobredimensionadas, otras hoy inexistentes, generan tarifas que no corresponden con los costos reales ni se adecuan a la capacidad de pago promedio de la población capitalina. En otras palabras, la regulación existente genera tarifas que excluyen de manera directa a la población de menores ingresos, y afecta seriamente la economía familiar de quienes no tienen otra opción de transporte. Así mismo, la regulación generó una asignación de costos y beneficios donde la gran sacrificada es la ciudadanía, en la medida que las desproporcionadas ganancias de los operadores tienen que ser respaldadas por subsidios cada vez más altos (impuestos), para garantizar el funcionamiento de un sistema caro, de baja calidad, que se quedó pequeño para la capacidad que demanda una ciudad de las dimensiones de Bogotá, y que aumenta los costos de transacción, afectando la competitividad y el desarrollo de la capital de Colombia. 


\section{CAPÍTULO IV.}

\section{CONCLUSIONES Y UN EJERCICIO DE ANÁLISIS COSTO-BENEFICIO.}

Luego de hacer una revisión minuciosa a la economía de las concesiones de TM y SITP, resulta pertinente señalar que la pregunta de investigación fue resuelta con suficiencia, en el entendido que se pudo verificar que las cláusulas económicas de los contratos de concesión tanto de TM, como del SITP, SÍ constituyen una limitación injustificada al acceso real y efectivo al servicio de trasporte público, prestación esencial de la que son excluidos segmentos poblacionales vulnerables de la ciudad (los estratos más bajos), y que afecta de manera significativa la economía familiar de los estratos medios, aspecto que genera graves repercusiones y externalidades negativas, pues si los ciudadanos no pueden movilizarse dentro de la urbe aumentan sus dificultades para el aprovisionamiento de bienes y servicios de primera necesidad como el trabajo, la educación, la salud y la recreación entre otros, aumentando así los costos de transacción debido a los ineficientes e inequitativos arreglos institucionales. La falta de un servicio de transporte accesible afecta la productividad de la sociedad, el progreso, el desarrollo colectivo y el bienestar general, máxime si se tiene en cuenta que del ingreso depende la movilidad urbana, y que de la movilidad urbana depende la movilidad social, comprendida como la superación de la pobreza y el mejoramiento de las condiciones económicas de las familias. En síntesis, la tarifa que deben pagar los habitantes de Bogotá por acceder al servicio de transporte, desconoce la capacidad de pago promedio de los ciudadanos, y contrasta profundamente con la realidad socioeconómica de la capital.

\subsection{Conclusiones.}

La regulación del servicio de transporte resulta ineficiente e inequitativa, por las siguientes razones:

1) Inadecuada Estructuración Tarifaria. El sobrestimado costo de la prima de riesgo 15\%, más los costos otorgados al operador del recaudo 7\%, más los costos de capital totalmente cubiertos y amortizados $26.8 \%$, permiten afirmar que la tarifa al usuario presenta sobrecostos del orden del 48.8\%, lo que significa que de cada $\$ 1.700$ que entran al sistema, $\$ 850$ no tienen razón de ser, más que alimentar las arcas de los operadores privados, y lo que significa que los usuarios al día están pagando en promedio $\$ 1.530$ millones de pesos más de lo que deberían estar pagando, recursos que 
son apropiadas en su totalidad por las firmas privadas. Las tarifas reales del transporte público, incluyendo la "justa" utilidad para los operadores, rondan los $\$ 850$, costos que constituiría una alivio a la economía de las familias de la Capital, y permitirían el acceso a una prestación de primera necesidad, vital para incrementar la competitividad y el ingreso de la ciudadanía. En consecuencia, las altas tarifas derivadas de la regulación, en particular de la estructuración tarifaria, constituyen una restricción injustificada al servicio esencial del transporte público, que afecta principalmente a los sectores más vulnerables y lesiona de manera directa el desarrollo y el progreso social, pues el transporte tiene una dimensión funcional estratégica para el avance del conglomerado.

2) Desproporcionada distribución de Costos y Beneficios. La asignación de recursos derivada de la regulación es abiertamente inequitativa y desproporcionada pues asignó el grueso de los costos y de los riesgos del negocio a la administración pública, a través del ente Gestor TMSA quien opera en déficit, y requiere cuantiosos subsidios para asegurar el cumplimiento de las obligaciones contractuales, lo que ha incrementado el monto de los recursos públicos que se deben destinar para el funcionamiento del sistema; mientras que el grueso de los beneficios fueron asignados a los operadores privados, quienes se apropian de las eficiencias derivadas de las economías de escala, reciben doble remuneración tanto por la tarifa como por el sistema residual de participación, y aumentan sus utilidades entre más aumente el hacinamiento en los buses, mientras que los riesgos que deben asumir por los agentes privados son mínimos, y su obligación principal, que consiste en suministrar la flota para operar el sistema, fue postergada más de 4 años, lo que les permite seguir usufructuando la explotación de buses que ya debían ser reemplazados a costa de ninguna contraprestación.

3) Costosas Externalidades Negativas. La regulación del servicio de transporte no solo ha generado los altos costos referidos líneas atrás otras, también ha producido costos indirectos que no se aprecian de inmediato y que son asumidos por la sociedad en general, dentro de los cuales se destaca, la congestión vehicular derivada del aumento en el uso de servicios de transporte sustitutos como motos (7\%), medios humanos (16\%), vehículos particulares (30\%), aspecto que incrementa la accidentalidad, la contaminación y aumento en los tiempos de viaje. Así mismo, la gran congestión tanto en estaciones, buses y filas de acceso aumenta los tiempos de espera y desplazamiento, y con ellos la calidad del servicio, lo que genera estrés en la ciudadanía, lesiona el bienestar social y produce condiciones de inseguridad, lo que explica las más de 1.000 capturas en flagrancia que se 
presentan al año, y las 110 denuncias por robo. La intolerancia por la incomodidad ha dejado picos como las 1.284 capturas por riñas en 2012. Todo estas externalidades negativas producen un amplio inconformismo social, que se expresa en estrés, violencia, falta de cultura ciudadana y en los más de 200 bloqueos al año que se presentan en TM a causa del descontento con la prestación del servicio, situación que explica por qué la movilidad es uno de los problemas principales de la ciudad que demanda soluciones estructurales de corto, mediano y largo plazo.

4) Desconoce los Derechos de Acceso de los Usuarios. Los inmensos costos del servicio de transporte afectan los derechos reconocidos por el sistema constitucional, pues no se garantiza el derecho a la movilización y al transporte de los individuos, y de ninguna manera se asegura el derecho colectivo al acceso a un servicio esencial, lo que desconoce sin justificación alguna fundamentos del Estado Social de Derecho como la igualdad material, la solidaridad y la dignidad humana, pues se restringe el uso de un servicio indispensable para lograr la calidad de vida mínima que los poderes públicos deben proveer en cumplimiento de los Mandatos Constitucionales a los que se encuentran sujetos. La imposibilidad real y efectiva de acceder al servicio de transporte público en condiciones de eficiencia y oportunidad, afecta el ejercicio material de derechos fundamentales como el derecho a la salud, la educación, la recreación y la participación democrática tanto en las decisiones colectivas, como en la producción económica, social y cultural.

Ajustes de la Regulación. En los anteriores términos, una vez efectuado el análisis económico sobre la regulación del sistema de transporte público de Bogotá, se advierte la necesidad de ajustar profundamente los arreglos institucionales existentes, con miras a 1) eliminar las serias barreras de acceso generadas por las altas tarifas y adecuarlas a la capacidad de pago de los usuarios en aplicación del principio de costeabilidad. Así mismo resulta necesario 2) replantear la desproporcionada distribución de costos y beneficios, que genera enormes costos públicos a cambio de una baja rentabilidad social, que produce inmensas perdidas colectivas y enormes costos de oportunidad. De la misma manera, se debe 3) asegurar la sostenibilidad del sistema, lo que implica revisar la participación de los agentes privados, ajustando sus utilidades o eliminando su intervención en la prestación del servicio. En definitiva, se debe propender por un sistema que no genere altos costos de acceso, que requiera costos de mantenimiento sostenibles, y que responda a la capacidad que demanda una ciudad de las características y las proporciones de Bogotá. 


\subsection{Un Ejercicio de Análisis Costo - Beneficio.}

Una vez examinados los costos directos del sistema de transporte, derivados tanto de su estructuración tarifaria como la distribución de costos y beneficios, y revisado el impacto de los denominados costos ocultos o externalidades negativas, se cuenta con suficiente evidencia material para efectuar un Análisis Costo-Beneficio de la regulación del servicio de transporte, el cual consiste en determinar si la suma de los beneficios obtenidos por la medida (regulación) excede la suma de sus costos. En tal sentido, siempre que los beneficios sean mayores que los costos hay un superávit que, con una redistribución adecuada, podría mejorar a algunos individuos sin empeorar a otros.

El Análisis Costo-Beneficio que se realiza en la presente investigación es ex post, pues versa sobre una decisión ya tomada (regulación expedida / elección TM), es positivo (Posner) en la medida que estudia la regulación existente, y es cualitativo en tanto se circunscribe a identificar aquellas variables que no fueron tenidas en cuenta al momento de hacer el análisis Costo-Beneficio (como las externalidades no introducidas), y cuestionar los resultados generados por la forma como se calcularon algunos costos a través de la tarifa. Vale anotar que la siguiente tabla se inspiró en el ejercicio realizado por los profesores Monroy Cely y Pinzón Camargo (2012) en su estudio sobre el análisis económico de los derechos colectivos.

Tabla No. 10. Variables a considerar en Análisis Costo-Beneficio.

\begin{tabular}{|c|c|c|}
\hline Costos & Descripción & Objeciones \\
\hline Prima de Riesgo & $\begin{array}{l}\text { Se calculó el costo de reposición de los } \\
\text { buses bajo supuestos macro- } \\
\text { económicos pesimistas. La realidad } \\
\text { posterior produciría menores costos de } \\
\text { capital, lo que genera cerca de un } 15 \% \\
\text { de sobrecostos por este rubro. }\end{array}$ & $\begin{array}{l}\text { No solo se sobredimensionaron los costos de capital, sino que no se } \\
\text { introdujo ningún mecanismo para poder ajustarlos conforme a la } \\
\text { realidad. Adicionalmente, los riesgos principales fueron asignados a } \\
\text { TMSA. }\end{array}$ \\
\hline $\begin{array}{ll}\text { Operador } & \text { de } \\
\text { Recaudo } & \end{array}$ & $\begin{array}{l}\text { Fueron separadas las funciones de } \\
\text { operación y recaudo y asignadas a } \\
\text { operadores distintos. El operador del } \\
\text { recaudo tiene derechos de participación } \\
\text { del } 7 \% \text { en los contratos de TM, y del } \\
13 \% \text { en SITP. }\end{array}$ & $\begin{array}{l}\text { Esta es una función propia de los operadores, no tiene por qué entregarse } \\
\text { a otro agente económico, y mucho menos asignarle un porcentaje tan alto } \\
\text { como el otorgado, que resultó mayor que la participación otorgada a } \\
\text { TMSA. }\end{array}$ \\
\hline
\end{tabular}




\begin{tabular}{|c|c|c|}
\hline Asignación TMSA & $\begin{array}{l}\text { Contractualmente se definió la } \\
\text { participación de TMSA en un costo fijo } \\
\text { equivalente al } 5,7 \% \text { en los contratos de } \\
\text { TM, y de un irrisorio } 2 \% \text { en los del } \\
\text { SITP. }\end{array}$ & $\begin{array}{l}\text { La participación de TMSA permite cubrir únicamente el } 44 \% \text { de sus } \\
\text { costos. Además resulta abiertamente desproporcionada al contrastarse } \\
\text { con sus obligaciones, pues TMSA se encarga del mantenimiento de } \\
\text { estaciones, patios, seguridad, aseo, control, vigilancia, gestión, entre } \\
\text { otras. }\end{array}$ \\
\hline $\begin{array}{l}\text { Sistema Residual de } \\
\text { participación }\end{array}$ & $\begin{array}{l}\text { La distribución de los ingresos del } \\
\text { sistema se efectúa en primer lugar a } \\
\text { TMSA, luego a la fiduciaria, operador } \\
\text { de recaudo y operador de los } \\
\text { alimentadores. Luego de dicha } \\
\text { distribución, los ingresos restantes, sin } \\
\text { importar su cuantía son asignados a los } \\
\text { operadores troncales. }\end{array}$ & $\begin{array}{l}\text { Dicho sistema de distribución entrega recursos a los operadores troncales } \\
\text { por encima de sus costos de operación, los cuales ya incorporan su } \\
\text { "justa" remuneración. Esto ha generado una doble remuneración a estos } \\
\text { operadores, pues vía tarifa se les aseguran utilidades, y vía sistema } \\
\text { residual, los recursos restantes son apropiados por ellos. Los ingresos } \\
\text { recibidos por esta vía provienen de subsidios públicos. }\end{array}$ \\
\hline $\begin{array}{l}\text { Aumento de vida } \\
\text { útil de los buses. }\end{array}$ & $\begin{array}{l}\text { En la renegociación de los contratos de } \\
2013 \text {, se aumentó la vida útil de los } \\
\text { buses en } 400.000 \mathrm{~km} \text {, lo que otorgó un } \\
\text { tiempo adicional de } 4,3 \text { años por bus. }\end{array}$ & $\begin{array}{l}\text { Esta medida afecta a los usuarios porque impide la incorporación de } \\
\text { nueva flota, en su mayoría Biarticulados que transportan mayor cantidad } \\
\text { de pasajeros. Así mismo, elimina de facto la fase de reversión contenida } \\
\text { en los contratos, y que obliga a la entrega de los buses al cabo de } 10 \\
\text { años, los cuales ya transcurrieron, lo que permite contar con flota propia } \\
\text { por parte del Distrito con la que puede apoyar la prestación del servicio. } \\
\text { Pero lo más grave de esta modificación, consiste en que el aumento de } \\
\text { vida útil no se acompañó con el respectivo ajuste tarifario, pues los } \\
\text { vehículos que seguirán prestando el servicio ya fueron pagados en su } \\
\text { totalidad. En efecto, tanto el capital invertido, como los intereses, la } \\
\text { "justa" remuneración y la depreciación de la flota son valores que ya } \\
\text { fueron amortizados, y cancelados por los usuarios vía tarifa. Tales costos } \\
\text { representan el } 26.8 \% \text { de la tarifa técnica actual, en esa misma proporción } \\
\text { se ha debido ajustar la tarifa técnica. }\end{array}$ \\
\hline Altas tarifas & $\begin{array}{l}\text { El costo de la tarifa es de } \$ 1.700 \text {, pero } \\
\text { la tarifa integrada (TM }+ \text { SITP), } \\
\text { quedará en } \$ 2.000 \text { contando el precio } \\
\text { del transbordo, esto hace del sistema } \\
\text { uno de los más caros de América } \\
\text { Latina. }\end{array}$ & $\begin{array}{l}\text { El } 13,1 \% \text { de los usuarios considera que el problema principal del } \\
\text { transporte es su alto costo. El } 34 \% \text { considera que la tarifa es alta y el } 8 \% \\
\text { señala que es exagerada. Las tarifas desconocen la capacidad de pago } \\
\text { promedio de los habitantes de la capital, donde el } 80 \% \text { pertenecen a los } \\
\text { estratos } 1,2 \text { y } 3 \text {. }\end{array}$ \\
\hline Límites al acceso & $\begin{array}{l}\text { Las altas tarifas han generado serias } \\
\text { barreras de acceso para segmentos } \\
\text { considerables de la población, quienes } \\
\text { se ven excluidos del uso real y efectivo }\end{array}$ & $\begin{array}{l}\text { El sistema de transporte ha resultado sumamente costoso para los estratos } \\
\text { bajos y poco atractivo para los estratos altos. Cerca de } 800.000 \text { personas } \\
\text { en promedio recorren } 33 \text { cuadras de ida y } 33 \text { de vuelta a pie para llegar a } \\
\text { su lugar de trabajo o estudio. El } 16 \% \text { de los ciudadanos se transportan }\end{array}$ \\
\hline
\end{tabular}




\begin{tabular}{|c|c|c|}
\hline & $\begin{array}{l}\text { de esta prestación, o ven seriamente } \\
\text { afectadas su economía familiar debido a } \\
\text { los altos costos del transporte. }\end{array}$ & $\begin{array}{l}\text { por medios humanos (a pie o en bicicleta), y el uso de sustitutos como la } \\
\text { motocicleta se ha incrementado, pasando del } 4 \% \text { al } 7 \% \text {. Esto se explica } \\
\text { porque la elasticidad de la demanda del transporte es cercana a la unidad. } \\
\text { El aumento de } \$ 150 \text { representa una reducción de la demanda del } 17 \% \text {, lo } \\
\text { que indica que si se reducen los ingresos, se sacrifica los gastos en } \\
\text { materia de transporte, a pesar de su carácter esencial, en un mundo donde } \\
\text { "el ingreso condiciona la capacidad de movilidad, y a su vez, la } \\
\text { capacidad de movilidad condiciona el ingreso" (Carty, 2006). }\end{array}$ \\
\hline Hacinamiento & $\begin{array}{l}\text { La distribución de costos y beneficios, } \\
\text { asignó los ingresos adicionales que } \\
\text { puedan obtenerse por transportar más } \\
\text { personas por km a los operadores, lo } \\
\text { que generó un incentivo para estos } \\
\text { agentes, que consiste en que entre más } \\
\text { gente se transporte por } \mathrm{km} \text {, mayores } \\
\text { serán sus utilidades. }\end{array}$ & $\begin{array}{l}\text { Esta situación condujo a que en un periodo de } 4 \text { años (2008-2012) el } \\
\text { aumento de buses fuera de } 20 \% \text {, mientras que el aumento de personas } \\
\text { por bus ascendiera } 57 \% \text {. Por tal razón, el } 43 \% \text { de los usuarios consideran } \\
\text { que el problema principal de TM es el sobrecupo. Los incrementos del } \\
\text { hacinamiento en los buses han venido acompañado del incremento en las } \\
\text { utilidades de los operadores, lo que pone en evidencia su estrecha } \\
\text { relación. Así mismo, el hacinamiento se da en estaciones, filas para } \\
\text { entrar y en los portales. }\end{array}$ \\
\hline $\begin{array}{l}\text { Congestión } \\
\text { Vehicular }\end{array}$ & $\begin{array}{l}\text { Los problemas de TM, han hecho que la } \\
\text { demanda se desplace hacia el consumo } \\
\text { de sustitutos, aumentando el número de } \\
\text { vehículos, motos, transporte alternativo, } \\
\text { bici-taxis, moto -taxis, situación que ha } \\
\text { aumentado la congestión vehicular. }\end{array}$ & $\begin{array}{l}\text { El aumento de carros particulares, que en } 10 \text { años pasaron de } 600.000 \text { a } \\
\text { 1'150.000, la venta de motos que en los últimos } 4 \text { años alcanzó la cifra } \\
\text { de } 660.000 \text { unidades, son evidencia del desplazamiento de la demanda } \\
\text { hacia medios de transporte sustitutos. Los tiempos de velocidad de los } \\
\text { carros particulares pasaron de } 30,4 \mathrm{k} / \mathrm{h} \text { a } 23,8 \mathrm{k} / \mathrm{h} \text { y los del TPC pasaron } \\
\text { de } 23,4 \% \text { a } 19,3 \% \text {, aspectos que demuestran el aumento de la congestión } \\
\text { vehicular. }\end{array}$ \\
\hline $\begin{array}{l}\text { Manifestaciones y } \\
\text { Bloqueos }\end{array}$ & $\begin{array}{l}\text { Cerca de } 200 \text { bloqueos se presentan al } \\
\text { año por motivos relacionados con la } \\
\text { prestación del servicio de transporte. }\end{array}$ & $\begin{array}{l}\text { Los bloqueos afectan la movilidad, el tiempo de los usuarios y la } \\
\text { productividad de la ciudad, que se ha visto paralizada por las protestas y } \\
\text { las manifestaciones. }\end{array}$ \\
\hline Inseguridad & $\begin{array}{l}\text { Los robos, atracos, las riñas y los } \\
\text { ataques a las mujeres son una variable } \\
\text { en continuo aumento. }\end{array}$ & $\begin{array}{l}\text { El } 17 \% \text { de los usuarios considera que el problema principal de TM es la } \\
\text { seguridad, (lo que la ubica de } 2 \mathrm{da} \text { ). Buenas parte de los problemas de } \\
\text { seguridad se derivan del hacinamiento, pues el sobrecupo propicia riñas, } \\
\text { ataques a mujeres, y el "chalequeo" modalidad principal de robo dentro } \\
\text { del sistema, que presenta más de } 1.000 \text { captura en flagrancia al año. }\end{array}$ \\
\hline Subsidios & $\begin{array}{l}\text { Los ingresos del sistema no resultan } \\
\text { suficientes para cubrir los altos costos } \\
\text { operacionales, razón por la cual, el } \\
\text { Distrito, en cumplimiento del Acuerdo } \\
\text { de Pago Extendido (TM y SITP), se } \\
\text { encuentra obligado a girar los recursos }\end{array}$ & $\begin{array}{l}\text { Los ingresos no operacionales, provenientes de las transferencias del } \\
\text { Distrito Capital, han presentado un crecimiento del } 299 \% \text {, ( } \$ 404.872 \\
\text { millones) para respaldar la política tarifaria del Sistema Transmilenio } \\
\text { (2013). El subsidio a los discapacitados, generó un incremento en } \\
\text { subsidios de } \$ 6.098 .000 \text { millones a } \$ 82.059 .000 \text { millones, en solo un } \\
\text { año. Los subsidios a los adultos mayores tienen un costo de }\end{array}$ \\
\hline
\end{tabular}




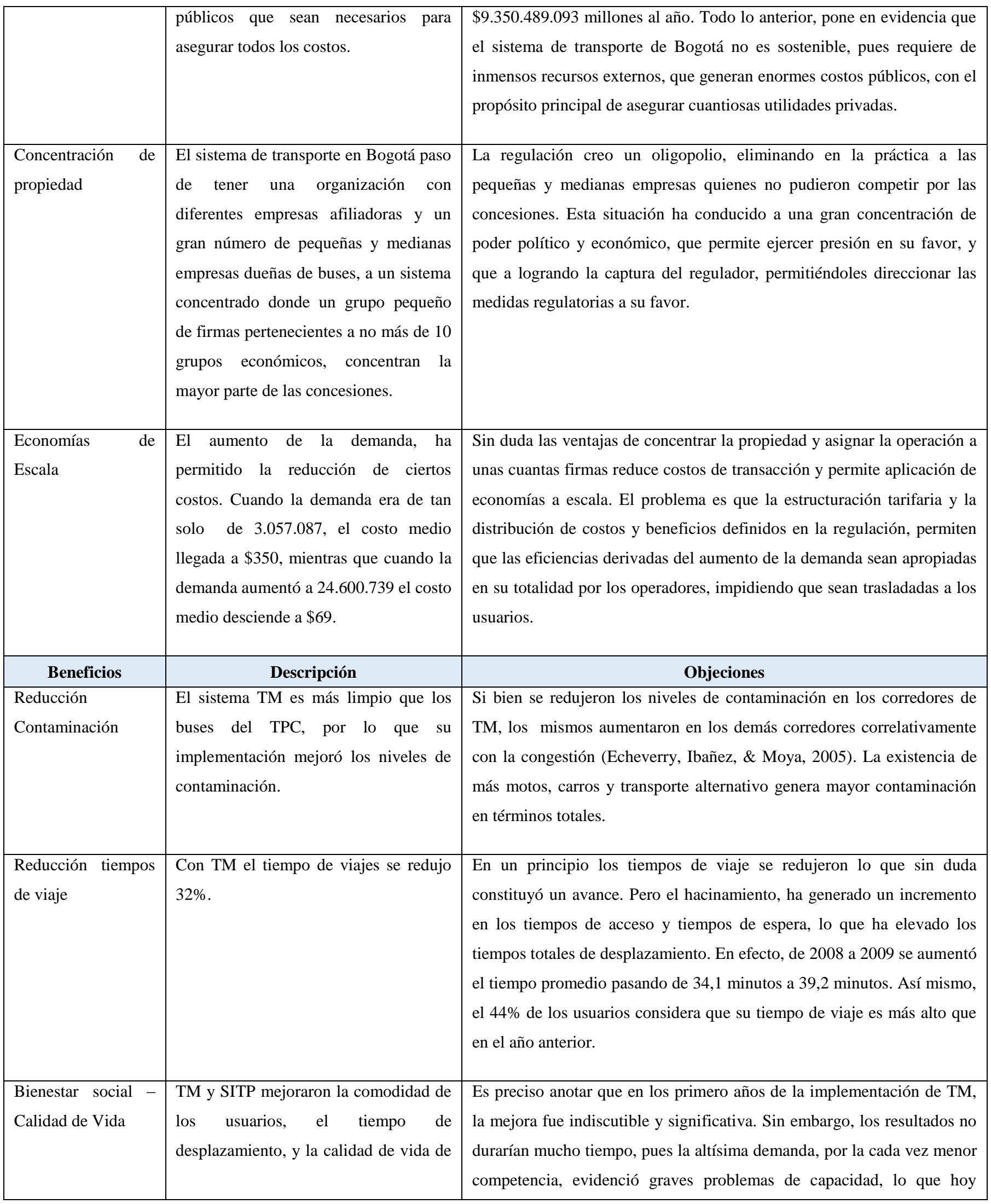




\begin{tabular}{|c|c|c|}
\hline & los usuarios. & $\begin{array}{l}\text { genera sobrecupo, inseguridad e incomodidad. Los usuarios le otorgan la } \\
\text { peor calificación a TM, asignándolo solo } 2,8 \text { puntos, mientras que el TPC } \\
\text { recibe } 3,3 \text { y la bicicleta } 4,3 \text {. Con el SITP se ha presentado un fenómeno } \\
\text { similar, pues al comienzo los buses van vacíos generando mejoras de } \\
\text { bienestar, el problema consiste en que cuando se encuentre totalmente } \\
\text { implementado en su mayoría funcionará como alimentador de TM, } \\
\text { aumentando los usuarios en las troncales, y con ellos el hacinamiento, la } \\
\text { incomodidad y la falta de bienestar. El eje central del Transporte de una } \\
\text { ciudad con la densidad de Bogotá, tiene que ser un sistema de alta } \\
\text { capacidad como un metro, y no uno de mediana capacidad como TM. }\end{array}$ \\
\hline Accidentalidad & $\begin{array}{l}\text { Con la implementación de TM la } \\
\text { accidentalidad se redujo. }\end{array}$ & $\begin{array}{l}\text { Efectivamente la accidentalidad derivada del sistema de transporte bajó. } \\
\text { Sin embargo, la accidentalidad derivada del aumento de la congestión y } \\
\text { el uso de sustitutos ha aumentado. El uso de moto como medio de } \\
\text { transporte pasó de } 4 \% \text { a } 7 \% \text {, vehículos que se encuentran implicados en } \\
\text { el } 42 \% \text { de los accidentes de tránsito. Es decir, que el aumento de motos } \\
\text { significa aumento de accidentalidad. }\end{array}$ \\
\hline $\begin{array}{l}\text { Equipamiento } \\
\text { urbano }\end{array}$ & $\begin{array}{l}\text { Mejora de infraestructura urbana y } \\
\text { espacio público. }\end{array}$ & $\begin{array}{l}\text { La organización de la ciudad mejoró de manera significativa con la } \\
\text { implementación de TM y ahora con SITP. }\end{array}$ \\
\hline $\begin{array}{l}\text { Organización del } \\
\text { Transporte }\end{array}$ & $\begin{array}{l}\text { El sistema TM y ahora SITP eliminó la } \\
\text { guerra del centavo, desligo las } \\
\text { funciones de recaudo de los } \\
\text { conductores y les asignó un sueldo fijo } \\
\text { independientemente del número de } \\
\text { pasajeros recogidos. }\end{array}$ & $\begin{array}{l}\text { El sistema de transporte actual, sin lugar a duda es mucho mejor que el } \\
\text { que se tenía antes, TPC, sin embargo, dicho sistema resultó insuficiente } \\
\text { para la demanda que existe en Bogotá y sumado a las ineficiencias } \\
\text { derivadas de la estructuración tarifaria y la distribución de costos y } \\
\text { beneficios, limitó el acceso de parte importante de la población y genero } \\
\text { hacinamiento, inseguridad y baja calidad. }\end{array}$ \\
\hline $\begin{array}{l}\text { Mejor consumo de } \\
\text { energía }\end{array}$ & $\begin{array}{l}\text { Los buses de TM y algunos del SITP } \\
\text { presentan mejor desempeño de } \\
\text { consumo de energía. Incluso algunos } \\
\text { buses del SITP son híbridos y manejan } \\
\text { tecnologías limpias. }\end{array}$ & $\begin{array}{l}\text { Sin duda este aspecto representó un importante avance en materia de } \\
\text { movilidad, y de ahorro de energía. }\end{array}$ \\
\hline Costo versus metro. & $\begin{array}{l}\text { El Km de TM costó } 40 \text { millones de } \\
\text { dólares, mientras que el } \mathrm{Km} \text { del Metro } \\
\text { tendría un costo de } 100 \text { millones de } \\
\text { dólares. }\end{array}$ & $\begin{array}{l}\text { Es indiscutible que los costos de un metro son } 60 \% \text { más costosos que los } \\
\text { del sistema TM, sin embargo ese tipo de sistema a largo plazo es el único } \\
\text { que puede resolver los problemas estructurales de movilidad en una } \\
\text { ciudad con más de } 7 \text { millones de habitantes. El metro es un sistema que } \\
\text { permite la mayor velocidad posible pues no tiene intersecciones y } \\
\text { presenta costos marginales decrecientes, contrario a TM, pues para } \\
\text { aumentar su capacidad solo es necesario agregar vagones a cada tren y no } \\
\text { comprar nuevos buses como sucede con TM. }\end{array}$ \\
\hline
\end{tabular}

Fuente: Elaboración propia basada en la propuesta planteada por (Monroy Cely \& Pinzón Camargo, 2012) 


\subsubsection{Resultados.}

El solo hecho de examinar las variables que no fueron tenidas en cuenta, sumados a la gravedad de la situación evidenciada por los hechos, permite advertir que desde el punto de vista cualitativo, el análisis costo beneficio arroja resultados negativos, pues son más altos los costos que los beneficios producidos por la regulación que gobierna la materia y por el sistema de transporte seleccionado. Los resultados son negativos, i) porque la estructuración de costos incorporó una serie de variables sobredimensionadas e incluso inexistentes que hace de la tarifa un cobro extremadamente alto, que benefició exclusivamente a los operadores privados en perjuicio de la entidad pública y de los beneficios sociales; ii) porque la distribución de costos y beneficios se efectuó desde una perspectiva microeconómica, centrando todo el análisis en el funcionamiento de las firmas encargadas de la operación, desconociendo el impacto y los efectos sobre aspectos macro como el acceso real y efectivo al servicio de transporte, el bienestar social, la rentabilidad colectiva y la calidad de vida de los ciudadanos, generando tarifas que desconocen la capacidad de pago promedio de los usuarios de la capital; y, iii) porque el sistema seleccionado no era el más adecuado atendiendo la demanda de transporte y las proporciones de la capital de Colombia, lo que generó un aplazamiento de la construcción de soluciones estructurales que resuelvan los problemas de fondo de la movilidad urbana.

\subsubsection{Criterios para la Producción de la Regulación.}

A partir del análisis realizado, surgen una serie de criterios que se deben tener en cuenta al momento de abordar las problemáticas del transporte y de ajustar o expedir las disposiciones regulatorias que regirán la prestación de este servicio esencial.

1. La estructura tarifaria debe fundamentarse en costos reales, e incorporar mecanismos que permitan realizar ajustes periódicos. Así mismo, se deben adelantar estudios técnicos que determinen

la capacidad de pago promedio de los ciudadanos para fijar montos máximo de tarifas, que hagan accesible este servicio esencial.

2. La distribución de costos y beneficios debe ser proporcional y equitativa. Se debe examinar a profundidad la necesidad de la participación de los particulares en la prestación de este tipo de servicios. 
3. Al momento de seleccionar el sistema de transporte para la ciudad se deben tener en consideración todos los impactos que puedan presentarse, e incluirlos dentro de las valoraciones. Resulta determinante incorporar los costos de todas las posibles externalidades.

4. La ponderación que se realice no debe examinar únicamente el comportamiento microeconómico de las firmas prestadoras del servicio, sino que debe fundamentarse, principalmente, en la rentabilidad social que genere el proyecto, los costos y beneficios colectivos que produce y sus impactos en el bienestar general, pues el servicio de transporte es una prestación esencial para la sociedad, que vista desde su dimensión funcional, resulta primordial para asegurar el progreso, el desarrollo y la calidad de vida de los ciudadanos.

5. El análisis se debe hacer a largo plazo, pues adoptar un sistema más económico que al cabo de 10 años resultó ser insuficiente, solamente hizo que se retrasara la construcción de soluciones estructurales que resuelvan la alta demanda de una ciudad con más de 7 millones de habitantes como Bogotá.

6. Los sistemas BRT (como Transmilenio) funcionan como una excelente herramienta para complementar un sistema de transporte de alta capacidad, que corresponde a un sistema férreo tipo metro, el cual debe ser el eje estructural del transporte en Bogotá. Un sistema como TM como eje central resulta insuficiente.

7. El Metro es el único sistema que responde a la demanda que existe en Bogotá (más de 45.000 pasajeros hora/sentido). En el mundo únicamente existen tres ciudades con más de 7 millones de habitantes que no tienen metro, Kinshasa (Congo), Daka (Bangladesh) y Bogotá (Colombia), lo que demuestra la necesidad de implementar el Metro en la Capital. Lo anterior no quiere decir que se deba desmantelar TM, éste sistema debe continuar y su red debe ser ampliada, pero no puede constituirse en el eje central del transporte en Bogotá (clausula 6, Concesiones SITP, 2009), sino como sistema complementario al Metro como sistema principal. 


\section{BIBLIOGRAFÍA}

\section{Textos.}

- Alcaldía Mayor, B. (2011). Documento Técnico de Soporte Modificación al Plan de Ordenamiento Territorial de Bogotá. Bogotá.

- Alcaldía Mayor, d. B. (2011). metrodebogota.gov.co. Recuperado el 14 de septiembre de 2014, de http://metrodebogota.gov.co/por-que-necesitamos-el-metro/

- Alexy, Robert. (1997). Teoría de la Argumentación Jurídica. Madrid:Centro de Estudios Constitucionales

- Alzate, M. C. (2006). La estratificación socioeconómica para el cobro de los servicios públicos Domiciliarios en Colombia ¿Solidaridad o Focalización? Santiago de Chile: Publicación de las Naciones Unidas.

- Amador Cabra, L. E. (2011). Los servicios públicos frente a las reformas económicas en Colombia. Bogotá: Universidad Externado de Colombia.

- Amador, L. E. (2012). Serie de Derecho Económico: casos de estudio de aplicación del Análisis Económico del Derecho. Bogotá: Universidad Externado de Colombia.

- Andi. (2011). INFORME ESTADÍSTICO DE TRANSPORTE URBANO 2011 MOVILIZACIÓN DE PASAJEROS. Estadiítico, Asociación Nacional de Industriales, ANDI - Comité Sectorial de Transporte, Bogotá.

- Arango, R. (2012). El concepto de los derechos sociales fundamentales (Segunda edición ed.). Bogotá: Legis Editores.

- Ardila Gómez, A. (Noviembre de 2005). Cinco Cuestionamientos y una recomendación a los autores del artículo "Una evaluación económica del Sistema Transmilenio" . Revista de Ingeniería, 152-160.

- Ariño, G. (2003). Principios de Derecho Público Económico. . Bogotá: Universidad Externado de Colombia.

- Atehortúa, C. (2003). Servicios Públicos Domiciliarios, Legislación y Jurisprudencia. Medellín: Biblioteca Jurídica Dike.

- Banco de la República, t. d. (28 de febrero de 2014). www.banrep.gov.co. Recuperado el 24 de agosto de 2014, de http://www.banrep.gov.co/es/comunicado-28-02-2014

- Banco Mundial, T. d. (2014). datos.bancomundial.org. Recuperado el 24 de agosto de 2014, de http://datos.bancomundial.org/indicador/FR.INR.RINR?page=3

- Bejarano, R. (1993). Las Acciones Populares. Bogotá: Ediciones Jurídicas Forum Pacis. 
- Botero, L. F. (2004). Acción Popular y Nulidad de los Actos Administrativos. Bogotá: Legis.

- Caballero, G., \& Kinsgton, C. (2005). Cambio cultural, dinámica institicional y ciencia cognitiva; hacía una comprencion mutudisciplinaria del desarrollo económico. Economía Institucional, 327-335.

- Calabresi, G. (2000). Reflexiones sobre el futuro de la teoría económica en la enseñanza del derecho. En A. Roemer, Derecho y Economía: una revisión a la literatura. (págs. 579 - 591). México D.F.: Fondo de Cultura Económica.

- Calsamiglia, A. (2000). Cuestiones de Lealtad. Limites del Liberalismo: corrupción, nacionalismo y multiculturalismo. Barcelona: Paidós.

- Coase, R. (2000). El Problema del Costo Social. En A. Roemer, Derecho y Economía: una revision de la literatura (págs. 512-557). México: Fondo de Cultura Económica.

- Contraloría de Bogotá. (2007). Auditoría Gubernamental con Enfóque Integral - Modalidad Regular sobre Empresa de Transporte Tercer Milenio. Bogotá.

- Cooter, R. D. (2000). Las mejores leyes correctas: fundamentos axiológicos del Análisis Económico del Derecho. En A. Roemer, Derecho y Economía: una revisión a la literatura (págs. 133 - 158). México D.F.: Fondo de Cultura Económica.

- Correa, H. M. (2009). Libertad de empresa en el Estado social de Derecho. Bogotá: Universidad Externado de Colombia.

- Cruz Parcero, J. A. (2006). Observar la ley. Ensayos sobre metodología de la investigacion juridica. Madrid: Trota S.A.

- Cruz Parcero, J. A. (2006). Observar la ley. Ensayos sobre metodología de la investigación jurídica. Madrid: Trota S.A.

- Cuellar, Á. A. (13 de marzo de 2012). http://www.portafolio.co. Recuperado el 13 de junio de 2014, de http://www.portafolio.co/economia/pasaje-transmilenio-el-quinto-mas-caro

- DANE. (2005). Estimación y proyecciones de población 2005 - 2020 total Departamental por área. Departamento Administrativo Nacional de Estadistica, Bogotá.

- DANE, D. N. (2007). Encuesta de Ingresos y Gastos. Bogotá.

- DANE, D. N. (2013). Encuesta de Calidad de Vida. Bogotá.

- Echeverry, J. C., Ibañez, A. M., \& Moya, A. (Mayo de 2005). Una evaluación económica del Sistema Transmilenio. Revista de Ingeniería, 68-77.

- El Tiempo. (10 de mayo de 2009). www.eltiempo.com. Recuperado el 14 de septiembre de 2014, de http://www.eltiempo.com/archivo/documento/CMS-5178449 
- Encuesta de percepción ciudadana. (2013). www.bogotacomovamos.org. Recuperado el 12 de septiembre de 2014, de http://www.bogotacomovamos.org/media/uploads/documento/195/encuesta-de-percepcionciudadana-2013-bogota_1.pdf

- Estado, C. d. (2007). Sala de lo contencioso Administrativo, Sección Tercera, M.P. Ruth Stella Correa Palacio.

- Expósito, J. C. (2003). EL contrato estatal y a noción de servicio público. III Jornadas de DErecho Constitucional y Administrativo, 347 - 370.

- García, O. F. (2006). Evaluación de viabilidad económica y financiera de Transmilenio S.A. . En J. I. González Borrero, La concesión de Transmilenio y su sostenibilidad financiera (págs. 40-83). Bogotá: Universidad Nacional de Colombia.

- Gil Alzate, W. (2009). ¿Son los servicios públicos bienes de mercado? Letras jurídicas Vol 14, No. 1, Marzo de 2009. EPM. , 69-106.

- Gil, W. (2004). El Usuario de los Servicios Públicos Domiciliarios. Medellín.

- Gonzalez Borrero, B. S. (2006). La autosostenibilidad del sistema de transporte público masivo Transmilenio en Bogotá. En J. I. Gonzalez Borrero, La concesión de Transmilenio y su sostenibilidad financiera (págs. 11-30). Bogotá: Universidad Nacional de Colombia .

- González, B. S. (2006). La autosostenibilidad del sistema de transporte público masivo Transmilenio en Bogotá. En J. I. Gonzalez Borrero, La concesión de Transmilenio y su sostenibilidad financiera (págs. 1130). Bogotá: Universidad Nacional de Colombia.

- Instituto Internacional de Gobernabilidad. (1998). Douglass C. North: La teoría económica neoinstitucionalista y el desarrollo latinoamericano. Barcelona: PNUD.

- Jauregui, G. (2001). Derechos individuales versus Derechos Colectivos: una realidad Inescindible. Dykinson.

- Juan Antonio, C. P. (2006). Observar la ley. Ensayos sobre metoddologí de la investigacion juridica. Madrid: Trota S.A.

- Kelman, M. (2011). La mala comprensión de la vida social: una crítica a las premisas fundamentales del Análisis Económico del Derecho. En C. Morales de Setién, Análisis Económico del Derecho (págs. 245 269). Bogotá: Siglo del Hombre.

- Kitch, E. W. (2000). Los Fundamentos Intelectuales del Análisis Económico del Derecho . En A. Roemer, Derecho y Economía una Revisión de la Literatura (págs. 51 - 65). México: Fondo de Cultura Económica. 
- Leguizamo Acosta, W. (2007). Teorias y doctrina sobre las relaciones: del derecho y la economía. Revista Contexto, 11 - 28.

- Lleras E, G. C. (2005 de mayo de 2005). Transmilenio y el transporte colectivo tradicional, una relación incierta. . Revista de Ingeniería.

- López, Diego. (2013). El Derecho de los Jueces. Bogotá: Legis.

- Martinez, C. (24 - 31 de Agosto de 2014). Inundados por las motos. Revista Semana(168), págs. 58-59.

- Monroy Cely, D., \& Pinzón Camargo, M. (2012). Análisis económico de los derechos colectivos y su mecanismo de protección jurisdiccional en Colombia. Con-Texto. Revista de Derecho y Economía, 1158.

- Montaña Plata, A. (2010). Fundamentos de Derecho Administrativo. . Bogotá: Universidad Externado de Colombia.

- Montes, S. (2000). Concesiones viales. La inadecuada dustribución de los riesgos, eventual causa de crisis en los contratos. Revista de Derecho Público, 39 - 125.

- Morales Alzate, J. J. (2010). Derecho Economico Constitucional Colombiano (Sexta ed.). Bogotá: Ediciones Doctrina y Ley.

- Morales de Setién, C. (2011). Las bases del análisis económico del derecho. En C. Morales de Setién, Análisis Económico del Derecho (págs. 11-76). Bogotá: Siglo del Hombre.

- Murcia, A. M. (2012). Los Derechos Colectivo y la Contratación Estatal. Bogotá: Universidad Externado de Colombia.

- North, D. (1993). Instituciones, Cambio Institucional y Desempeño Económico. Ciudad de México: Fondo de Cultura Económica.

- Palacios, A. (2009). Introducción al Análisis Económico del Derecho Administrativo. Revista de DErecho Público, Universidad de los Andes, 3 - 23.

- Peso colombiano, u. d. (2 de enero de 2013). www.portafolio.co. Recuperado el 25 de agosto de 2014, de http://www.portafolio.co/economia/peso-los-mas-revaluados-del-mundo

- Pib, d. C. (2014). http://www.datosmacro.com. Recuperado el 23 de agosto de 2014, de http://www.datosmacro.com/pib/colombia

- Pinzón, M. A. (2010). Aproximaciones al Análisis Económico del Derecho . Bogotá: Universidad Externado de Colombia .

- Planeación, S. D. (2009). Conociendo a Bogotá D.C. y sus localidades. Diagnostico de los aspectos físicos, demográficos y socioeconómicos. Bogotá: Alcaldía Mayor. 
- Planeación, S. D. (2010). Población, viviendas y hogares a junio 30 de 2010 en relación con la estratificación socioeconómica vigente a 2010. Bogotá Ciudad de Estadísticas. Boletin No. 18, 1-60.

- Posner, R. (2000). Usos y Abusos de la Teoría Económica en el Derecho. En A. Roemer, Derecho y Economía: una revisión de la literatura. México: Fondo de Cultura Económica.

- Posner, R. A. (2000). El Movimiento del Análisis Económico del Derecho. En A. Roemer, Derecho y Economía: una revision de la literatura. (págs. 221 - 241). México D.F.: Fondo de Cultura Económica.

- Posner, R. A. (2011). El Enfoque Económico del Derecho. En C. Morales de Setién, Análisis Económico del Derecho. Bogotá: Siglo del Hombre.

- Posner, R. A. (2013). Análisis Económico del Derecho . México: Fondo de Cultura Económica.

- Quiroga Natale, A. (2007). El control constitucional como instrumento de la intervención econonómica. Revista Contexto No. 21, 11 - 28.

- Quiroga Natale, E. V. (2008). La constitucionalidad de los contratos de estabilidad jurídica. Universitas, 141 - 159.

- Ramirez, M. (2007). Pobreza y Servicios Públicos Domiciliarios. Bogotá: Departamento Nacional de Planeación.

- Rawls, John. (2006). Teoría de la Justicia. México: Fondo de Cultura Económica.

- Reporte Anual de Movilidad, D. D. (2010). camara.ccb.org.co. Recuperado el 14 de septiembre de 2014, de http://camara.ccb.org.co/documentos/6525_costo_servicio_observa2010.pdf

- Silva Aparicio, L. (2010). El impacto del transporte en el ordenamiento de la ciudad: el caso de Transmilenio en Bogotá. Territorios, 22, 33-64.

- Suárez, A. (2011). Confianza Inversionista, Economía Colombiana de 2000 a 2010. Bogotá: Ediciones Aurora.

- Suárez, A. (6 de noviembre de 2012). www.elespectador.com. Recuperado el 24 de agosto de 2014, de Fuente: http://www.elespectador.com/noticias/bogota/transmilenio-una-guaca-urbana-articulo456797

- Suárez, A. (12 de marzo de 2012). www.eltiempo.com. Recuperado el 25 de agosto de 2014, de http://www.eltiempo.com/archivo/documento/CMS-11411481

- Tamayo, J. (2001). Las acciones Populares y de Grupo en la Responsabilidad Civil. Editor Raisbeck.

- Torres Corredor, H. (2002). La Corte Constitucional entre la Economía y el Derecho. Pensamiento Jurídico, No. 15, 165 - 2010. 
- Transmilenio, S. (2013). Análisis para la posible negociacion y/o modificacion de los contratos de concesion para la Fase I y Fase II del sistema Transmilenio. Bogotá.

- Transmilenio, S. (2013). Informe de Gestión. Bogotá D.C.: Alcaldía Mayor de Bogotá.

- Velandia, M. (2011). Derecho de la competencia y el consumo. Bogotá: Universidad Externado de Colombia.

- Williamson, O. E. (2000). Los fundamentos intelectuales: la necesidad de una perspectiva más amplia. En A. Roemer, Derecho y Economía: una revisión a la literatura. (págs. 242 - 250). México D.F.: Fondo de Cultura Económica.

\section{Fuentes jurisprudenciales.}

- Corte Constitucional. Sentencia T-427 de 1992. M.P. Eduardo Cifuentes Muñoz

- Corte Constitucional.Sentencia T-604 de 1992. M.P. Eduardo Cifuentes Muñoz

- Corte Constitucional. Sentencia T-401 de 1992. M.P. Eduardo Cifuentes Muñoz.

- Corte Constitucional. Sentencia C-052 de 1993. M.P. Jaime Sanin Greiffenstein.

- Corte Constitucional. Sentencia C- 013 de 1993. M.P. Eduardo Cifuentes Muñoz.

- Corte Constitucional. Sentencia T 254 de 1993. M.P. Antonio Barrera Carbonell.

- Corte Constitucional. Sentencia C- 407 de 1994. M.P. Alejandro Martínez Caballero.

- Corte Constitucional. Sentencia C-265 de 1994. M.P. Alejandro Martínez Caballero.

- Corte Constitucional. Sentencia C-566 de 1995. M.P. Eduardo Cifuentes Muñoz.

- Corte Constitucional. Sentencia T-288 de 1995. M.P. Eduardo Cifuentes Muñoz.

- Corte Constitucional. Sentencia C- 250 de 1996. M.P. Hernando Herrera Vergara.

- Corte Constitucional. Sentencia C- 535 de 1997. M.P. Eduardo Cifuentes Muñoz.

- Corte Constitucional. Sentencia C- 066 de 1997. M.P. Fabio Morón Díaz.

- Corte Constitucional. Sentencia C-237 de 1997. M.P. Carlos Gaviria Díaz.

- Corte Constitucional. Sentencia T-643 de 1998. M.P. Antonio Barrera Carbonell. 
- Corte Constitucional. Sentencia C-521 de 1998. M.P. Antonio Barrera Carbonell.

- Corte Constitucional. Sentencia C-043 de 1998. M.P. Vladimiro Naranjo Mesa.

- Corte Constitucional. Sentencia C-624 de 1998. M.P. Alejandro Martínez Caballero.

- Corte Constitucional. Sentencia C-616 de 2001. M.P. Rodrigo Escobar Gil.

- Corte Constitucional. Sentencia C-815 de 2001. M.P. Rodrigo Escobar Gil.

- Corte Constitucional. Sentencia T-595 de 2002. M.P. Manuel José Cepeda Espinosa

- Corte Constitucional. Sentencia T-467 de 2002. M.P. Eduardo Montealegre Lynett

- Corte Constitucional. Sentencia T-595 de 2002. M.P. Manuel José Cepeda Espinosa

- Corte Constitucional. Sentencia T-884 de 2003. M.P. Jaime Córdoba Triviño

- Corte Constitucional. Sentencia T-197 de 2003. M.P. Jaime Córdoba Triviño

- Corte Constitucional.Sentencia C-568 de 2003. M.P. Alvaro Tafur Galvis

- Corte Constitucional. Sentencia C-355 de 2003. M.P. Marco Gerardo Monroy Cabra.

- Corte Constitucional. Sentencia C-408 de 2004. M.P. Alfredo Beltrán Sierra

- Corte Constitucional. Sentencia T-1094 de 2005. M.P. Jaime Araujo Rentería

- Corte Constitucional. T-905 de 2005. M.P. Humberto Antonio Sierra Porto.

- Corte Constitucional. T-1087 de 2007. M.P. Jaime Córdoba Triviño

- Corte Constitucional. Sentencia T-760 de 2008. M.P. Manuel José Cepeda Espinosa

- Corte Constitucional. Sentencia T-1259 de 2008. M.P. Rodrigo Escobar Gil

- Corte Constitucional. Sentencia C-336 de 2008. M.P. Clara Inés Vargas Hernández.

- Corte Constitucional. T-542 de 2009. M.P. Jorge Ignacio Pretelt Chaljub

- Corte Constitucional.Sentencia C-885 de 2010. M.P. María Victoria Calle Correa

- Corte Constitucional. Sentencia T-312 de 2010. M.P. Jorge Ignacio Pretelt Chaljub.

- Corte Constitucional. Sentencia T-312 de 2010 . M.P. Jorge Ignacio Pretelt Chaljub. 
- Corte Constitucional. Sentencia C-263 de 2011. M.P. Jorge Ignacio Pretelt Chaljub.

- Corte Constitucional. T-709 de 2011. Maria Victoria Calle Correa

- Corte Constitucional. Sentencia C-439 de 2011. M.P. Juan Carlos Henao Perez

- Corte Constitucional. Sentencia T-690 de 2012. M.P. María Victoria Calle Correa

- Corte Constitucional. Sentencia C-033 de 2014. M.P. Nilson Pinilla Pinilla

- Consejo de Estado, Sala de lo Contencioso Administrativo, Sección Tercera, Sentencia 6 de diciembre de 2007, Expediente No. 11493,

- Consejo de Estado, Sala de lo Contencioso Administrativo, Sección Cuarta, Auto del 30 de enero de 2003.

- Consejo de Estado, Sala de lo Contencioso Administrativo, Sección Tercera, M.P. Freddy Ibarra Martinez. Bogotá. (2006).

- Tribunal Administrativo de Cundinamarca, Sala Segunda, Subsección A, Sentencia del 11 de noviembre de 2011, Expediente: AP 03-2488.

\section{Fuentes legales y contractuales.}

- C.P. (1991). Constitución Política. Bogotá. Colombia.

- Ley 336 (Congreso de la República 20 de Diciembre de 1996).

- Decreto Distrital No. 319, "Por el cual se adopta el Plan Maestro de Movilidad para Bogotá Distrito Capital, que incluye el ordenamiento de estacionamientos, y se dictan otras disposiciones (2006).

- Decreto 3069 (Gobierno Nacional 2013).

- Contrato de Concesión Transmilenio, 001 (EMPRESA DE TRANSPORTE TERCER MILENIO, TRANSMILENIO S.A. 2000).

- Contrato Concesión SITP, Licitación Pública No. TMSA-LP-004-2009 (EMPRESA DE TRANSPORTE TERCER MILENIO, TRANSMILENIO S.A. 2010). 